\title{
The role of PI3K/AKT/TSC/p70S6K1 pathway in tumor growth and angiogenesis
}

Qiao Meng

West Virginia University

Follow this and additional works at: https://researchrepository.wvu.edu/etd

\section{Recommended Citation}

Meng, Qiao, "The role of PI3K/AKT/TSC/p70S6K1 pathway in tumor growth and angiogenesis" (2006). Graduate Theses, Dissertations, and Problem Reports. 2513.

https://researchrepository.wvu.edu/etd/2513

This Dissertation is protected by copyright and/or related rights. It has been brought to you by the The Research Repository @ WVU with permission from the rights-holder(s). You are free to use this Dissertation in any way that is permitted by the copyright and related rights legislation that applies to your use. For other uses you must obtain permission from the rights-holder(s) directly, unless additional rights are indicated by a Creative Commons license in the record and/ or on the work itself. This Dissertation has been accepted for inclusion in WVU Graduate Theses, Dissertations, and Problem Reports collection by an authorized administrator of The Research Repository @ WVU.

For more information, please contact researchrepository@mail.wvu.edu. 


\title{
The Role of PI3K/AKT/TSC/p70S6K1 Pathway in Tumor Growth and Angiogenesis
}

\author{
Qiao Meng \\ Forestry and Consumer Sciences \\ at West Virginia University \\ in partial fulfillment of the requirements \\ for the degree of \\ Doctor of Philosophy \\ in \\ Genetics \& Developmental Biology \\ Bing-Hua Jiang, Ph.D., Chair \\ Xianglin Shi, Ph.D. \\ Sharon L.Wenger, Ph.D. \\ Yon Rojanasakul, Ph.D. \\ Jia Luo, Ph.D.
}

Dissertation submitted to the Davis college of Agriculture,

Genetics \& Developmental Biology Program

Morgantown, West Virginia

2006

Keywords: PI3K, AKT, TSC, p70S6K1, tumor growth, angiogenesis

Copyright 2006 Qiao Meng 


\section{Abstract \\ The Role of PI3K/AKT/TSC/p70S6K1 Pathway \\ in Tumor Growth and Angiogenesis}

Qiao Meng

PI3K/AKT pathway plays an important role in tumor progression and angiogenesis. To determine the specific role of PI3K isoform $\mathrm{p} 110 \alpha$ in ovarian cancer, we designed small interfering RNA (siRNA) against p110 $\alpha$. The expression of $\mathrm{p} 110 \alpha$ siRNA significantly decreased cell migration, invasion, and proliferation. AKT has three different isoforms: AKT1, AKT2 and AKT3. We found that downregulation of AKT1 is sufficient to inhibit cell migration, invasion, and proliferation in ovarian cancer cells. The activation of p70S6K1 was decreased in both p110 $\alpha$ and AKT1 siRNA-expressing cells. Inhibition of p70S6K1 activity also decreased cell migration, invasion, and proliferation.

The tuberous sclerosis complex-2 (TSC2) lies upstream of mTOR/p70S61 and downstream of AKT. Loss of TSC2 expression is observed in human cancer. To study the function of TSC2 in ovarian tumor angiogenesis, we established stable cell lines that express siRNA specific to TSC1 and TSC2. In this study, we show that inhibition of TSC 1 and TSC 2 increased the expression of HIF- $1 \alpha$ in ovarian cancer cells. Inhibition of TSC1 and TSC2 upregulated VEGF expression at both mRNA and protein levels. Downregulation of TSC2 induced ovarian tumor angiogenesis and tumor growth through mTOR/p70S6K1. The expression of p70S6K1 siRNA decreased VEGF protein expression and VEGF transcriptional activation through the HIF-1 $\alpha$ binding site. The expression of p70S6K1 siRNA specifically inhibited HIF-1 $\alpha$ expression in ovarian cancer cells. We also found that p70S6K1 down-regulation decreased ovarian tumor growth and tumor angiogenesis. This study provides a novel molecular mechanism of human ovarian cancer induced by the activation of p70S6K1.

Survivin gene is highly expressed in ovarian cancer cell lines and is a potential target of gene therapy for ovarian cancer. Our study showed that expression of survivin siRNA induced cell apoptosis when combined with LY294002 or taxol treatment. We determined that suvivin mRNA is regulated by PI3K/AKT/p70S6K1 pathway. Survivin is an important downstream molecule of $\mathrm{PI} 3 \mathrm{~K} / \mathrm{AKT} / \mathrm{p} 70 \mathrm{~S} 6 \mathrm{~K} 1$ pathway that plays a role in antiapoptosis in ovarian cancer cells. 


\section{Dedication}

I dedicate this dissertation to my parents, Xian-Xing Meng and Dao-Zi Chang, who gave me so much love, help and encouragement during my study and to my husband, Bai-Yun Gong, whose assistance have encouraged me to fulfill my dream of Ph.D. 


\section{Acknowledgements}

I would like to express my deepest gratitude to my advisor, Dr. Bing-Hua Jiang for his great academic and financial support. His guidance, suggestions and patience have been invaluable to the completion of my dissertation. I deeply appreciate that he gave me the opportunity to finish my Ph.D. study under his supervision.

With respect and gratitude, I wish to thank Dr. Xiang-Lin Shi, Dr. Sharon L. Wenger, Dr. Yon Rojanasakul and Dr. Jia Luo for their agreeing to be on the committee. Their assistance and critical comments to the research work and dissertation have been very helpful in the completion of the dissertation.

I would like to thank every member in the Dr. Bing-Hua Jiang's laboratory. I am especially thankful for the cooperation with Chang Xia, Zong-Xian Cao and Jing Fang. They were very nice and supportive. I will miss the time I spent with them and keep the valuable friendship with them.

Finally, I sincerely thank my parents, my husband and my daughter with their invaluable love and devotion to me. I could not finish my Ph.D. study without their strong support. 


\section{Table of Contents}

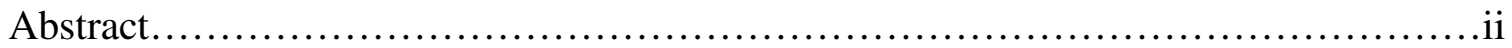

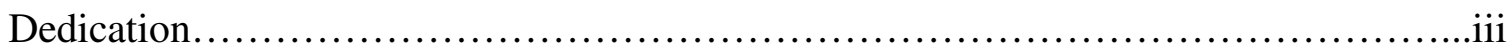

Acknowledgements...........................................................

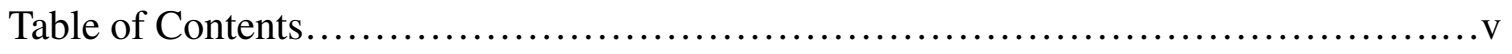

Abbreviation.................................................................. viii

\section{Chapter I}

Introduction and Literature Review.....................................

I. The PI3K/AKT pathway and tumorigenesis................................4

II. The PI3K/AKT pathway and angiogenesis..................................

III. TSC and tumor angiogenesis...........................................

IV. p70S6K1 and tumorigenesis......................................... 10

V. Survivin and PI3K/AKT pathway........................................

VI. Reference............................................................. 14

\section{Chapter II}

Role of PI3K and AKT specific isoforms in ovarian cancer cell migration, invasion

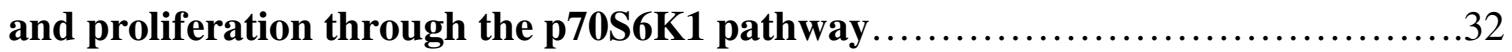

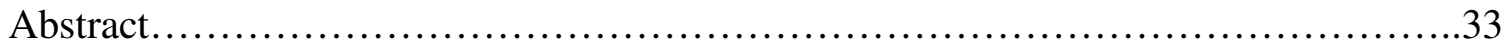

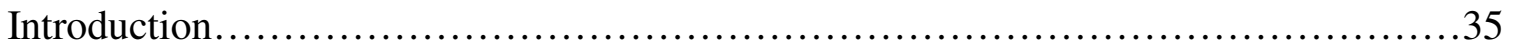


Materials and Methods.

Results.

Discussion.

References. .58

Figure Legends. .66

Figures. .74

\section{Chapter III}

TSC2/p70S6K1 in regulating tumor growth and angiogenesis through VEGF and

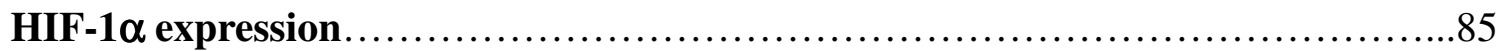

Abstract............................................................................ 86

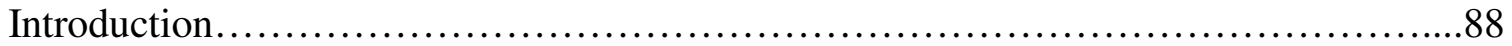

Materials and Methods....................................................... 92

Results .................................................................. 100

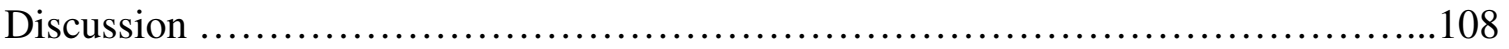

Acknowledgements........................................................111

References............................................................... 112

Figure Legends......................................................... 126

Figures...................................................................... 


\section{Chapter IV}

Regulation of Survivin by PI3K/AKT /p70S6K1 Pathway and Role of Survivin in Ovarian Cancer.

Abstract. . .152

Introduction. .153

Materials and Methods. 155

Results. 160

Discussion .164

References. 166

Figure Legends. .174

Figures. .179

\section{Chapter V}

Summary and Conclusions. .183

References.

Curriculum Vitae. .195 


\section{Abbreviations}

ASV 16

Ang-1

AMPK

BIR

CAM

CDK

CKIs

DMSO

EGF

eIF-4E

4EBP-1

$\beta-\mathrm{Gal}$

GM-CSF

HIF- $1 \alpha$

IAP

$\mathrm{LOH}$

MAPK

mTOR

p70S6K1

PDGF

PI3K

$\mathrm{PIP}_{3}$

PTEN

RCAS

SHIP

SiRNA

5' TOP

TSC

VEGF
Avian Sarcoma Virus 16

Angiopoietin-1

AMP-activated protein kinase

Baculovirus IAP repeat

Chicken Chorioallantoic Membrane

cyclin-dependent kinase

cyclin-dependent kinase inhibitors

Dimethyl Sulfoxide

epidermal growth factor

eukaryotic initiation factor $4 \mathrm{E}$

4E-Binding Protein-1

$\beta$-Galactosidase

Granulocyte-Marcrophage Colony Stimulating Factor

hypoxia-inducible factor- $1 \alpha$

Inhibitor of Apoptosis

Loss of Heterozygosity

Mitogen-Activated Protein Kinase

mammalian Target of Rapamycin

70 KDa ribosomal S6 kinase 1

platelet-derived growth factor

phosphatidylinositol-3-kinase

PI-3, 4, 5-triphosphate

phosphatase and tensin homologue

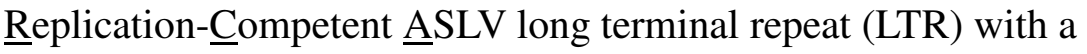
Splice acceptor.

$\mathrm{SH} 2$ containing inositol phosphatase

small interfering RNA

5' Tract of Pyrimidines

Tuberous Sclerosis Complex

Vascular Endothelial Growth Factors 


\section{CHAPTER I}

INTRODUCTION AND LITERATURE REVIEW 


\section{Introduction}

Phosphatidylinositol-3-kinase (PI3K) plays an important role in cell proliferation, differentiation, anti-apoptosis, tumorigenesis and angiogenesis. PI3K are activated by receptor tyrosine kinases, and activation of PI3K has been implicated in several human cancers. Recently PIK3CA was found to be the only gene affected by somatic mutations in a mutational screen of eight PI3K genes and eight PI3K-like genes ${ }^{1}$. PIK3CA, the gene encoding the $\mathrm{p} 110 \alpha$ catalytic subunit, has somatic mutations in many cancers including gastric adenocarcinoma ${ }^{2}$, brain cancers ${ }^{3}$, colorectal carcinomas ${ }^{4}$, breast cancer and ovarian cancer ${ }^{5}$. PI3KCA is also frequently increased in copy number in $40 \%$ of ovarian cancer cell lines and patient tumor samples ${ }^{6}$. Mutations of the phosphatase and tensin homologue (PTEN) tumor-suppressor gene are frequently detected in glioblastomas, prostate cancer and endometroid epithelial cancer ${ }^{7}$. An important downstream target of PI3K is the serine-threonine kinase AKT. AKT1 kinase activity is frequently elevated in ovarian cancer. P70S6K1 is activated through the PI3K pathway, the MAPK pathway and TSC/mTOR pathway ${ }^{8-10}$. Gene encoding for p70S6K1 is also amplified in ovarian cancer cells ${ }^{11}$ and its p70S6K1 kinase is constitutively phosphorylated in ovarian cancer cells. P70S6K1 is known to play a role in cell proliferation, cell size and cell cycle progression, but little is known about its role in angiogenesis. This research work is to study the roles and mechanism of TSC2 and p70S6K1 in regulating tumor growth and angiogenesis.

Survivin is a new member of the inhibitor of apoptosis gene family. Increased survivin expression is a negative prognostic marker in many tumors, including ovarian 
cancer $^{12-14}$. Survivin plays an important role in anti-apoptosis. However it remains to be elucidated how PI3K/AKT/p70S6K1 pathway regulates survivin expression and what the role of survivin in ovarian tumor growth is.

This research work provides us with the data to determine the role of PI3K downstream targets TSC, p70S6K1 and survivin in tumor progression. 


\section{Literature Review}

\section{The PI3K/AKT signaling pathway and tumorigenesis}

The PI3K family consists of a large family of lipid and serine/thronine kinases. Class IA PI3Ks are composed of heterodimers of an inhibitory adaptor/regulatory (p85) and a catalytic subunit $\mathrm{p} 110$. The $\mathrm{SH}_{2}$ domain of $\mathrm{p} 85$ has two functions: activation of small G protein and relief of trans-inhibition of p110. The catalytic p110 subunit has both serine-thronine protein kinase activity ${ }^{15}$ and phosphoinositide kinase activity ${ }^{16}$.

The activation of PI3K/AKT pathway is commonly triggered by the activation of receptor tyrosine kinases in response to the stimulation of growth factors that leads to the autophosphorylation on tyrosine residues and transphosphorylation of adaptor proteins. Activation of $\mathrm{PI} 3 \mathrm{~K}$ occurs upon binding its $\mathrm{SH}_{2}$ domains of the p85 regulatory subunit to specific tyrosine residues on the activated receptor or associated adaptor proteins. This leads to the translocation of PI3K from cytoplasm to plasma membrane and the activation of $\mathrm{p} 110 \alpha$ catalytic subunit ${ }^{17}$. Activated PI3K can add a phosphate group to the $\mathrm{D} 3-\mathrm{OH}$ position of the inner membrane phosphoinositides leading to the production of the second messengers PI-3, 4-biphosphate and PI-3, 4, 5-triphosphate $\left(\mathrm{PIP}_{3}\right)^{18}$. These lipids have a high affinity to the pleckstrin-homology domain of AKT and PDK1. This binding recruits AKT from the cytoplasm to the plasma membrane ${ }^{19}$. The translocation of AKT to plasma membrane can result in a conformational change of AKT that exposes two amino acids: threonine 308, which is phospharylated by $\mathrm{PDK}^{20}$; serine 473 , which is phosphorylated by $\mathrm{PDK} 2^{21}$. The phosphorylation of these two amino acids is necessary for the activation of AKT. AKT 
transmits signal to many target proteins that are involved in the control of apotosis and cell proliferation. The termination of PI3K pathway is mediated by two different types of phosphatases. The $\mathrm{SH}_{2}$ containing inositol phosphatase (SHIP) dephosphorylates PIP3 at position D5, producing PI-3, 4-biphosphate ${ }^{22}$. Phosphatase and tensin homolog (PTEN) acts as an antagonist to remove the phosphate group at the D3 position and convert PIP3 back to PI-4, 5-biphosphate ${ }^{23}$.

There are three known isoforms of Class IA p110 (p110 $/ \mathrm{p} 110 \beta / \mathrm{p} 110 \delta)$ and seven known p85/p55 subunits generated by alternative splicing of three genes (p85 $/ \mathrm{p} 85 \beta / \mathrm{p} 85 \gamma)$. Biochemical and gene knock out studies suggest that different isoforms mediate specific signaling pathway and have different functions ${ }^{24-26}$. PI3K is an enzyme involved in many cellular processes. Its activity has been linked to cell survival, cell proliferation, cell cycle progression, protein synthesis, cell transformation, cytoskeleton organization and angiogenesis $^{27}$. PI3K was first reported as an oncogene by the analysis of the avian sarcoma virus 16 (ASV 16) genome. ASV16 encodes an oncogene that is derived from the cellular gene for the catalytic p110 $\alpha$ subunit of PI3K. The viral p110 $\alpha$ gene has PI3K activity. Subcutaneous injection of one-day-old chickens with chicken embryo fibroblasts transfected with the viral chicken $\mathrm{p} 110 \alpha$ cDNA in an avian retroviral expression vector RCAS, RCAS-v-P3K, resulted in the induction of hemangiosarcomas at the injection site in two weeks ${ }^{28}$. Abnormalities in the PI3K pathway are common in cancer. PI3K is a frequent target of mutation. PIK3CA, the gene encoding the p110 $\alpha$ catalytic subunit, has somatic mutations in 74 of 199 colorectal cancers (32\%), 4 of 15 glioblastomas (27\%), 3 of 12 gastric cancers 
(25\%), 1 of 12 breast cancers (8\%), and 1 of 24 lung cancers (4\%) ${ }^{29}$. Somatic missense mutations were also observed in 24 of $198(12 \%)$ ovarian carcinomas, and in 13 of $72(18 \%)$ breast carcinomas ${ }^{5}$. The gene copy number of the p110 $\alpha$ catalytic subunit of PI3K is frequently increased in ovarian cancers ${ }^{6,30}$. Although $\mathrm{p} 85 \alpha$ mutation is rare, a mutated form of the $\mathrm{p} 85$ subunit of PI3K has been detected in a human lymphoma cell line ${ }^{31}$. PTEN and AKT are also targets of frequent genomic changes in human cancers. PI3K antagonist PTEN is frequently mutated in many human cancers such as glioblastoma, melanoma, endometrial cancer, prostate cancer, breast cancer and ovarian carcinoma ${ }^{7,10,32-35}$. AKT is a very important downstream target of PI3K. AKT has three different isoforms that have been implicated in specific functions in cancer $^{36}$. AKT2 plays an important role in cell motility and invasion ${ }^{37}$. AKT3 has a role in hormone independence. AKT amplification or overexpression is found in some human cancers ${ }^{38-42}$. A 20 fold amplification of AKT1 is found in a primary gastric adenocarcinoma ${ }^{43}$. AKT2 was shown to be amplified and overexpressed in ovarian carcinomas ${ }^{38}$, pancreatic cancer ${ }^{40}$ and breast carcinomas ${ }^{44}$. AKT3 was found to be upregulated in estrogen receptor negative tumors and androgen-independent prostate cancers ${ }^{45}$. AKT is activated by growth factor signaling through PI3K and strongly enhances cell growth and proliferation by phosphorylating regulators of cell cycle, apoptosis, metabolism and cell growth and translation. Activation of AKT has also been reported in a wide variety of human cancers. AKT activation has been shown to correlate with advanced disease and/or poor prognosis in some tumor types ${ }^{46-50}$. 


\section{The PI3K/AKT pathway and angiogenesis}

The role of $\mathrm{PI} 3 \mathrm{~K}$ in angiogenesis, an important process involved in neovascularization, has been established ${ }^{51}$. Tumor growth and metastasis were proposed to be angiogenesis-dependent in $1971^{52}$. Angiogenesis is the generation of new blood vessels derived from the existing vasculature ${ }^{53}$. Tumor vasculature is highly disorganized. Vessels are tortuous and dilated with excessive branching and shunts. Tumor angiogenesis is a highly regulated process that is controlled genetically by alterations in oncogene and tumor suppressor gene expression and physiologically by the tumor microenvironment. Vascular endothelial growth factors (VEGF) are the most powerful angiogenic cytokines in many cancers. VEGF expression is regulated by tissue oxygen content $\mathrm{t}^{54,55}$ and by growth factors and cytokines, including platelet-derived growth factor ${ }^{56}$, epidermal growth factor ${ }^{57}$, insulin, insulin-like growth factor- $\mathrm{I}^{58}$, and tumor necrosis factor $\alpha^{59}$. VEGF transcription is regulated by many transcription factors that include AP- $1^{60}, \mathrm{NF}-\kappa \mathrm{B}^{61}$ and hypoxia-inducible factor 1 alpha $(\mathrm{HIF}-1 \alpha)^{62}$. Hypoxia is the major physiological stimulus for VEGF expression. Hypoxia stimulates VEGF expression through gene transcription ${ }^{55}$, mRNA stablization ${ }^{63}$ and translational regulation ${ }^{64,65}$. The transcriptional regulation of VEGF is mediated by HIF- $1 \alpha^{66}$. HIF-1 regulates both hypoxia- and growth factor-induced VEGF expression in tumor cells. Activated receptor tyrosine kinases increase HIF-1 $\alpha$ protein synthesis through $\mathrm{PI} 3 \mathrm{~K} / \mathrm{AKT} / \mathrm{mTOR}$ pathway and ERK mitogen-activated protein kinase (MAPK) pathway ${ }^{67-69}$. Activation of oncogene Ras $^{70}$ and the activation of PI3K pathway stimulate the expression and secretion of VEGF in tumor cells ${ }^{67,71}$. 
PI3K/AKT pathway regulates the expression of VEGF mediated by HIF-1 $\alpha$ independent of hypoxic condition in tumor cells ${ }^{72}$. The inhibitor of PI3K LY294002 or the mTOR inhibitor rapamycin inhibited secretion of VEGF by growth factors in prostate cancer cells and this effect linked the EGF/PI3K/PTEN/AKT/FRAP pathway to angiogenesis ${ }^{73}$. Similarly, LY294002 reduced both constitutive and hypoxia-inducible levels of VEGF in ovarian carcinoma cells ${ }^{74}$. In addition, overexpression of the v-P3k protein or of cellular PI3K with a myristylation signal, Myr-P3k, can induce angiogenesis in the chorioallantoic membrane (CAM) of the chicken embryo. Overexpression of the myristylated form of the PI3K target Akt, Myr-Akt, also induces angiogenesis. Moreover, the VEGF mRNA level is elevated in cells expressing activated PI3K or Myr-Akt ${ }^{75}$ AKT has effects on tumor-induced angiogenesis that is mediated partially through hypoxia-inducible factor-1 $\alpha(\mathrm{HIF}-1 \alpha)$ and vascular endothelial growth factor (VEGF). AKT can also preferentially increase the rate of translation of VEGF mRNA $^{76,77}$. Activation of AKT can lead to the stablization of HIF-1 $\alpha$ and increased production of VEGF via mTOR/FRAP in breast $^{73}$ and prostate cancer cells ${ }^{69}$. PTEN is also involved in tumor angiogenesis. PTEN can induce secretion of thrombospondin-1, a negative regulator of angiogenesis ${ }^{78}$.

\section{TSC and tumor angiogenesis}

Tuberous sclerosis complex (TSC) is an autosomal dominant disorder and is characterized by the development of hamartomas, which is unusual tumor-like growth found in the central nervous system, kidney, heart, lung and $\operatorname{skin}^{79}$. Considerable 
progress has been made in understanding the molecular genetics of TSC, highlighted by the identification of the two-tumor suppressor genes $t s c 1$ and $t s c 2^{80,81}$. The $t s c 1$ and $t s c 2$ genes encode the protein hamartin and tuberin ${ }^{82}$. Mutation of either TSC gene leads to the development of the heritable disorder TSC. The TSC genes undergo loss of heterozygosity(LOH) in the majority of the TSC lesions ${ }^{83}$. LOH in TSC gene-associated regions is also frequently observed in neoplasms such as angiomyolipoma, lymphangiomyomatosis ${ }^{84}$, renal cell carcinoma ${ }^{85}$ and lung adenocarcinoma with multiple atypical adenomatous hyperplasis ${ }^{86}$.

Genetic studies in Drosophila show that TSC1 and TSC2 take part in the control of cell size via the insulin/p70S6K pathway ${ }^{87}$. TSC2 encodes a protein of $200 \mathrm{kDa}$, TSC2 (also called Tuberin), which is ubiquitously expressed and localized to the perinuclear Golgi ${ }^{88}$. TSC2 forms a complex with TSC1 that negatively regulates mammalian target of Rapamycin (mTOR) ${ }^{89}$. Recent biochemical analyses confirmed that tuberin is a substrate of $\mathrm{AKT}{ }^{90}$ and can regulate PI3K-dependent activation of p70S6 $\mathrm{K}^{91}$. AKT is activated by growth factors and phosphorylates TSC2, which disrupts TSC2 binding to TSC1. TSC2 acts as a GTPase-activating protein for Rap1 and Rab5 $5^{92}$. Disruption of TSC2/TSC1 complex allows for activation of mTOR. Activated mTOR phosphorylates 4E-BP and S6 kinase, leading to an increase in the rates of protein translation ${ }^{93}$.

One common phenotype of the TSC lesions is the highly angiogenic vascular vessel in the benign and malignant tumors. Abnormal blood vessels can be found in angiomyolipomas and cutaneous angiofibromas ${ }^{85}$. Several studies suggested that TSC 
plays a role in the regulation of angiogenesis. Loss of tuberin is accompanied by increased levels of HIF-1 $\alpha$ and VEGF ${ }^{94}$. Inactivation of $\mathrm{TSC} 2$ results in the accumulation of HIF-2 $\alpha$ and upregulation of VEGF in rat renal cell carcinoma ${ }^{95}$. TSC2 regulates VEGF through mTOR-dependent and -independent pathways ${ }^{96}$.

\section{P70S6K1 and tumorigenesis}

P70S6K1 is an important regulator of cell proliferation and cell growth. The 70kDa ribosomal S6 kinase (p70S6K) is activated by PI3K and MAPK. Full activation of p70S6K1 requires phosphorylation of T229 by PDK $1^{97}$ and phosphorylation by T389, possibly by mTOR ${ }^{98,99}$. Growth factors such as insulin, PDGF and EGF can activate p70S6K1 through the activation of PI3K and AKT ${ }^{100}$. PI3K activation is necessary and sufficient for the activation of p70S6K1 which specifically phosphorylate the ribosomal protein $\mathrm{S} 6$ required for cells to enter the $\mathrm{S}$ phase after mitogenic stimulation 101. Activated PI3K or AKT can induce cell transformation through the phosphorylation and activation of p70S6K1 ${ }^{102}$. P70S6K1 regulates cell growth by inducing protein synthesis components. The physiological target of growth factor activated p70S6K1 is the 40s subunit of the S6 ribosomal protein. Phosphorylation of S6 induces the selective translation of 5 ' tract of pyrimidines (5' TOP) mRNA, a subset of mRNA that contains an oligopyrimidine tract at its $5^{\prime}$ untranslated region. The 5' TOP mRNA encodes components of the translational machinery such as elongation factors, ribosomal proteins and poly (A)-binding protein ${ }^{103}$.

It has been suggested that p70S6K1 is involved in tumor progression. A recent 
finding in expression profiles of cancer cells is the upregulation of mRNAs that code for ribosomal proteins, suggesting involvement of $\mathrm{p} 70 \mathrm{~S} 6 \mathrm{~K} 1^{104}$. A marked increase in p70S6K mRNA and protein expressions have been demonstrated in breast cancer cell lines as well as in primary breast tumors ${ }^{105}$. P70S6K1 is overactivated in the majority of human papillary cancer cells ${ }^{106}$, small cell lung cancer cells ${ }^{107}$ and pancreatic cancer cells $^{108}$. P70S6K1 is implicated in playing an important role in PTEN negative and in AKT-overexpressing tumors ${ }^{109,110}$. PTEN $^{+/-}$mice show increased incidence of uterine and adrenal medullary tumors. PTEN levels are decreased and S6K is activated in these tumors. Treatment of mice with the rapamycin analog CCI-779 causes a reduction in p70S6K1 activation and inhibits tumor growth ${ }^{110}$. Human tumor cell lines lacking PTEN showed an increase of phosphorylated S6 and total S6 when compared to PTEN wild-type cells ${ }^{109}$. Tumor formation by PTEN-negative or by AKT-overexpressing human cancer cells in SCID mice is inhibited by CCI-779. These findings suggest that the activity of p70S6K1 is correlated with PI3K-induced tumorigenesis.

The pharmacological agent rapamycin can block the activation of p70S6K1. Rapamycin binds the immunophilin, FK-506-binding protein $12^{111}$, and this complex inhibits the cellular target of rapamycin, mTOR/RAFT/FRAP ${ }^{112}$. The complex inhibits the function of mTOR, blocking growth factor induced activation of $\mathrm{p} 70 \mathrm{~S} 6 \mathrm{~K} 1^{103}$ and phosphorylation of the suppressor of the eukaryotic initiation factor $4 \mathrm{E}$ (eIF-4E) ${ }^{113}$. This results in the specific inhibition of translation of transcripts encoding ribosomal proteins, and several proteins essential for cell cycle progression such as cyclin D $1^{114}$ 
and $\mathrm{p} 21^{115}$.

The PI3K-p70S6K1 signaling pathway is required for VEGF-mediated proliferation of endothelial cells ${ }^{116}$. P70S6K1-mediated protein synthesis is a critical step for vascular endothelial cell proliferation. Selective inhibition of p70S6K1 with rapamycin inhibited VEGF stimulated HUVEC proliferation ${ }^{117}$. Rapamycin inhibits primary and metastatic tumor growth by inhibiting angiogenesis in vivo ${ }^{118}$. Rapamycin also effectively controlled the growth of established tumors. Rapamycin showed antiangiogenic activities linked to a decrease in the production of VEGF in vitro. Hypoxia increases sprout formation in rat and mouse 3-dimensional models of angiogenesis via a rapamycin-sensitive mechanism ${ }^{119}$.

Loss of PTEN and the gain-of-function of PI3K signaling render HIF-1 $\alpha$ induction pathway sensitive to rapamycin. Rapamycin inhibits both stabilization of HIF- $1 \alpha$ and transcriptional activity of HIF-1 in hypoxic cancer cells ${ }^{69}$. The inhibitory effect of rapamycin on HIF-1-dependent transcription in PC-3 cells is mediated through the suppression of mTOR function. Rapamycin interferes with HIF-1 activation in hypoxic cells by increasing the rate of HIF-1 $\alpha$ degradation ${ }^{120}$.

\section{Survivin and PI3K/AKT pathway}

The evasion from apoptosis during homeostasis is thought to be a critical step for tumorigenesis. The inhibitor of apoptosis (IAP), including ML-IAP, XIAP, cIAP1, cIAP2, NIAP, apollon and survivin, is mainly involved in antiapoptosis. This family of proteins are characterized by a signature domain of about 70 amino acids (aa) termed 
baculovirus IAP repeat (BIR) ${ }^{76,121-125}$, which is evolutionarily conserved including virus, yeast, nematode, fly, and mammalian. Survivin, a unique member in the IAP family, is expressed primarily in fetal but not adult tissues, but it is highly expressed in cancer ${ }^{126}$. Survivin is cell cycle regulated, and involved in both control of apoptosis and regulation of cell division. The anti-apoptotic function of survivin results from its binding to the mitotic spindle during G2/M in transformed cells, probably in a complex with cdk4 and p21 which blocks caspase-3 activation ${ }^{127}$.

Non-cell-cycle-dependent mechanisms influencing survivin expression involve responses to hematopoietic and vascular remodeling cytokines, STAT3-dependent signaling and PI3K activity ${ }^{128}$. The upregulation of survivin induced by granulocyte-macrophage colony stimulating factor (GM-CSF), angiopoietin-1 (Ang-1) and VEGF is accompanied by the activation of PI3K/AKT. PI3K inhibitor LY294002 inhibited survivin expression on GM-CSF stimulation of acute myeloid leukemia cells 129. Angiopoietin-1 acting via the Tie 2 receptor induces phosphorylation of the AKT, which is associated with up-regulation of survivin in endothelial cells ${ }^{130}$. VEGF up-regulates survivin via the PI3K/AKT signaling pathway in human neuroblastoma cells $^{131}$. VEGF leads to the induction of the survivin protein in human umbilical vein endothelial cells ${ }^{132}$. Survivin plays a pivotal role in VEGF-mediated endothelial cell protection by preserving the microtubule network ${ }^{133}$. The activation and regulation of survivin was induced by hypoxic preconditioning during human coronary arteriolar endothelial cells survival and tubular morphogenesis ${ }^{134}$. They showed the involvement of NF- $\kappa \mathrm{B}$ and PI3-kinase as essential components of survivin expression. 


\section{Reference List}

1. Samuels, Y., Wang, Z., Bardelli, A., Silliman, N., Ptak, J., Szabo, S., Yan, H., Gazdar, A., Powell, S. M., Riggins, G. J., Willson, J. K., Markowitz, S., Kinzler, K. W., Vogelstein, B., and Velculescu, V. E. High frequency of mutations of the PIK3CA gene in human cancers. Science, 304: 554, 2004.

2. Li, V. S., Wong, C. W., Chan, T. L., Chan, A. S., Zhao, W., Chu, K. M., So, S., Chen, X., Yuen, S. T., and Leung, S. Y. Mutations of PIK3CA in gastric adenocarcinoma. BMC.Cancer, 5: 29, 2005.

3. Hartmann, C., Bartels, G., Gehlhaar, C., Holtkamp, N., and von Deimling, A. PIK3CA mutations in glioblastoma multiforme. Acta Neuropathol.(Berl), 109: 639-642, 2005.

4. Velho, S., Oliveira, C., Ferreira, A., Ferreira, A. C., Suriano, G., Schwartz S Jr, Duval, A., Carneiro, F., Machado, J. C., Hamelin, R., and Seruca, R. The prevalence of PIK3CA mutations in gastric and colon cancer. Eur.J.Cancer, 41: $1649-1654,2005$

5. Levine, D. A., Bogomolniy, F., Yee, C. J., Lash, A., Barakat, R. R., Borgen, P. I., and Boyd, J. Frequent mutation of the PIK3CA gene in ovarian and breast cancers. Clin.Cancer Res., 11: 2875-2878, 2005.

6. Shayesteh, L., Lu, Y., Kuo, W. L., Baldocchi, R., Godfrey, T., Collins, C., Pinkel, D., Powell, B., Mills, G. B., and Gray, J. W. PIK3CA is implicated as an oncogene in ovarian cancer. Nat.Genet., 21: 99-102, 1999.

7. Besson, A., Robbins, S. M., and Yong, V. W. PTEN/MMAC1/TEP1 in signal transduction and tumorigenesis. Eur.J.Biochem., 263: 605-611, 1999.

8. Berven, L. A. and Crouch, M. F. Cellular function of p70S6K: a role in regulating cell motility. Immunol.Cell Biol., 78: 447-451, 2000. 
9. Chen, R. H., Sarnecki, C., and Blenis, J. Nuclear localization and regulation of erk- and rsk-encoded protein kinases. Mol.Cell Biol., 12: 915-927, 1992.

10. Mills, G. B., Lu, Y., Fang, X., Wang, H., Eder, A., Mao, M., Swaby, R., Cheng, K. W., Stokoe, D., Siminovitch, K., Jaffe, R., and Gray, J. The role of genetic abnormalities of PTEN and the phosphatidylinositol 3-kinase pathway in breast and ovarian tumorigenesis, prognosis, and therapy. Semin.Oncol., 28: 125-141, 2001.

11. Mills, G. B., Fang, X., Lu, Y., Hasegawa, Y., Eder, A., Tanyi, J., Tabassam, F. H., Mao, M., Wang, H., Cheng, K. W., Nakayama, Y., Kuo, W., Erickson, J., Gershenson, D., Kohn, E. C., Jaffe, R., Bast, R. C., Jr., and Gray, J. Specific keynote: molecular therapeutics in ovarian cancer. Gynecol.Oncol., 88: S88-S92, 2003.

12. Cohen, C., Lohman, C. M., Cotsonis, G., Lawson, D., and Santoianni, R. Survivin expression in 49 ovarian carcinomas. Mod.Pathol., 17: 603, 2004.

13. Komuro, Y., Watanabe, T., Tsurita, G., Muto, T., and Nagawa, H. Survivin expression in ovarian carcinoma: correlation with apoptotic markers and prognosis. Mod.Pathol., 17: 264, 2004.

14. Takai, N., Miyazaki, T., Nishida, M., Nasu, K., and Miyakawa, I. Expression of survivin is associated with malignant potential in epithelial ovarian carcinoma. Int.J.Mol.Med., 10: 211-216, 2002.

15. Dhand, R., Hiles, I., Panayotou, G., Roche, S., Fry, M. J., Gout, I., Totty, N. F., Truong, O., Vicendo, P., Yonezawa, K., and . PI 3-kinase is a dual specificity enzyme: autoregulation by an intrinsic protein-serine kinase activity. EMBO J., 13: 522-533, 1994.

16. Whitman, M., Downes, C. P., Keeler, M., Keller, T., and Cantley, L. Type I phosphatidylinositol kinase makes a novel inositol phospholipid, 
phosphatidylinositol-3-phosphate. Nature, 332: 644-646, 1988.

17. Luo, J., Manning, B. D., and Cantley, L. C. Targeting the PI3K-Akt pathway in human cancer: rationale and promise. Cancer Cell, 4: 257-262, 2003.

18. Cantley, L. C. The phosphoinositide 3-kinase pathway. Science, 296: 1655-1657, 2002 .

19. Sable, C. L., Filippa, N., Filloux, C., Hemmings, B. A., and Van Obberghen, E. Involvement of the pleckstrin homology domain in the insulin-stimulated activation of protein kinase B. J.Biol.Chem., 273: 29600-29606, 1998.

20. Stokoe, D., Stephens, L. R., Copeland, T., Gaffney, P. R., Reese, C. B., Painter, G. F., Holmes, A. B., McCormick, F., and Hawkins, P. T. Dual role of phosphatidylinositol-3,4,5-trisphosphate in the activation of protein kinase B. Science, 277: 567-570, 1997.

21. Nicholson, K. M. and Anderson, N. G. The protein kinase B/Akt signalling pathway in human malignancy. Cell Signal., 14: 381-395, 2002.

22. Damen, J. E., Liu, L., Rosten, P., Humphries, R. K., Jefferson, A. B., Majerus, P. W., and Krystal, G. The $145-\mathrm{kDa}$ protein induced to associate with She by multiple cytokines is an inositol tetraphosphate and phosphatidylinositol 3,4,5-triphosphate 5-phosphatase. Proc.Natl.Acad.Sci.U.S.A, 93: 1689-1693, 1996.

23. Cantley, L. C. and Neel, B. G. New insights into tumor suppression: PTEN suppresses tumor formation by restraining the phosphoinositide 3-kinase/AKT pathway. Proc.Natl.Acad.Sci.U.S.A, 96: 4240-4245, 1999.

24. Bi, L., Okabe, I., Bernard, D. J., Wynshaw-Boris, A., and Nussbaum, R. L. Proliferative defect and embryonic lethality in mice homozygous for a deletion in the p110alpha subunit of phosphoinositide 3-kinase. J.Biol.Chem., 274: 
10963-10968, 1999.

25. Bilancio, A., Okkenhaug, K., Camps, M., Emery, J. L., Ruckle, T., Rommel, C., and Vanhaesebroeck, B. Key role of the p110delta isoform of PI3K in B-cell antigen and IL-4 receptor signaling: comparative analysis of genetic and pharmacologic interference with p110delta function in B cells. Blood, 107: 642-650, 2006.

26. Brachmann, S. M., Ueki, K., Engelman, J. A., Kahn, R. C., and Cantley, L. C. Phosphoinositide 3-kinase catalytic subunit deletion and regulatory subunit deletion have opposite effects on insulin sensitivity in mice. Mol.Cell Biol., 25: 1596-1607, 2005.

27. Roymans, D. and Slegers, H. Phosphatidylinositol 3-kinases in tumor progression. Eur.J.Biochem., 268: 487-498, 2001.

28. Chang, H. W., Aoki, M., Fruman, D., Auger, K. R., Bellacosa, A., Tsichlis, P. N., Cantley, L. C., Roberts, T. M., and Vogt, P. K. Transformation of chicken cells by the gene encoding the catalytic subunit of PI 3-kinase. Science, 276: 1848-1850, 1997.

29. Samuels, Y., Wang, Z., Bardelli, A., Silliman, N., Ptak, J., Szabo, S., Yan, H., Gazdar, A., Powell, S. M., Riggins, G. J., Willson, J. K., Markowitz, S., Kinzler, K. W., Vogelstein, B., and Velculescu, V. E. High frequency of mutations of the PIK3CA gene in human cancers. Science, 304: 554, 2004.

30. Jimenez, C., Jones, D. R., Rodriguez-Viciana, P., Gonzalez-Garcia, A., Leonardo, E., Wennstrom, S., von Kobbe, C., Toran, J. L., Borlado, L., Calvo, V., Copin, S. G., Albar, J. P., Gaspar, M. L., Diez, E., Marcos, M. A., Downward, J., Martinez, A., Merida, I., and Carrera, A. C. Identification and characterization of a new oncogene derived from the regulatory subunit of phosphoinositide 3-kinase. EMBO J., 17: 743-753, 1998. 
31. Jucker, M., Sudel, K., Horn, S., Sickel, M., Wegner, W., Fiedler, W., and Feldman, R. A. Expression of a mutated form of the p85alpha regulatory subunit of phosphatidylinositol 3-kinase in a Hodgkin's lymphoma-derived cell line (CO). Leukemia, 16: 894-901, 2002.

32. Di Cristofano, A. and Pandolfi, P. P. The multiple roles of PTEN in tumor suppression. Cell, 100: 387-390, 2000.

33. Esteller, M., Xercavins, J., and Reventos, J. Advances in the molecular genetics of endometrial cancer (Review). Oncol.Rep., 6: 1377-1382, 1999.

34. Li, J., Yen, C., Liaw, D., Podsypanina, K., Bose, S., Wang, S. I., Puc, J., Miliaresis, C., Rodgers, L., McCombie, R., Bigner, S. H., Giovanella, B. C., Ittmann, M., Tycko, B., Hibshoosh, H., Wigler, M. H., and Parsons, R. PTEN, a putative protein tyrosine phosphatase gene mutated in human brain, breast, and prostate cancer. Science, 275: 1943-1947, 1997.

35. Rasheed, B. K., Wiltshire, R. N., Bigner, S. H., and Bigner, D. D. Molecular pathogenesis of malignant gliomas. Curr.Opin.Oncol., 11: 162-167, 1999.

36. Bellacosa, A., Testa, J. R., Moore, R., and Larue, L. A portrait of AKT kinases: human cancer and animal models depict a family with strong individualities. Cancer Biol.Ther., 3: 268-275, 2004.

37. Arboleda, M. J., Lyons, J. F., Kabbinavar, F. F., Bray, M. R., Snow, B. E., Ayala, R., Danino, M., Karlan, B. Y., and Slamon, D. J. Overexpression of AKT2/protein kinase Bbeta leads to up-regulation of beta1 integrins, increased invasion, and metastasis of human breast and ovarian cancer cells. Cancer Res., 63: 196-206, 2003.

38. Cheng, J. Q., Godwin, A. K., Bellacosa, A., Taguchi, T., Franke, T. F., Hamilton, T. C., Tsichlis, P. N., and Testa, J. R. AKT2, a putative oncogene encoding a member of a subfamily of protein-serine/threonine kinases, is amplified in 
human ovarian carcinomas. Proc.Natl.Acad.Sci.U.S.A, 89: 9267-9271, 1992.

39. Liao, Y., Grobholz, R., Abel, U., Trojan, L., Michel, M. S., Angel, P., and Mayer, D. Increase of AKT/PKB expression correlates with gleason pattern in human prostate cancer. Int.J.Cancer, 107: 676-680, 2003.

40. Miwa, W., Yasuda, J., Murakami, Y., Yashima, K., Sugano, K., Sekine, T., Kono, A., Egawa, S., Yamaguchi, K., Hayashizaki, Y., and Sekiya, T. Isolation of DNA sequences amplified at chromosome 19q13.1-q13.2 including the AKT2 locus in human pancreatic cancer. Biochem.Biophys.Res.Commun., 225: 968-974, 1996.

41. Roy, H. K., Olusola, B. F., Clemens, D. L., Karolski, W. J., Ratashak, A., Lynch, H. T., and Smyrk, T. C. AKT proto-oncogene overexpression is an early event during sporadic colon carcinogenesis. Carcinogenesis, 23: 201-205, 2002.

42. Ruggeri, B. A., Huang, L., Wood, M., Cheng, J. Q., and Testa, J. R. Amplification and overexpression of the AKT2 oncogene in a subset of human pancreatic ductal adenocarcinomas. Mol.Carcinog., 21: 81-86, 1998.

43. Staal, S. P. Molecular cloning of the akt oncogene and its human homologues AKT1 and AKT2: amplification of AKT1 in a primary human gastric adenocarcinoma. Proc.Natl.Acad.Sci.U.S.A, 84: 5034-5037, 1987.

44. Bellacosa, A., de Feo, D., Godwin, A. K., Bell, D. W., Cheng, J. Q., Altomare, D. A., Wan, M., Dubeau, L., Scambia, G., Masciullo, V., and . Molecular alterations of the AKT2 oncogene in ovarian and breast carcinomas. Int.J.Cancer, 64: 280-285, 1995.

45. Nakatani, K., Thompson, D. A., Barthel, A., Sakaue, H., Liu, W., Weigel, R. J., and Roth, R. A. Up-regulation of Akt3 in estrogen receptor-deficient breast cancers and androgen-independent prostate cancer lines. J.Biol.Chem., 274: 21528-21532, 1999. 
46. Amornphimoltham, P., Sriuranpong, V., Patel, V., Benavides, F., Conti, C. J., Sauk, J., Sausville, E. A., Molinolo, A. A., and Gutkind, J. S. Persistent activation of the Akt pathway in head and neck squamous cell carcinoma: a potential target for UCN-01. Clin.Cancer Res., 10: 4029-4037, 2004.

47. Nam, S. Y., Lee, H. S., Jung, G. A., Choi, J., Cho, S. J., Kim, M. K., Kim, W. H., and Lee, B. L. Akt/PKB activation in gastric carcinomas correlates with clinicopathologic variables and prognosis. APMIS, 111: 1105-1113, 2003.

48. Schlieman, M. G., Fahy, B. N., Ramsamooj, R., Beckett, L., and Bold, R. J. Incidence, mechanism and prognostic value of activated AKT in pancreas cancer. Br.J.Cancer, 89: 2110-2115, 2003.

49. Vestey, S. B., Sen, C., Calder, C. J., Perks, C. M., Pignatelli, M., and Winters, Z. E. Activated Akt expression in breast cancer: correlation with p53, Hdm2 and patient outcome. Eur.J.Cancer, 41: 1017-1025, 2005.

50. Zhou, X., Tan, M., Stone, H., V, Klos, K. S., Lan, K. H., Yang, Y., Yang, W., Smith, T. L., Shi, D., and Yu, D. Activation of the Akt/mammalian target of rapamycin/4E-BP1 pathway by ErbB2 overexpression predicts tumor progression in breast cancers. Clin.Cancer Res., 10: 6779-6788, 2004.

51. Brader, S. and Eccles, S. A. Phosphoinositide 3-kinase signalling pathways in tumor progression, invasion and angiogenesis. Tumori, 90: 2-8, 2004.

52. Folkman, J. Tumor angiogenesis: therapeutic implications. N.Engl.J.Med., 285: 1182-1186, 1971.

53. Auerbach, W. and Auerbach, R. Angiogenesis inhibition: a review. Pharmacol.Ther., 63: 265-311, 1994.

54. Ikeda, E., Achen, M. G., Breier, G., and Risau, W. Hypoxia-induced transcriptional activation and increased mRNA stability of vascular endothelial 
growth factor in C6 glioma cells. J.Biol.Chem., 270: 19761-19766, 1995.

55. Levy, A. P., Levy, N. S., Wegner, S., and Goldberg, M. A. Transcriptional regulation of the rat vascular endothelial growth factor gene by hypoxia. J.Biol.Chem., 270: 13333-13340, 1995.

56. Wang, D., Huang, H. J., Kazlauskas, A., and Cavenee, W. K. Induction of vascular endothelial growth factor expression in endothelial cells by platelet-derived growth factor through the activation of phosphatidylinositol 3-kinase. Cancer Res., 59: 1464-1472, 1999.

57. Maity, A., Pore, N., Lee, J., Solomon, D., and O'Rourke, D. M. Epidermal growth factor receptor transcriptionally up-regulates vascular endothelial growth factor expression in human glioblastoma cells via a pathway involving phosphatidylinositol 3'-kinase and distinct from that induced by hypoxia. Cancer Res., 60: 5879-5886, 2000.

58. Miele, C., Rochford, J. J., Filippa, N., Giorgetti-Peraldi, S., and Van Obberghen, E. Insulin and insulin-like growth factor-I induce vascular endothelial growth factor mRNA expression via different signaling pathways. J.Biol.Chem., 275: 21695-21702, 2000.

59. Ryuto, M., Ono, M., Izumi, H., Yoshida, S., Weich, H. A., Kohno, K., and Kuwano, M. Induction of vascular endothelial growth factor by tumor necrosis factor alpha in human glioma cells. Possible roles of SP-1. J.Biol.Chem., 271: 28220-28228, 1996.

60. Damert, A., Ikeda, E., and Risau, W. Activator-protein-1 binding potentiates the hypoxia-induciblefactor-1-mediated hypoxia-induced transcriptional activation of vascular-endothelial growth factor expression in C6 glioma cells. Biochem.J., 327 ( Pt 2): 419-423, 1997.

61. Huang, S., Robinson, J. B., Deguzman, A., Bucana, C. D., and Fidler, I. J. 
Blockade of nuclear factor-kappaB signaling inhibits angiogenesis and tumorigenicity of human ovarian cancer cells by suppressing expression of vascular endothelial growth factor and interleukin 8. Cancer Res., 60: 5334-5339, 2000 .

62. Ryan, H. E., Lo, J., and Johnson, R. S. HIF-1 alpha is required for solid tumor formation and embryonic vascularization. EMBO J., 17: 3005-3015, 1998.

63. Stein, I., Neeman, M., Shweiki, D., Itin, A., and Keshet, E. Stabilization of vascular endothelial growth factor mRNA by hypoxia and hypoglycemia and coregulation with other ischemia-induced genes. Mol.Cell Biol., 15: 5363-5368, 1995.

64. Akiri, G., Nahari, D., Finkelstein, Y., Le, S. Y., Elroy-Stein, O., and Levi, B. Z. Regulation of vascular endothelial growth factor (VEGF) expression is mediated by internal initiation of translation and alternative initiation of transcription. Oncogene, 17: 227-236, 1998.

65. Stein, I., Itin, A., Einat, P., Skaliter, R., Grossman, Z., and Keshet, E. Translation of vascular endothelial growth factor mRNA by internal ribosome entry: implications for translation under hypoxia. Mol.Cell Biol., 18: 3112-3119, 1998.

66. Forsythe, J. A., Jiang, B. H., Iyer, N. V., Agani, F., Leung, S. W., Koos, R. D., and Semenza, G. L. Activation of vascular endothelial growth factor gene transcription by hypoxia-inducible factor 1. Mol.Cell Biol., 16: 4604-4613, 1996.

67. Fukuda, R., Hirota, K., Fan, F., Jung, Y. D., Ellis, L. M., and Semenza, G. L. Insulin-like growth factor 1 induces hypoxia-inducible factor 1-mediated vascular endothelial growth factor expression, which is dependent on MAP kinase and phosphatidylinositol 3-kinase signaling in colon cancer cells. J.Biol.Chem., 277: 38205-38211, 2002. 
68. Treins, C., Giorgetti-Peraldi, S., Murdaca, J., Semenza, G. L., and Van Obberghen, E. Insulin stimulates hypoxia-inducible factor 1 through a phosphatidylinositol 3-kinase/target of rapamycin-dependent signaling pathway. J.Biol.Chem., 277: 27975-27981, 2002.

69. Zhong, H., Chiles, K., Feldser, D., Laughner, E., Hanrahan, C., Georgescu, M. M., Simons, J. W., and Semenza, G. L. Modulation of hypoxia-inducible factor 1alpha expression by the epidermal growth factor/phosphatidylinositol 3-kinase/PTEN/AKT/FRAP pathway in human prostate cancer cells: implications for tumor angiogenesis and therapeutics. Cancer Res., 60: 1541-1545, 2000.

70. Rak, J., Yu, J. L., Klement, G., and Kerbel, R. S. Oncogenes and angiogenesis: signaling three-dimensional tumor growth. J.Investig.Dermatol.Symp.Proc., 5: 24-33, 2000.

71. Jiang, B. H., Jiang, G., Zheng, J. Z., Lu, Z., Hunter, T., and Vogt, P. K. Phosphatidylinositol 3-kinase signaling controls levels of hypoxia-inducible factor 1. Cell Growth Differ., 12: 363-369, 2001.

72. Semenza, G. L. HIF-1 and tumor progression: pathophysiology and therapeutics. Trends Mol.Med., 8: S62-S67, 2002.

73. Laughner, E., Taghavi, P., Chiles, K., Mahon, P. C., and Semenza, G. L. HER2 (neu) signaling increases the rate of hypoxia-inducible factor 1alpha (HIF-1alpha) synthesis: novel mechanism for HIF-1-mediated vascular endothelial growth factor expression. Mol.Cell Biol., 21: 3995-4004, 2001.

74. Zhang, L., Yang, N., Katsaros, D., Huang, W., Park, J. W., Fracchioli, S., Vezzani, C., Rigault de la Longrais IA, Yao, W., Rubin, S. C., and Coukos, G. The oncogene phosphatidylinositol 3'-kinase catalytic subunit alpha promotes angiogenesis via vascular endothelial growth factor in ovarian carcinoma. 
Cancer Res., 63: 4225-4231, 2003.

75. Jiang, B. H., Zheng, J. Z., Aoki, M., and Vogt, P. K. Phosphatidylinositol 3-kinase signaling mediates angiogenesis and expression of vascular endothelial growth factor in endothelial cells. Proc.Natl.Acad.Sci.U.S.A, 97: 1749-1753, 2000 .

76. Chung, J., Bachelder, R. E., Lipscomb, E. A., Shaw, L. M., and Mercurio, A. M. Integrin (alpha 6 beta 4) regulation of eIF-4E activity and VEGF translation: a survival mechanism for carcinoma cells. J.Cell Biol., 158: 165-174, 2002.

77. Segrelles, C., Ruiz, S., Santos, M., Martinez-Palacio, J., Lara, M. F., and Paramio, J. M. Akt mediates an angiogenic switch in transformed keratinocytes. Carcinogenesis, 25: 1137-1147, 2004.

78. Wen, S., Stolarov, J., Myers, M. P., Su, J. D., Wigler, M. H., Tonks, N. K., and Durden, D. L. PTEN controls tumor-induced angiogenesis. Proc.Natl.Acad.Sci.U.S.A, 98: 4622-4627, 2001.

79. Mak, B. C. and Yeung, R. S. The tuberous sclerosis complex genes in tumor development. Cancer Invest, 22: 588-603, 2004.

80. Cheadle, J. P., Reeve, M. P., Sampson, J. R., and Kwiatkowski, D. J. Molecular genetic advances in tuberous sclerosis. Hum.Genet., 107: 97-114, 2000.

81. Young, J. and Povey, S. The genetic basis of tuberous sclerosis. Mol.Med.Today, 4: 313-319, 1998.

82. Green, A. J., Johnson, P. H., and Yates, J. R. The tuberous sclerosis gene on chromosome 9q34 acts as a growth suppressor. Hum.Mol.Genet., 3: 1833-1834, 1994.

83. Carbonara, C., Longa, L., Grosso, E., Borrone, C., Garre, M. G., Brisigotti, M., and Migone, N. 9q34 loss of heterozygosity in a tuberous sclerosis astrocytoma 
suggests a growth suppressor-like activity also for the TSC1 gene. Hum.Mol.Genet., 3: 1829-1832, 1994.

84. Smolarek, T. A., Wessner, L. L., McCormack, F. X., Mylet, J. C., Menon, A. G., and Henske, E. P. Evidence that lymphangiomyomatosis is caused by TSC2 mutations: chromosome 16p13 loss of heterozygosity in angiomyolipomas and lymph nodes from women with lymphangiomyomatosis. Am J Hum.Genet., 62: 810-815, 1998.

85. Parry, L., Maynard, J. H., Patel, A., Clifford, S. C., Morrissey, C., Maher, E. R., Cheadle, J. P., and Sampson, J. R. Analysis of the TSC1 and TSC2 genes in sporadic renal cell carcinomas. Br.J Cancer, 85: 1226-1230, 2001.

86. Takamochi, K., Ogura, T., Suzuki, K., Kawasaki, H., Kurashima, Y., Yokose, T., Ochiai, A., Nagai, K., Nishiwaki, Y., and Esumi, H. Loss of heterozygosity on chromosomes $9 \mathrm{q}$ and $16 \mathrm{p}$ in atypical adenomatous hyperplasia concomitant with adenocarcinoma of the lung. Am J Pathol, 159: 1941-1948, 2001.

87. Gao, X. and Pan, D. TSC1 and TSC2 tumor suppressors antagonize insulin signaling in cell growth. Genes Dev., 15: 1383-1392, 2001.

88. Wienecke, R., Maize, J. C., Jr., Shoarinejad, F., Vass, W. C., Reed, J., Bonifacino, J. S., Resau, J. H., de Gunzburg, J., Yeung, R. S., and DeClue, J. E. Co-localization of the TSC2 product tuberin with its target Rap1 in the Golgi apparatus. Oncogene, 13: 913-923, 1996.

89. Tee, A. R., Fingar, D. C., Manning, B. D., Kwiatkowski, D. J., Cantley, L. C., and Blenis, J. Tuberous sclerosis complex-1 and -2 gene products function together to inhibit mammalian target of rapamycin (mTOR)-mediated downstream signaling. Proc.Natl.Acad.Sci.U.S.A, 99: 13571-13576, 2002.

90. Inoki, K., Li, Y., Zhu, T., Wu, J., and Guan, K. L. TSC2 is phosphorylated and inhibited by Akt and suppresses mTOR signalling. Nat.Cell Biol., 4: 648-657, 
2002.

91. Harrington, L. S., Findlay, G. M., Gray, A., Tolkacheva, T., Wigfield, S., Rebholz, H., Barnett, J., Leslie, N. R., Cheng, S., Shepherd, P. R., Gout, I., Downes, C. P., and Lamb, R. F. The TSC1-2 tumor suppressor controls insulin-PI3K signaling via regulation of IRS proteins. J.Cell Biol., 166: 213-223, 2004.

92. Zhang, Y., Gao, X., Saucedo, L. J., Ru, B., Edgar, B. A., and Pan, D. Rheb is a direct target of the tuberous sclerosis tumour suppressor proteins. Nat.Cell Biol., 5: 578-581, 2003.

93. Fingar, D. C. and Blenis, J. Target of rapamycin (TOR): an integrator of nutrient and growth factor signals and coordinator of cell growth and cell cycle progression. Oncogene, 23: 3151-3171, 2004.

94. El Hashemite, N., Walker, V., Zhang, H., and Kwiatkowski, D. J. Loss of Tsc1 or Tsc2 induces vascular endothelial growth factor production through mammalian target of rapamycin. Cancer Res, 63: 5173-5177, 2003.

95. Liu, M. Y., Poellinger, L., and Walker, C. L. Up-regulation of hypoxia-inducible factor 2alpha in renal cell carcinoma associated with loss of Tsc-2 tumor suppressor gene. Cancer Res, 63: 2675-2680, 2003.

96. Brugarolas, J. B., Vazquez, F., Reddy, A., Sellers, W. R., and Kaelin, W. G., Jr. TSC2 regulates VEGF through mTOR-dependent and -independent pathways. Cancer Cell, 4: 147-158, 2003.

97. Currie, R. A., Walker, K. S., Gray, A., Deak, M., Casamayor, A., Downes, C. P., Cohen, P., Alessi, D. R., and Lucocq, J. Role of phosphatidylinositol 3,4,5-trisphosphate in regulating the activity and localization of 3-phosphoinositide-dependent protein kinase-1. Biochem.J., 337 ( Pt 3): 575-583, 1999. 
98. Burnett, P. E., Barrow, R. K., Cohen, N. A., Snyder, S. H., and Sabatini, D. M. RAFT1 phosphorylation of the translational regulators p70 S6 kinase and 4E-BP1. Proc.Natl.Acad.Sci.U.S.A, 95: 1432-1437, 1998.

99. Isotani, S., Hara, K., Tokunaga, C., Inoue, H., Avruch, J., and Yonezawa, K. Immunopurified mammalian target of rapamycin phosphorylates and activates p70 S6 kinase alpha in vitro. J.Biol.Chem., 274: 34493-34498, 1999.

100. Burgering, B. M. and Coffer, P. J. Protein kinase B (c-Akt) in phosphatidylinositol-3-OH kinase signal transduction. Nature, 376: 599-602, 1995.

101. Sekulic, A., Hudson, C. C., Homme, J. L., Yin, P., Otterness, D. M., Karnitz, L. M., and Abraham, R. T. A direct linkage between the phosphoinositide 3-kinase-AKT signaling pathway and the mammalian target of rapamycin in mitogen-stimulated and transformed cells. Cancer Res., 60: 3504-3513, 2000.

102. Aoki, M., Blazek, E., and Vogt, P. K. A role of the kinase mTOR in cellular transformation induced by the oncoproteins P3k and Akt. Proc.Natl.Acad.Sci.U.S.A, 98: 136-141, 2001.

103. Jefferies, H. B., Fumagalli, S., Dennis, P. B., Reinhard, C., Pearson, R. B., and Thomas, G. Rapamycin suppresses 5'TOP mRNA translation through inhibition of p70s6k. EMBO J., 16: 3693-3704, 1997.

104. Ross, D. T., Scherf, U., Eisen, M. B., Perou, C. M., Rees, C., Spellman, P., Iyer, V., Jeffrey, S. S., Van de, R. M., Waltham, M., Pergamenschikov, A., Lee, J. C., Lashkari, D., Shalon, D., Myers, T. G., Weinstein, J. N., Botstein, D., and Brown, P. O. Systematic variation in gene expression patterns in human cancer cell lines. Nat.Genet., 24: 227-235, 2000.

105. Barlund, M., Forozan, F., Kononen, J., Bubendorf, L., Chen, Y., Bittner, M. L., Torhorst, J., Haas, P., Bucher, C., Sauter, G., Kallioniemi, O. P., and Kallioniemi, 
A. Detecting activation of ribosomal protein S6 kinase by complementary DNA and tissue microarray analysis. J.Natl.Cancer Inst., 92: 1252-1259, 2000.

106. Miyakawa, M., Tsushima, T., Murakami, H., Wakai, K., Isozaki, O., and Takano, K. Increased expression of phosphorylated p70S6 kinase and Akt in papillary thyroid cancer tissues. Endocr.J., 50: 77-83, 2003.

107. Seufferlein, T. and Rozengurt, E. Rapamycin inhibits constitutive p70s6k phosphorylation, cell proliferation, and colony formation in small cell lung cancer cells. Cancer Res., 56: 3895-3897, 1996.

108. Shah, S. A., Potter, M. W., Ricciardi, R., Perugini, R. A., and Callery, M. P. FRAP-p70s6K signaling is required for pancreatic cancer cell proliferation. J.Surg.Res., 97: 123-130, 2001.

109. Neshat, M. S., Mellinghoff, I. K., Tran, C., Stiles, B., Thomas, G., Petersen, R., Frost, P., Gibbons, J. J., Wu, H., and Sawyers, C. L. Enhanced sensitivity of PTEN-deficient tumors to inhibition of FRAP/mTOR. Proc.Natl.Acad.Sci.U.S.A, 98: 10314-10319, 2001.

110. Podsypanina, K., Lee, R. T., Politis, C., Hennessy, I., Crane, A., Puc, J., Neshat, M., Wang, H., Yang, L., Gibbons, J., Frost, P., Dreisbach, V., Blenis, J., Gaciong, Z., Fisher, P., Sawyers, C., Hedrick-Ellenson, L., and Parsons, R. An inhibitor of mTOR reduces neoplasia and normalizes p70/S6 kinase activity in Pten+/- mice. Proc.Natl.Acad.Sci.U.S.A, 98: 10320-10325, 2001.

111. Harding, M. W., Galat, A., Uehling, D. E., and Schreiber, S. L. A receptor for the immunosuppressant FK506 is a cis-trans peptidyl-prolyl isomerase. Nature, 341: 758-760, 1989.

112. Scott, P. H., Brunn, G. J., Kohn, A. D., Roth, R. A., and Lawrence, J. C., Jr. Evidence of insulin-stimulated phosphorylation and activation of the mammalian target of rapamycin mediated by a protein kinase B signaling pathway. 
Proc.Natl.Acad.Sci.U.S.A, 95: 7772-7777, 1998.

113. Hara, K., Yonezawa, K., Kozlowski, M. T., Sugimoto, T., Andrabi, K., Weng, Q. P., Kasuga, M., Nishimoto, I., and Avruch, J. Regulation of eIF-4E BP1 phosphorylation by mTOR. J.Biol.Chem., 272: 26457-26463, 1997.

114. Rosenwald, I. B., Kaspar, R., Rousseau, D., Gehrke, L., Leboulch, P., Chen, J. J., Schmidt, E. V., Sonenberg, N., and London, I. M. Eukaryotic translation initiation factor 4E regulates expression of cyclin D1 at transcriptional and post-transcriptional levels. J.Biol.Chem., 270: 21176-21180, 1995.

115. Gaben, A. M., Saucier, C., Bedin, M., Barbu, V., and Mester, J. Rapamycin inhibits cdk4 activation, p 21(WAF1/CIP1) expression and G1-phase progression in transformed mouse fibroblasts. Int.J.Cancer, 108: 200-206, 2004.

116. Vinals, F., Chambard, J. C., and Pouyssegur, J. p70 S6 kinase-mediated protein synthesis is a critical step for vascular endothelial cell proliferation. J.Biol.Chem., 274: 26776-26782, 1999.

117. Yu, Y. and Sato, J. D. MAP kinases, phosphatidylinositol 3-kinase, and p70 S6 kinase mediate the mitogenic response of human endothelial cells to vascular endothelial growth factor. J.Cell Physiol, 178: 235-246, 1999.

118. Guba, M., von Breitenbuch, P., Steinbauer, M., Koehl, G., Flegel, S., Hornung, M., Bruns, C. J., Zuelke, C., Farkas, S., Anthuber, M., Jauch, K. W., and Geissler, E. K. Rapamycin inhibits primary and metastatic tumor growth by antiangiogenesis: involvement of vascular endothelial growth factor. Nat.Med., 8 : 128-135, 2002.

119. Humar, R., Kiefer, F. N., Berns, H., Resink, T. J., and Battegay, E. J. Hypoxia enhances vascular cell proliferation and angiogenesis in vitro via rapamycin (mTOR)-dependent signaling. FASEB J., 16: 771-780, 2002. 
120. Hudson, C. C., Liu, M., Chiang, G. G., Otterness, D. M., Loomis, D. C., Kaper, F., Giaccia, A. J., and Abraham, R. T. Regulation of hypoxia-inducible factor 1alpha expression and function by the mammalian target of rapamycin. Mol.Cell Biol., 22: 7004-7014, 2002.

121. Hinds, M. G., Norton, R. S., Vaux, D. L., and Day, C. L. Solution structure of a baculoviral inhibitor of apoptosis (IAP) repeat. Nat.Struct.Biol., 6: 648-651, 1999.

122. Liu, Z., Sun, C., Olejniczak, E. T., Meadows, R. P., Betz, S. F., Oost, T., Herrmann, J., Wu, J. C., and Fesik, S. W. Structural basis for binding of Smac/DIABLO to the XIAP BIR3 domain. Nature, 408: 1004-1008, 2000.

123. Sun, C., Cai, M., Gunasekera, A. H., Meadows, R. P., Wang, H., Chen, J., Zhang, H., Wu, W., Xu, N., Ng, S. C., and Fesik, S. W. NMR structure and mutagenesis of the inhibitor-of-apoptosis protein XIAP. Nature, 401: 818-822, 1999.

124. Verdecia, M. A., Huang, H., Dutil, E., Kaiser, D. A., Hunter, T., and Noel, J. P. Structure of the human anti-apoptotic protein survivin reveals a dimeric arrangement. Nat.Struct.Biol., 7: 602-608, 2000.

125. Wu, G., Chai, J., Suber, T. L., Wu, J. W., Du, C., Wang, X., and Shi, Y. Structural basis of IAP recognition by Smac/DIABLO. Nature, 408: 1008-1012, 2000.

126. Ambrosini, G., Adida, C., and Altieri, D. C. A novel anti-apoptosis gene, survivin, expressed in cancer and lymphoma. Nat.Med., 3: 917-921, 1997.

127. Suzuki, A., Ito, T., Kawano, H., Hayashida, M., Hayasaki, Y., Tsutomi, Y., Akahane, K., Nakano, T., Miura, M., and Shiraki, K. Survivin initiates procaspase 3/p21 complex formation as a result of interaction with $\mathrm{Cdk} 4$ to resist Fas-mediated cell death. Oncogene, 19: 1346-1353, 2000.

128. Altieri, D. C. Survivin, versatile modulation of cell division and apoptosis in 
cancer. Oncogene, 22: 8581-8589, 2003.

129. Carter, B. Z., Milella, M., Altieri, D. C., and Andreeff, M. Cytokine-regulated expression of survivin in myeloid leukemia. Blood, 97: 2784-2790, 2001.

130. Papapetropoulos, A., Fulton, D., Mahboubi, K., Kalb, R. G., O'Connor, D. S., Li, F., Altieri, D. C., and Sessa, W. C. Angiopoietin-1 inhibits endothelial cell apoptosis via the Akt/survivin pathway. J.Biol.Chem., 275: 9102-9105, 2000.

131. Beierle, E. A., Nagaram, A., Dai, W., Iyengar, M., and Chen, M. K. VEGF-mediated survivin expression in neuroblastoma cells. J.Surg.Res., 127: 21-28, 2005.

132. Tran, J., Rak, J., Sheehan, C., Saibil, S. D., LaCasse, E., Korneluk, R. G., and Kerbel, R. S. Marked induction of the IAP family antiapoptotic proteins survivin and XIAP by VEGF in vascular endothelial cells. Biochem.Biophys.Res.Commun., 264: 781-788, 1999.

133. Tran, J., Master, Z., Yu, J. L., Rak, J., Dumont, D. J., and Kerbel, R. S. A role for survivin in chemoresistance of endothelial cells mediated by VEGF. Proc.Natl.Acad.Sci.U.S.A, 99: 4349-4354, 2002.

134. Zhu, L., Fukuda, S., Cordis, G., Das, D. K., and Maulik, N. Anti-apoptotic protein survivin plays a significant role in tubular morphogenesis of human coronary arteriolar endothelial cells by hypoxic preconditioning. FEBS Lett., 508: 369-374, 2001. 


\title{
CHAPTER II
}

Role of PI3K and AKT specific isoforms in ovarian cancer cell migration, invasion and proliferation through the p70S6K1 pathway

\author{
Qiao Meng*, Chang Xia*, Jing Fang, Yon Rojanasakul and Bing-Hua Jiang\#
}

Mary Babb Randolph Cancer Center, Department of Microbiology, Immunology and Cell

Biology, West Virginia University, Morgantown, WV 26505-9300, USA.

This manuscript has been accepted by Cellular Signalling. 


\begin{abstract}
Ovarian cancer is the leading cause of death from gynecological malignancy for women. The amplification of the PI3K catalytic subunit (p110 $\alpha)$ and the lost function of PTEN are frequently detected in ovarian cancer cells. PI3K plays an important role in tumorigenesis. To specifically inhibit PI3K activity in ovarian cancer cells, we constructed small interfering RNA (siRNA) against p110 $\alpha$. The expression of p110 $\alpha$ siRNA significantly decreased cell migration, invasion, and proliferation compared to the siSCR control cells. The expression of p110 $\alpha$ siRNA induced CDK inhibitor $\mathrm{p} 27^{\mathrm{KIP} 1}$ levels, while it decreased levels of cyclin D1, CDK4, and phosphorylated retinoblastoma protein. PI3K transmits the mytogenic signal through AKT. AKT has three isoforms in the cells: AKT1, AKT2 and AKT3. We found that inhibition of AKT1 is sufficient to affect cell migration, invasion, and proliferation. Expression of AKT1 siRNA had a similar effect as p110 $\alpha$ siRNA in the cells. We showed the roles of specific PI3K and AKT isoforms in the cells, which are important to understanding the mechanism of PI3K/AKT signaling in ovarian cancer cells. Both p110 $\alpha$ and AKT1 siRNA-expressing cells decreased the activation of p70S6K1. Inhibition of p70S6K1 activity by its siRNA also decreased cell migration, invasion, and proliferation associated with the induction of $\mathrm{p} 27^{\mathrm{KIP} 1}$ levels, and with the inhibition of cell cycle-associated proteins including cyclin D1, CDK2, and phosphorylated retinoblastoma protein. This study demonstrates the important role of the $\mathrm{PI} 3 \mathrm{~K} / \mathrm{AKT} / \mathrm{mTOR} / \mathrm{p} 70 \mathrm{~S} 6 \mathrm{~K} 1$ pathway in cell proliferation,
\end{abstract}


migration, and invasion in ovarian cancer cells by using siRNA-mediated gene silencing as a reverse genetic method. 


\section{INTRODUCTION}

Of the gynecological malignancies affecting women in Western countries, ovarian cancer has the highest mortality rate and is among the most common of female malignancies ${ }^{1}$. Ovarian cancer poses many treatment difficulties. The cancer is often undetectable in its early stages, and therefore diagnosis usually occurs when surgical treatment is no longer an effective option. Moreover, ovarian cancer cells are known to develop resistance to chemotherapeutic treatments, resulting in a dramatic decrease in the overall survival rate, with a significant decrease to $30 \%$ for patients in advanced stages ${ }^{2}$. Recent genetic studies have shown that ovarian cancer contains frequent mutations in phosphatidylinositol 3-kinase (PI3K) and phosphatase and tensin homologue (PTEN) ${ }^{3}$. PIK3CA (the gene encoding the p110 $\alpha$ catalytic subunit of PI3K) is frequently increased in copy number in $40 \%$ of ovarian cancer cell lines and patient tumor samples ${ }^{4}$. PIK3CA has somatic mutations in several other cancers, including $32 \%$ of colorectal cancers, $27 \%$ of glioblastomas, $25 \%$ of gastric cancers ${ }^{5}$. PTEN is mutated in a subset of late-stage ovarian cancer patient samples and decreased PTEN expression accompanies the progression of ovarian cancer ${ }^{6}$. Furthermore, mutations of the PTEN tumor-suppressor gene are frequently detected in many human cancers ${ }^{3,7,8}$.

PI3K are heterodimers comprised of a regulatory and a catalytic subunit ${ }^{9}$. PI3K catalyzes the phosphorylation of phosphatidylinositol-containing lipids at their 3-position. Receptor tyrosine kinases activate $\mathrm{PI} 3 \mathrm{~K}{ }^{10}$, and this activation has been implicated in 
several human cancers ${ }^{11}$. Cellular functions such as proliferation, differentiation, anti-apoptosis, tumorigenesis and angiogenesis have been linked to PI3K activity ${ }^{12}$. We recently found that PI3K expression mediated cell differentiation and angiogenesis ${ }^{13-15}$. Therefore, understanding the precise role of PI3K in ovarian cancer would provide a successful approach for treating human ovarian cancer. PTEN is a lipid phosphatase that functions as an antagonist to PI3K through specific activity to remove phosphate from the D3 position of the inositol ring ${ }^{16}$. Thus, inhibition of PI3K or molecules involved in the PI3K signaling pathway would provide the potential for cancer treatment. LY294002 and wortmannin are two widely used PI3K inhibitors that inhibit its catalytic activity. The PI3K inhibitor LY294002 has been shown to inhibit ovarian cancer cell proliferation in vitro and to decrease ovarian cancer growth and ascites formation in mice inoculated with OVCAR-3 cells in vivo ${ }^{17}$. LY294002 also has been proven to increase the efficacy of the chemotherapeutic agent paclitaxel ${ }^{18}$. However, there are three major classes of PI3K isoforms existing in the cells ${ }^{19}$ and LY294002 has a broad inhibitory effect against all the PI3K catalytic isoforms as well as other kinases such as ATM and ATR. Thus, in this study we want to specifically inhibit the p110 $\alpha$ subunit of PI3K by small interference RNA (siRNA).

siRNA is a post-transcriptional gene-silencing mechanism induced by double-stranded RNA homologous to the sequence of the target gene ${ }^{18,20}$, and contains small 21-23-nt dsRNAs that mediate post-transcriptional gene-silencing ${ }^{21}$. Introduction of chemically synthesized siRNAs can induce gene silencing in mammalian cells. 
Transfection of short 21-nt RNA duplexes into mammalian cells interferes with gene expression and does not induce the unspecific anti-viral response ${ }^{22}$. Chemically synthesized siRNA usually induce only a transient reduction of endogenously expressed target mRNA. Recently, a number of groups have developed siRNA-based expression systems to establish stably transfected mammalian cell lines expressing functional siRNA molecules ${ }^{23-25}$. The stable cell lines can be used to study the loss-of-function phenotypes. The potential of using siRNA technology to "knock down" the expression of any gene in mammalian cells is set to revolutionize the ability of reverse genetics to assess the function of a gene.

The precise function of the PI3K pathway in ovarian cancer progression has not been fully studied. In this study, we wanted to determine the function of the p110 $\alpha$ subunit in ovarian cancer. We used a vector-based siRNA expression system to knockdown the expression of $\mathrm{p} 110 \alpha$ in ovarian cancer cells. To investigate the role of p110 $\alpha$ siRNA (siP2) in ovarian cancer progression, we performed cell migration, invasion, and proliferation assays using cells expressing siRNA against the p110 $\alpha$ subunit. An important downstream target of PI3K is the serine-threonine kinase AKT ${ }^{26}$. AKT has three different isoforms: AKT1, AKT2 and AKT3 which share a high degree of structural similarity ${ }^{27}$. AKT1 kinase activity is frequently elevated in ovarian cancer ${ }^{28}$, and this results in high levels of AKT phosphorylation and activity. Deregulation of AKT kinase activity has been implicated in the regulation of tumor cell survival, resistance to apoptosis, cell proliferation, and growth ${ }^{11}$. AKT2 amplification was found 
in ovarian carcinomas ${ }^{29}$. The specific role of each AKT isoform in ovarian tumor formation is unknown. We hypothesize that AKT1 plays an important role in ovarian cancer cells. To determine the role of the AKT1 isoform in ovarian cancer cells, we inhibited AKT1 using siRNA specific to AKT1, and analyzed how siRNA expression affects migration, invasion, and proliferation. Because AKT has been shown to phosphorylate p70S6K1 ${ }^{30}$, we will also study ovarian cancer progression using siRNA against p70S6K1.

The 70KDa ribosomal S6 kinase p70S6K1 is known to regulate cell growth by inducing protein synthesis components ${ }^{31}$. p70S6K1 is activated through the PI3K pathway ${ }^{32,33}$ and the MAPK pathway ${ }^{34}$. Gene encoding for p70S6K1 is also amplified in ovarian cancer cells ${ }^{35}$, and its p70S6K1 kinase is constitutively phosphorylated in ovarian cancer cells. We hypothesize that PI3K/AKT may regulate cell migration, invasion, and proliferation through p70S6K1. Thus, we determined whether inhibition of PI3K and AKT by siRNA affected p70S6K1 activation, and whether siRNA against p70S6K1 has similar inhibitory effects as siRNA against PI3K/AKT. 


\section{MATERIALS AND METHODS}

\section{Reagents and Cell Culture}

Total RNA was isolated using the Trizol reagent from Invitrogen (Life Technology). The primers for the p110 $\alpha$, AKT1, AKT2 and GAPDH were from GenScript Corp. (Piscataway, NJ). The antibodies against p21, p27, CDC25A, CDK2, CDK4, cyclin E, PCNA, AKT1 and AKT2 were from Santa Cruz Biotechnology (Santa Cruz, CA) and the antibodies against $\mathrm{Rb}$, phospho-Rb (Ser780, Ser795, or Ser807/811), Rb C-terminal, cyclin D1, p70S6K1, and phospho-p70S6K1 (Thr421/Ser424) were from Cell Signaling Technology (Beverly, MA). The antibody against $\beta$-actin was from Sigma (St. Louis, MO). The horseradish peroxidase (HRP)-conjugated anti-rabbit IgG and anti-mouse IgG were from Perkin Elmer Life Sciences (Boston, MA). The human ovarian cancer cell line OVCAR-3 (American Type Culture Collection, Manassas, VA) was maintained in RPMI 1640 (GIBCO BRL, Grand Island, NY) supplemented with 10\% FBS, 2 mM L-glutamine, and $0.2 \%$ insulin, $100 \mathrm{U} / \mathrm{ml}$ penicillin, and $100 \mu \mathrm{g} / \mathrm{ml}$ streptomycin, and cultured at $37^{\circ} \mathrm{C}$ in $5 \% \mathrm{CO}_{2}$ incubator. Trypsin $(0.25 \%) /$ EDTA solution was used to detach the cells from the culture plate for passing the cells.

siRNA and Plasmid Constructs

The oligonucleotides encoding 19-mer hairpin sequences specific to the p110 $\alpha$, AKT1, and p70S6K1 were designed using siRNA converter software. The sequence of 
small interfering RNA construct targeted to p110 $\alpha$, AKT1 and p70S6K1 were as follows: p110 $\alpha$, sense strand, AGTTCCCAGATATGTCAGTuu, and antisense strand, ACTGACATATCTGGGAACTuu; AKT1, sense strand, GAAGGAAGTCATCGTGGCCuu, and antisense strand, GGCCACGATGACTTCCTTCuu; p70S6K1, sense strand, GUUCAAGCUCAUCCAUUCUuu, and antisense strand, siRNA AGAAUGGAUGAGCUUGAACuu. A scramble siRNA with the same nucleotide composition as the siRNA but which lacks significant sequence homology to the genome was also designed. The oligonucleotides were synthesized, annealed, and ligated into the linearized pSilencer 2.0-U6 vector (Ambion, Austin, TX). The plasmids that express siRNA against p110 $\alpha$, AKT1, and p70S6K1 were named as siP2, siA1 and sip70S6K1. The scramble siRNA was named as siSCR.

Selecting a population of cells that stably express siRNA

OVCAR-3 cells were plated into 6 well plates. $2 \mu \mathrm{g}$ of siP2, siA1, sip70S6K or siSCR was transfected into OVCAR-3 cells using Lipofectamine (Invitrogen) and cultured for $24 \mathrm{~h}$ without antibiotic selection. Then the cells were cultured in medium containing $500 \mu \mathrm{g} / \mathrm{ml} \mathrm{G} 418$ (Sigma) until all of the cells in the non-transfected control culture were killed. The antibiotic-resistant cells were pooled and passaged in medium containing $250 \mu \mathrm{g} / \mathrm{ml} \mathrm{G} 418$ as needed. 
Semi-Quantitative RT-PCR

Total RNA was isolated from 1 x $10^{6}$ cultured cells with Trizol reagent (Invitrogen).

First-strand cDNA was synthesized from $1 \mu \mathrm{g}$ of total RNA using AMV Reverse Transcriptase, an oligo(dT) primer and dNTP(Promega). Primers used for amplification and internal probes for hybridization were as follows: PIK3CA forward, 5'-TATGGTTGTCTGTCAATCGGTGA-3'; PIK3CA reverse,

5'-GCCTTTGCAGTGAATTTGCAT-3'; AKT1 forward, 5'-ATGAGCGACGTGGCTATTGTGAAG-3'; AKT1 reverse, 5'-GAGGCCGTCAGCCACAGTCTGGATG-3'; AKT2 forward, 5'-ATGAATGAGGTGTCTGTCATCAAAGAAGGC-3'; AKT2 reverse, 5' TGCTTGAGGCTGTTGGCGACC-3’; GAPDH forward, 5'-CCACCCATGGCAAATTCCATGGCA-3'; $\quad$ GAPDH reverse 5'-TCTAGACGGCAGGTCAGGTCCACC-3'. Each RT-PCR reaction consisted of 32 cycles of $1 \mathrm{~min}$ at $94^{\circ} \mathrm{C}, 1 \mathrm{~min}$ at $55^{\circ} \mathrm{C}$ and $1 \mathrm{~min}$ at $72^{\circ} \mathrm{C}$. Quantitation of the amount of PCR product was performed after electrophoresis on $2 \%$ agarose gels and ethidium bromide staining.

Wound-Healing Assays

OVCAR-3 cells expressing siRNA or siSCR were cultured to $100 \%$ confluence. The wound-healing assays were performed using a sterile $200 \mu \mathrm{l}$ pipette tip to scratch the cells to form a wound. The cells were then cultured in 10\% FBS medium for $24 \mathrm{~h}$, and 
then fixed with formalin. Migration of wounded cells was evaluated at 0 and $24 \mathrm{~h}$ with an inverted Olympus phase-contrast microscope.

\section{Cell Migration Assays}

The migration assay was conducted by the transwell assay. The cells were split at a ratio of 1:2 the day before the assay. The transwells were coated with collagen at a concentration of $20 \mu \mathrm{g} / \mathrm{ml}$ in 1x PBS. The top chambers of the transwells were added with $0.2 \mathrm{ml}$ of cells $\left(5 \times 10^{5}\right.$ cells $\left./ \mathrm{ml}\right)$ in serum-free medium, and the bottom chambers were added with $0.25 \mathrm{ml}$ of RPMI 1640 medium containing $10 \%$ FBS. The cells were incubated in the transwells at $37^{\circ} \mathrm{C}$ in $5 \% \mathrm{CO}_{2}$ for $24 \mathrm{~h}$. Migrated cells were fixed and stained with hematoxylin. The migrated cells in each well were counted in three different fields per experiment under the microscope. The mean values were obtained from three replicate experiments and were subjected to the t-test.

\section{Cell Invasion Assays}

OVCAR-3 cells were cultured to near confluence in RPMI 1640 medium containing 10\% FBS. The cells were harvested by trypsinization and washed in RPMI medium without serum. The cells were suspended in RPMI 1640 medium at $5 \times 10^{5}$ cells $/ \mathrm{ml}$. Prior to preparing the cell suspension, the dried layer of matrigel matrix was rehydrated with serum-free RPMI 1640 medium for $2 \mathrm{~h}$ at $37^{\circ} \mathrm{C}$. The rehydration solution was carefully removed, $0.75 \mathrm{ml}$ RPMI 1640 medium containing 10\% FBS was added to each 
well as a chemoattractant, and $0.5 \mathrm{ml}\left(2.5 \times 10^{5}\right.$ cells $)$ of cell suspension was added to each well. The plates were incubated for $48 \mathrm{~h}$ at $37^{\circ} \mathrm{C}$. The invaded cells on the bottom surface of the membrane were fixed and stained by sequentially transferring them through wells of a second 24-well plate containing the three solutions from the Diff-Quik® staining kit (Dade Behring Inc.). The cells were enumerated by taking photomicrographs at 200x magnification. The cells in three different fields of each well were counted with two wells per treatment. The mean values were obtained from three replicate experiments and were subjected to the t-test.

\section{Cell Proliferation Assays}

Cells were seeded in 12-well plates at a density of $2 \times 10^{5}$ cells/well in RPMI 1640 medium supplemented with $10 \% \mathrm{FBS}$ at $37^{\circ} \mathrm{C}$ in $5 \% \mathrm{CO}_{2}$ incubator for $24 \mathrm{~h}, 48 \mathrm{~h}$, and 72 h. Cells were scraped and washed twice with PBS and centrifuged at 1,000 rpm for 5 min. Cells were resuspended in $1 \mathrm{ml}$ of Hanks' balanced salt solution and counted. The total cell number was normalized to that in the control at $0 \mathrm{~h}$. All samples were assayed in triplicate. The proliferation assays were performed three times.

\section{Immunoblotting Analysis}

Cells were cultured in a $60 \mathrm{~mm}$ dish at a density of $5 \times 10^{5}$ cells/dish in RPMI 1640 medium with $10 \% \mathrm{FBS}$ for $24 \mathrm{~h}$ at $37^{\circ} \mathrm{C}$ in $5 \% \mathrm{CO}_{2}$ incubator. Cells were harvested and lysed on ice for $30 \mathrm{~min}$ in RIPA buffer [150 mM NaCl, $100 \mathrm{mM}$ Tris (pH 8.0), $1 \%$ Triton 
$\mathrm{X}-100,1 \%$ deoxycholic acid, $0.1 \%$ SDS, $5 \mathrm{mM}$ EDTA, and $10 \mathrm{mM} \mathrm{NaF}$, supplemented with $1 \mathrm{mM}$ sodium vanadate, $2 \mathrm{mM}$ leupeptin, $2 \mathrm{mM}$ aprotinin, $1 \mathrm{mM}$ phenylmethylsulfonylfluoride, $1 \mathrm{mM}$ dithiothreitol, and $2 \mathrm{mM}$ pepstatin A. After centrifugation at $12,000 \mathrm{rpm}$ for $15 \mathrm{~min}$, the supernatant was harvested as the total cellular protein extract. The protein concentrations were determined using Bio-Rad protein assay reagent (Richmond, CA). The total cellular protein extracts were separated by SDS-PAGE and transferred to nitrocellulose membrane. Membranes were blocked with 5\% nonfat dry milk in PBS containing $0.05 \%$ Tween 20 and incubated with antibodies against p27, p21, CDK4, cyclin D1, Rb C-terminal, phospho-Rb (Ser780), phospho-Rb (Ser795), phospho-Rb (Ser807/811), p70S6K1， phospho-p70S6K1 (Thr421/Ser424), p110 $\alpha$, AKT1, AKT2 and $\beta$-actin. Blots were washed three times in PBS buffer, followed by incubation with the appropriate HRP-linked secondary antibodies. The specific proteins in the blots were visualized using the enhanced chemiluminescence reagent (NEN, Boston, MA). The experiments were carried out on three separate occasions.

\section{Statistical analysis}

The data represent the mean \pm SD from three independent experiments. Statistical analysis was performed by Student's $t$ test at a significance level of $P<0.05$. 


\section{RESULTS}

Expression of siRNA against p110a Catalytic Subunit of PI3K (siP2) Inhibited Ovarian

\section{Cancer Cell Migration and Invasion}

Cell migration is a key cellular feature of tumor progression because it regulates metastasis. Both tumor cell migration and invasion through the basement membranes are crucial steps in the multistage process that leads to metastasis ${ }^{36}$. To determine the function of the $\mathrm{p} 110 \alpha$ subunit of PI3K in ovarian cancer cell migration, we used OVCAR-3 cells that express $\mathrm{p} 110 \alpha$ in high copy number. We showed that p110 $\alpha$ mRNA level and protein level were decreased in siP2 expression cells when compared to p110 $\alpha$ mRNA level and protein level in siSCR control cells (Fig. 1A). To determine if the siP2 expression can inhibit cell motility, we performed wound-healing experiments and measured the distance of cell migration to the wound area (Fig. 1B). Our results showed that the cells expressing siP2 had a 4-fold decrease in wound-healing rate in $24 \mathrm{~h}$ when compared to the siSCR control cells (Fig. 1C). We also analyzed cell migration using transwell assays to test the migration ability of cells expressing siP2. Similar results were obtained in the cells expressing siP2, which had a 4.2-fold decrease $(p<0.05)$ when compared to those expressing siSCR alone (Fig. 1D and 1E).

Cancer cells need to cross the basement membranes when they initially invade the lymphatic or vascular beds during dissemination. The invasion process is comprised of distinct events which include the attachment of cells to the basement membrane, 
secretion of enzymes which degrade the basement membrane, and the migration of cells into the target tissue in response to specific chemotactic stimuli ${ }^{37}$. To study whether p110 $\alpha$ plays an important role in cell invasion, we used the invasion chamber to measure the number of invasive cells migrating through matrigel, a solid gel of in vitro basement membrane. The matrigel layer contains the membrane and pores, blocking noninvasive cells from migrating through. We analyzed the number of invasive cells expressing the siP2 or siSCR alone. The results demonstrated that siP2-expressing cells had a cell invasion rate of 10 -fold less than those expressing siSCR alone $(p<0.05)$ (Fig. 2). These data showed that PI3K inhibition by siP2 expression in ovarian cancer cells inhibits cell invasion.

SiP2 Decreased Cell Proliferation and Inhibited Cell Cycle-Associated Proteins Through p27 $7^{\text {Kip } 1}$ Induction

Because PI3K is a key regulatory protein that is known to stimulate cell growth, we examined proliferation in cells in which the p110 $\alpha$ subunit had been silenced by siRNA. OVCAR-3 cells expressing siP2 or siSCR control were seeded and cultured. Total cell numbers were counted $24 \mathrm{~h}, 48 \mathrm{~h}$, and $72 \mathrm{~h}$ after the incubation. As shown in Fig. 3A, the cells expressing siSCR grew very quickly during the $72 \mathrm{~h}$ in culture, while the cells expressing siP2 had a much slower proliferation rate. The results indicated that $\mathrm{p} 110 \alpha$ plays an important role in the proliferation of ovarian cancer cells. To study cell proliferation in further detail, we then examined cell cycle regulatory proteins involved in 
cell cycle control. OVCAR-3 cells expressing siP2 or siSCR were cultured. Total proteins were analyzed by immunoblotting assay. We found that levels of cyclin D1, CDK4, cyclin E, CDK2, p21 and phosphorylated Rb were inhibited by siP2, and that the level of p27 was induced by siP2 when compared to siSCR control (Fig. 3B). The levels of PCNA, CDC25A and $\beta$-actin remained unchanged. These results suggest that inhibition of PI3K may inhibit cell cycle-associated proteins through the induction of CDK inhibitor p27. These data are consistent with our recent study indicating that $\mathrm{G}_{1}$ cell cycle progression and the expression of $\mathrm{G}_{1}$ cyclins are regulated by PI3K/AKT signaling in ovarian cancer cells ${ }^{38}$.

SiRNA Against AKT1 (siA1) Expression Inhibited the Migration and Invasion of Ovarian Cancer Cells

AKT is a major downstream target of PI3K. We showed that activation of AKT in ovarian cancer cells was inhibited by expression of siP2 (Fig. 4A). AKT has three different isoforms: AKT1, AKT2, and AKT3. The precise role of each AKT isoform in cancer cells is still unknown. To determine the role of AKT1 in ovarian cancer cell migration, we generated a stable cell line expressing siRNA specific to AKT1. We tested the effect of siA1 construct on the expression of AKT1 mRNA by RT-PCR. We showed that AKT1 mRNA level was decreased by the expression of siA1 in ovarian cancer cells and AKT2 mRNA level was unchanged in ovarian cancer cells expressing siA1 (Fig.4B). Western Blot results showed that AKT1 protein level was decreased by 
the expression of siA1 and AKT2 protein level was unchanged in ovarian cancer cells expressing siA1 (Fig.4B). A wound-healing assay was carried out to test the cell migration and proliferation of cells expressing siA1. The cells expressing siA1 had a much slower wound-healing rate when compared to siSCR control (Fig. 4C and 4D). To further determine the effect of siA1 expression on cell migration, the cell migration was analyzed by transwell assays. The cells expressing siA1 had a cell migration rate of 5-fold less than those expressing siSCR control (Fig. 4E and 4F). To study whether AKT1 affects cell invasion, we determined if siA1 expression would inhibit cell invasion by testing its ability to penetrate the matrigel. The cells expressing siA1 had a cell invasion rate of 2.7-fold less than those expressing siSCR (Fig. 5A and 5B). These results demonstrate that AKT1 is required for both cell migration and invasion in ovarian cancer cells.

\section{AKT1 Mediates Cell Proliferation and Cell Cycle Progression Induced by PI3K}

To investigate if AKT1 is involved in ovarian cancer cell proliferation, we examined proliferation in cells in which AKT1 had been silenced by siRNA. OVCAR-3 cells expressing siA1 or siSCR were seeded and cultured. Total cell numbers were counted $24 \mathrm{~h}, 48 \mathrm{~h}$, and $72 \mathrm{~h}$ after the incubation. As shown in Fig. 6A, the cells expressing siSCR multiplied much more quickly than the cells expressing siA1 $(p<0.05)$. The results indicate that AKT1 plays an important role in ovarian cancer cell proliferation. To investigate whether the inhibition of AKT1 affects cell cycle-associated protein 
expression, total cellular proteins were prepared and subjected to an immunoblot assay. As shown in Fig. 6B, the levels of cyclin D1, CDK4, CDK2, cyclin E, phospho-Rb (Ser780, Ser795 and Ser807/811), and CDK inhibitor p21 were decreased in OVCAR-3 cells expressing siA1, whereas the level of CDK inhibitor p27 was induced and the levels of PCNA, CDC25A and $\beta$-actin remained unchanged. These results suggest that AKT1 may mediate cell cycle progression through the expression of cyclins and CDKs.

p70S6K1 is A Potential Downstream Target of PI3K and AKT in Cell Migration and Invasion

To test whether p70S6K1 is a downstream target of PI3K and AKT, we showed that phosphorylated p70S6K1 was decreased in ovarian cancer cells expressing siP2 or siA1 (Fig. 7A). To investigate if p70S6K1 is required for ovarian cancer cell migration and invasion, we designed siRNA specific to p70S6K1 (sip70S6K1). The OVCAR-3 cells were transfected with sip70S6K1 construct and then selected with G418. After the selection, we established a stable cell line expressing sip70S6K1. The cells expressing sip70S6K1 or siSCR were analyzed for p70S6K1 expression and activation by an immunoblotting assay. Total p70S6K1 and phosphorylated p70S6K1 proteins were reduced in cells expressing sip70S6K1 (Fig. 7B). Phospho-S6 ribosomal protein, the physiological substrate of p70S6K1, was also reduced in the cells expressing sip70S6K1 plasmid (Fig. 7B). Thus, this result indicates that sip70S6K1 expression inhibits p70S6K1 expression/function. To determine the role of $p 70 S 6 K 1$ in ovarian cancer cell 
migration, transwell assays were performed. The cells expressing sip70S6K1 had a cell migration rate of 7 -fold less than those expressing siSCR $(\mathrm{p}<0.05)$ (Fig. 8A and 8B). To test if p70S6K1 is required for cell invasion, cell invasion assays were performed. The cells expressing siRNA specific to p70S6K1 had an invasion rate of 4-fold less than those expressing siSCR $(\mathrm{p}<0.05)$ (Fig. 8C and 8D). Taken together, these data demonstrate that p70S6K1 downstream of PI3K/AKT is required for ovarian cancer cell migration and invasion.

sip70S6K1 Expression Decreased Cell Proliferation Associated with the Decrease of Cell Cycle-Associated Protein Expression

To investigate if $\mathrm{p} 70 \mathrm{~S} 6 \mathrm{~K} 1$ can regulate ovarian cancer cell proliferation, we specifically inhibited p70S6K1 activity using the siRNA. OVCAR-3 cells expressing sip70S6K1 or siSCR were seeded and cultured. As shown in Fig. 9A, cells expressing siSCR proliferated much more quickly than the cells expressing sip70S6K1.

To study whether p70S6K1 regulates cell proliferation through the expression of proteins, OVCAR-3 cells expressing sip70S6K1 or siSCR were analyzed for the expression of cell cycle-associated protein expression. We found that levels of cyclin D1, CDK4, cyclin E, and phosphorylated $\mathrm{Rb}$ were lower in the OVCAR-3 cells expressing p70S6K1 $(p<0.05)$. The level of p27 was higher in OVCAR-3 cells expressing sip70S6K1 when compared with the cells expressing siSCR $(p<0.05)$ (Fig. 9B). The levels of CDC25A and $\beta$-actin were not changed. These results indicate that 
p70S6K1 is required for cell cycle progression. The induction of CDK inhibitor p27 may be a negative regulator for the expression of cyclins and CDKs in the ovarian cancer cells. 


\section{DISCUSSION}

Ovarian cancer has the worst prognosis of any gynecological disease; it is one of the most difficult cancers to detect and to treat ${ }^{1}$. The current major research focus is identifying an effective therapeutic treatment. PI3K has many cellular functions in response to growth factors and therefore an understanding of PI3K has the potential to lead to a treatment for ovarian cancer. Recent studies indicate that PIK3CA, the gene encoding the $\mathrm{p} 110 \alpha$ catalytic subunit of PI3K, is increased in copy number in primary ovarian cancer cells and several ovarian carcinoma cell lines ${ }^{4}$. Moreover, mutation of AKT, an important downstream target of PI3K, is frequently detected in ovarian cancer ${ }^{39}$. PI3K inhibitors could potentially provide useful information about the role of the PI3K/AKT pathway in human cancers; however, the most commonly used PI3K inhibitors, LY294002 and wortmannin, have broad inhibitory activity against all the p110 isoforms. Therefore, in this study we used the siRNA technique to inhibit specific isoforms of PI3K and AKT in ovarian cancer cells, and determined their effects on cell migration, invasion and proliferation. Our study demonstrates that inhibition of the p110 $\alpha$ subunit by siRNA resulted in decreased cell migration, invasion and proliferation in ovarian cancer cells.

Cell migration is a fundamental aspect of cancer cell growth ${ }^{36}$, and is a complex process that requires the high coordination of actin polymerization, formation, release of focal adhesions, and myosin motor activity ${ }^{37}$. Cell migration requires cell invasion, the 
process of cellular-induced degradation of the basal membrane through membrane penetration. Ovarian cancer is a highly metastatic cancer, and therefore cell migration and invasion are particularly important processes of ovarian cancer progression ${ }^{40}$. Investigation of the PI3K signaling pathway in cell migration and invasion will enable us to understand ovarian cancer progression. An important finding in this study is that the inhibition of $p 110 \alpha$ by siRNA significantly decreased the rate of cell migration and invasion in ovarian cancer cells. Cell migration may be affected by the rate of cell proliferation. In our study, we found that cells expressing siP2 had a 1-fold decrease in cell proliferation rate in $48 \mathrm{~h}$ when compared to the siSCR control cells. However, siP2-expressing cells had a cell migration rate of 4.2 fold less than those expressing siSCR and cell invasion rate of 10 -fold less than those expressing siSCR. It suggests cell proliferation may not play a major role on cell migration and invasion in this study. This demonstrates that the $\mathrm{p} 110 \alpha$ subunit affects multiple cell functions, and also reveals the major functions of the PI3K isoforms in ovarian cancer cells.

$\mathrm{PI} 3 \mathrm{~K}$ activation is required for cancer progression because it promotes tumor growth, including cell proliferation and cell cycle progression. In ovarian cancer specifically, the PI3K pathway has been implicated in cell proliferation and $\mathrm{G}_{1}$ cell cycle progression 38. In this study, we have shown that siRNA-inhibited $\mathrm{p} 110 \alpha$ expression decreased cell proliferation, which demonstrates that inhibition of p110 $\alpha$ can affect tumor cell growth. One cause of tumorigenesis is uncontrolled cell division. The cell cycle is regulated by the coordinated action of cyclin-dependent kinase (CDK) complexes and CDK inhibitors 
(CKIs) ${ }^{41}$. Therefore, we wanted to prove that inhibition of $\mathrm{p} 110 \alpha$ could also affect proliferation through signals to the cell cycle machinery. Our results showed that siP2 expression in ovarian cancer cells inhibited levels of cyclin D1, CDK4, cyclin E, p21 and phosphorylated $\mathrm{Rb}$, and that it induced the level of $\mathrm{p} 27^{\mathrm{KIP} 1}$. Since $\mathrm{p} 27^{\mathrm{KIP} 1}$ is known to inhibit CDKs, our results demonstrate that siP2 may decrease cell proliferation and inhibit cell cycle-associated proteins specifically through the induction of $\mathrm{p} 27^{\mathrm{KIP} 1}$ in ovarian cancer cells, thereby disrupting the regulation of $\mathrm{G}_{0} / \mathrm{G}_{1}$ cell cycle transition necessary for tumor growth. These results also suggest that $\mathrm{p} 110 \alpha$ subunit expression in ovarian cancer cells inhibits $\mathrm{p} 27^{\mathrm{KIP} 1}$, thereby inducing proliferation and increased cell cycle progression.

AKT is composed of three isoforms (AKT1, AKT2, and AKT3) and although all isoforms may be expressed, only certain isoforms may be active in a particular cell type. We hypothesize that AKT1 is the most prominent of the three in cellular functions. To determine the function of AKT1 isoform in ovarian cancer progression, we used siRNA against AKT1 and studied the role of siA1 cells in wound-healing and cell migration and invasion in ovarian cancer cells. Our results showed that siA1 expression in ovarian cancer cells significantly decreased the wound-healing rate as well as cell migration and invasion, demonstrating that AKT1 is the major AKT isoform for cellular migration and invasion in ovarian cancer. This result correlates with the inhibition of cell migration and invasion in siP2-expressing cells. Concomitantly, expression of siA1 inhibited the cell proliferation rate, decreased expression of cyclin D1, CDK4, cyclin E, p21 and 
phosphorylated $\mathrm{Rb}$, and induced the expression level of $\mathrm{p} 27^{\mathrm{Kip} 1}$ in ovarian cancer cells. This indicates that expression of siA1 can inhibit cell proliferation through regulation of cell cycle-associated proteins. These results also show that PI3K signaling can transmit through AKT1, and that PI3K induces AKT activation in ovarian cancer cells.

Research has demonstrated that the PI3K/AKT pathway induces p70S6K1, which is known to regulate cell growth by inducing protein synthesis components. Therefore, we wanted to determine whether p70S6K1 plays a role in ovarian cancer cell migration, invasion, and proliferation. Earlier data has shown that siP2 and siA1 expression can affect p70S6K1 expression. In this study, the results show that expression of siRNA specific to p70S6K1 in ovarian cancer cells can decrease cell migration and invasion rates, and that this decrease correlates with the inhibition of cell migration and invasion in p110 $\alpha$ knockdown cells. Furthermore, inhibition of p70S6K1 in ovarian cancer cells decreased cell proliferation and altered cell cycle-associated proteins. As in the experiments using siP2 and siA1, siRNA against p70S6K1 expression decreased levels of cyclin D1, CDK4 and phosphorylated $\mathrm{Rb}$, and induced levels of $\mathrm{p} 27^{\mathrm{KIP} 1}$. This demonstrates the significance of p70S6K1 in ovarian cancer cell proliferation.

There are some interesting observations that other transformed cells demonstrate cell type-specific and selective contribution of PI3K, AKT, mTOR and p70S6K1 in the cell proliferation, migration and invasion in contrast to OVCAR-3 ${ }^{42-45}$. In our study, we find the components of PI3K/AKT/mTOR/p70S6K1 pathway are critical for OVCAR-3 cell proliferation, migration and invasion. 
In summary, these results suggest that $\mathrm{p} 110 \alpha$ and AKT1 isoforms are major molecules in ovarian cancer progression. The data demonstrates that expression of these isoforms decreased levels of the natural CDK inhibitor $\mathrm{p} 27^{\mathrm{KIP}}$, thereby contributing to cell proliferation. We also have shown that $\mathrm{p} 27^{\mathrm{KIP} 1}$ is upregulated in the presence of siRNA against PI3K, AKT, and p70S6K1 and that this upregulation inhibits cyclin and CDK activity, resulting in ovarian tumor growth inhibition. Moreover, this study proves that through the induced expression of siRNA the PI3K/AKT/mTOR/p70S6K1 pathway is a novel target for therapeutic intervention in ovarian cancer. 


\section{CONCLUSIONS}

The expression of p110 $\alpha$ siRNA significantly decreased cell migration, invasion, and proliferation compared to the siSCR control cells. Inhibition of AKT1 is sufficient to affect cell migration, invasion, and proliferation in ovarian cancer cells. Inhibition of p70S6K1 activity by its siRNA also decreased cell migration, invasion, and proliferation associated with the induction of $\mathrm{p} 27^{\mathrm{KIP} 1}$ levels. $\mathrm{PI} 3 \mathrm{~K} / \mathrm{AKT} / \mathrm{mTOR} / \mathrm{p} 70 \mathrm{~S} 6 \mathrm{~K} 1$ pathway is critical for OVCAR-3 cell proliferation, migration and invasion. 


\section{Reference List}

1. Perez, R. P., Godwin, A. K., Hamilton, T. C., and Ozols, R. F. Ovarian cancer biology. Semin.Oncol., 18: 186-204, 1991.

2. Greenlee, R. T., Hill-Harmon, M. B., Murray, T., and Thun, M. Cancer statistics, 2001. CA Cancer J.Clin., 51: 15-36, 2001.

3. Yokomizo, A., Tindall, D. J., Hartmann, L., Jenkins, R. B., Smith, D. I., and Liu, W. Mutation analysis of the putative tumor suppressor PTEN/MMAC1 in human ovarian cancer. Int.J.Oncol., 13: 101-105, 1998.

4. Shayesteh, L., Lu, Y., Kuo, W. L., Baldocchi, R., Godfrey, T., Collins, C., Pinkel, D., Powell, B., Mills, G. B., and Gray, J. W. PIK3CA is implicated as an oncogene in ovarian cancer. Nat.Genet., 21: 99-102, 1999.

5. Samuels, Y., Wang, Z., Bardelli, A., Silliman, N., Ptak, J., Szabo, S., Yan, H., Gazdar, A., Powell, S. M., Riggins, G. J., Willson, J. K., Markowitz, S., Kinzler, K. W., Vogelstein, B., and Velculescu, V. E. High frequency of mutations of the PIK3CA gene in human cancers. Science, 304: 554, 2004.

6. Schondorf, T., Gohring, U. J., Roth, G., Middel, I., Becker, M., Moser, N., Valter, M. M., and Hoopmann, M. Time to progression is dependent on the expression of the tumour suppressor PTEN in ovarian cancer patients. Eur.J.Clin.Invest, 33: 256-260, 
2003.

7. Saito, M., Okamoto, A., Kohno, T., Takakura, S., Shinozaki, H., Isonishi, S., Yasuhara, T., Yoshimura, T., Ohtake, Y., Ochiai, K., Yokota, J., and Tanaka, T. Allelic imbalance and mutations of the PTEN gene in ovarian cancer. Int.J.Cancer, 85: 160-165, 2000.

8. Teng, D. H., Hu, R., Lin, H., Davis, T., Iliev, D., Frye, C., Swedlund, B., Hansen, K. L., Vinson, V. L., Gumpper, K. L., Ellis, L., El Naggar, A., Frazier, M., Jasser, S., Langford, L. A., Lee, J., Mills, G. B., Pershouse, M. A., Pollack, R. E., Tornos, C., Troncoso, P., Yung, W. K., Fujii, G., Berson, A., Steck, P. A., and . MMAC1/PTEN mutations in primary tumor specimens and tumor cell lines. Cancer Res., 57: 5221-5225, 1997.

9. Vanhaesebroeck, B. and Waterfield, M. D. Signaling by distinct classes of phosphoinositide 3-kinases. Exp.Cell Res., 253: 239-254, 1999.

10. Chen, H. C. and Guan, J. L. Association of focal adhesion kinase with its potential substrate phosphatidylinositol 3-kinase. Proc.Natl.Acad.Sci.U.S.A, 91: 10148-10152, 1994.

11. Vivanco, I. and Sawyers, C. L. The phosphatidylinositol 3-Kinase AKT pathway in human cancer. Nat.Rev.Cancer, 2: 489-501, 2002. 
12. Roymans, D. and Slegers, H. Phosphatidylinositol 3-kinases in tumor progression. Eur.J.Biochem., 268: 487-498, 2001.

13. Jiang, B. H., Zheng, J. Z., and Vogt, P. K. An essential role of phosphatidylinositol 3-kinase in myogenic differentiation. Proc.Natl.Acad.Sci.U.S.A, 95: 14179-14183, 1998.

14. Jiang, B. H., Zheng, J. Z., Aoki, M., and Vogt, P. K. Phosphatidylinositol 3-kinase signaling mediates angiogenesis and expression of vascular endothelial growth factor in endothelial cells. Proc.Natl.Acad.Sci.U.S.A, 97: 1749-1753, 2000.

15. Li, Y., Jiang, B., Ensign, W. Y., Vogt, P. K., and Han, J. Myogenic differentiation requires signalling through both phosphatidylinositol 3-kinase and p38 MAP kinase. Cell Signal., 12: 751-757, 2000.

16. Myers, M. P., Pass, I., Batty, I. H., Van der, K. J., Stolarov, J. P., Hemmings, B. A., Wigler, M. H., Downes, C. P., and Tonks, N. K. The lipid phosphatase activity of PTEN is critical for its tumor supressor function. Proc.Natl.Acad.Sci.U.S.A, 95: 13513-13518, 1998.

17. Hu, L., Zaloudek, C., Mills, G. B., Gray, J., and Jaffe, R. B. In vivo and in vitro ovarian carcinoma growth inhibition by a phosphatidylinositol 3-kinase inhibitor (LY294002). Clin.Cancer Res., 6: 880-886, 2000. 
18. Hu, L., Hofmann, J., Lu, Y., Mills, G. B., and Jaffe, R. B. Inhibition of phosphatidylinositol 3'-kinase increases efficacy of paclitaxel in in vitro and in vivo ovarian cancer models. Cancer Res., 62: 1087-1092, 2002.

19. Toker, A. and Cantley, L. C. Signalling through the lipid products of phosphoinositide-3-OH kinase. Nature, 387: 673-676, 1997.

20. Cogoni, C. and Macino, G. Post-transcriptional gene silencing across kingdoms. Curr.Opin.Genet.Dev., 10: 638-643, 2000.

21. Hammond, S. M., Caudy, A. A., and Hannon, G. J. Post-transcriptional gene silencing by double-stranded RNA. Nat.Rev.Genet., 2: 110-119, 2001.

22. Elbashir, S. M., Harborth, J., Lendeckel, W., Yalcin, A., Weber, K., and Tuschl, T. Duplexes of 21-nucleotide RNAs mediate RNA interference in cultured mammalian cells. Nature, 411: 494-498, 2001.

23. Miyagishi, M. and Taira, K. U6 promoter-driven siRNAs with four uridine 3' overhangs efficiently suppress targeted gene expression in mammalian cells. Nat.Biotechnol., 20: 497-500, 2002.

24. Paul, C. P., Good, P. D., Winer, I., and Engelke, D. R. Effective expression of small interfering RNA in human cells. Nat.Biotechnol., 20: 505-508, 2002.

25. Yu, J. Y., DeRuiter, S. L., and Turner, D. L. RNA interference by expression of 
short-interfering RNAs and hairpin RNAs in mammalian cells.

Proc.Natl.Acad.Sci.U.S.A, 99: 6047-6052, 2002.

26. Jiang, B. H., Aoki, M., Zheng, J. Z., Li, J., and Vogt, P. K. Myogenic signaling of phosphatidylinositol 3-kinase requires the serine-threonine kinase Akt/protein kinase B. Proc.Natl.Acad.Sci.U.S.A, 96: 2077-2081, 1999.

27. Coffer, P. J., Jin, J., and Woodgett, J. R. Protein kinase B (c-Akt): a multifunctional mediator of phosphatidylinositol 3-kinase activation. Biochem.J., 335 ( Pt 1): 1-13, 1998.

28. Sun, M., Wang, G., Paciga, J. E., Feldman, R. I., Yuan, Z. Q., Ma, X. L., Shelley, S. A., Jove, R., Tsichlis, P. N., Nicosia, S. V., and Cheng, J. Q. AKT1/PKBalpha kinase is frequently elevated in human cancers and its constitutive activation is required for oncogenic transformation in NIH3T3 cells. Am.J.Pathol., 159: 431-437, 2001.

29. Bellacosa, A., de Feo, D., Godwin, A. K., Bell, D. W., Cheng, J. Q., Altomare, D. A., Wan, M., Dubeau, L., Scambia, G., Masciullo, V., and . Molecular alterations of the AKT2 oncogene in ovarian and breast carcinomas. Int.J.Cancer, 64: 280-285, 1995.

30. Grammer, T. C., Cheatham, L., Chou, M. M., and Blenis, J. The p70S6K signalling pathway: a novel signalling system involved in growth regulation. Cancer Surv., 27: 271-292, 1996. 
31. Jefferies, H. B., Fumagalli, S., Dennis, P. B., Reinhard, C., Pearson, R. B., and Thomas, G. Rapamycin suppresses 5'TOP mRNA translation through inhibition of p70s6k. EMBO J., 16: 3693-3704, 1997.

32. Berven, L. A. and Crouch, M. F. Cellular function of p70S6K: a role in regulating cell motility. Immunol.Cell Biol., 78: 447-451, 2000.

33. Pullen, N., Dennis, P. B., Andjelkovic, M., Dufner, A., Kozma, S. C., Hemmings, B. A., and Thomas, G. Phosphorylation and activation of p70s6k by PDK1. Science, 279: 707-710, 1998.

34. Chen, R. H., Sarnecki, C., and Blenis, J. Nuclear localization and regulation of erkand rsk-encoded protein kinases. Mol.Cell Biol., 12: 915-927, 1992.

35. Mills, G. B., Fang, X., Lu, Y., Hasegawa, Y., Eder, A., Tanyi, J., Tabassam, F. H., Mao, M., Wang, H., Cheng, K. W., Nakayama, Y., Kuo, W., Erickson, J., Gershenson, D., Kohn, E. C., Jaffe, R., Bast, R. C., Jr., and Gray, J. Specific keynote: molecular therapeutics in ovarian cancer. Gynecol.Oncol., 88: S88-S92, 2003.

36. Jimenez, C., Portela, R. A., Mellado, M., Rodriguez-Frade, J. M., Collard, J., Serrano, A., Martinez, A., Avila, J., and Carrera, A. C. Role of the PI3K regulatory subunit in the control of actin organization and cell migration. J.Cell Biol., 151: 249-262, 2000. 
37. Lauffenburger, D. A. and Horwitz, A. F. Cell migration: a physically integrated molecular process. Cell, 84: 359-369, 1996.

38. Gao, N., Flynn, D. C., Zhang, Z., Zhong, X. S., Walker, V., Liu, K. J., Shi, X., and Jiang, B. H. G1 cell cycle progression and the expression of G1 cyclins are regulated by $\mathrm{PI} 3 \mathrm{~K} / \mathrm{AKT} / \mathrm{mTOR} / \mathrm{p} 70 \mathrm{~S} 6 \mathrm{~K} 1$ signaling in human ovarian cancer cells. Am.J.Physiol Cell Physiol, 287: C281-C291, 2004.

39. Altomare, D. A., Wang, H. Q., Skele, K. L., De Rienzo, A., Klein-Szanto, A. J., Godwin, A. K., and Testa, J. R. AKT and mTOR phosphorylation is frequently detected in ovarian cancer and can be targeted to disrupt ovarian tumor cell growth. Oncogene, 23: 5853-5857, 2004.

40. Westerlund, A., Hujanen, E., Hoyhtya, M., Puistola, U., and Turpeenniemi-Hujanen, T. Ovarian cancer cell invasion is inhibited by paclitaxel. Clin.Exp.Metastasis, 15: 318-328, 1997.

41. Tsihlias, J., Kapusta, L., and Slingerland, J. The prognostic significance of altered cyclin-dependent kinase inhibitors in human cancer. Annu.Rev.Med., 50: 401-423, 1999.

42. Liu, L. Y. [Metastatic cancer in the ovary--report of 57 cases]. Zhonghua Zhong.Liu Za Zhi., 11: 464-467, 1989. 
43. Qiang, Y. W., Yao, L., Tosato, G., and Rudikoff, S. Insulin-like growth factor I induces migration and invasion of human multiple myeloma cells. Blood, 103: 301-308, 2004.

44. Sawhney, R. S., Cookson, M. M., Sharma, B., Hauser, J., and Brattain, M. G. Autocrine transforming growth factor alpha regulates cell adhesion by multiple signaling via specific phosphorylation sites of p70S6 kinase in colon cancer cells. J Biol.Chem., 279: 47379-47390, 2004.

45. Staykova, M. A., Berven, L. A., Cowden, W. B., Willenborg, D. O., and Crouch, M. F. Nitric oxide induces polarization of actin in encephalitogenic T cells and inhibits their in vitro trans-endothelial migration in a p70S6 kinase-independent manner.

FASEB J, 17: 1337-1339, 2003. 


\section{FIGURE LEGENDS}

Fig. 1. SiP2 inhibited OVCAR-3 cell migration and wound-healing. (A) Cells expressing siP2 or siSCR plasmid were cultured at a density of $5 \times 10^{5}$ cells/dish in RPMI 1640 medium with $10 \% \mathrm{FBS}$ for $24 \mathrm{~h}$ at $37^{\circ} \mathrm{C}$ in $5 \% \mathrm{CO}_{2}$ incubator. The total RNA was prepared and first strand cDNA was synthesized using AMV and oligo(dT) primer. PIK3CA mRNA in OVCAR-3 cells expressing siP2 or siSCR was assayed by semiquantitative RT-PCR. The PIK3CA mRNA level was compared with the signal from control GAPDH mRNA level. $10 \mu \mathrm{l}$ of PCR product of siSCR and siP2 was run on $2 \%$ agrose gel. A single graph from triplicate determinations showing identical results is shown. The cells $\left(5 \times 10^{5}\right.$ cells $\left./ \mathrm{ml}\right)$ expressing siP2 or siSCR were cultured in normal

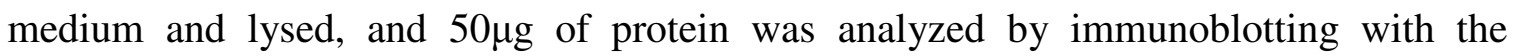
antibodies against $\mathrm{p} 110 \alpha$ and $\beta$-actin. (B) OVCAR-3 cells stably expressing siP2 or siSCR alone were cultured to $100 \%$ confluence. A sterile $200 \mu 1$ pipette tip was used to scratch the cells to form a wound. The cells were then washed with 1x PBS and cultured in $10 \%$ FBS medium for $24 \mathrm{~h}$ and fixed with formalin. Migration of the cells to the wound was visualized at $24 \mathrm{~h}$ with an inverted Olympus phase-contrast microscope. The representative fields were photographed. (C) The healing rate was quantified with measurements of the gap size after the culture. Three different areas in each assay were chosen to measure the distance of migrating cells to the origin of the wound. The healing rate of cells expressing siP2 was normalized to that of siSCR control cells. The 
mean values and the standard error were obtained from three experiments. (D) The migration assay was conducted by transwell assay. The cells expressing siP2 or siSCR were split(1:2) the day before the assay. Migrated cells were fixed and stained with hematoxylin. The representative fields were photographed. (E) The migrated cells in each well were counted in three different fields under the microscope. The mean values and the standard error were obtained from three individual experiments $(P<0.05$, Student's test).

Fig. 2. SiP2 decreased OVCAR-3 cell invasion. (A) OVCAR-3 cells expressing siP2 or siSCR were cultured to near confluence in RPMI 1640 medium containing $10 \%$ FBS. The invasion assay was carried out according to the invasion assay method described in Material and Methods. The invaded cells were enumerated by taking photomicrographs at 200x magnification. The representative fields were photographed. (B) The cells in three different fields of each experiment were counted. The mean values and the standard error were obtained from three independent experiments $(P<0.05, \mathrm{n}=3)$.

Fig. 3. SiP2 decreased OVCAR-3 cell proliferation. (A) Cell proliferation was measured by counting cell number of OVCAR-3 cells expressing siRNA against p110 $\alpha$ or siSCR. OVCAR-3 cells expressing siP2 or siSCR control were seeded in a 12-well plate at a density of $2 \times 10^{5}$ cells/ ml in RPMI 1640 medium with $10 \%$ FBS for $24 \mathrm{~h}, 48 \mathrm{~h}$, and $72 \mathrm{~h}$. Cells were harvested and counted using a hemocytometer. The number of 
total cells expressing siP2 was counted and normalized to the number obtained in the siSCR control at $0 \mathrm{~h}$. The data represented the mean and the standard error from three independent experiments. * indicates that the normalized cell number was significantly decreased compared to the control at the same time point $(P<0.05$, Student's test). $\mathrm{SiP} 2$ expression leads to a change of cell cycle regulatory proteins. Cells were cultured in a $60 \mathrm{~mm}$ dish at a density of $5 \times 10^{5}$ cells/dish in RPMI 1640 medium. The total cellular protein extracts were prepared and aliquots of proteins were separated on SDS-PAGE, analyzed by immunoblotting with antibodies against phospho-Rb (Ser795, Ser780, and Ser807/811), Rb C-terminal control, cyclin D1, CDK4, CDK2, cyclin E, CDC25A, p27 $7^{\mathrm{KIP} 1}, \mathrm{p} 21, \mathrm{PCNA}$, and $\beta$-actin. The experiments were carried out on three separate occasions. The bands were quantified by scanning densitometry using Eagleeye software. The relative mean densitometry between siRNA and siSCR was calculated. The mean ratio $\pm \mathrm{SD}$ was plotted on the graph.

Fig. 4. SiRNA against AKT1 inhibited OVCAR-3 cell migration and wound-healing. (A) Cells expressing siP2 or siSCR plasmid were cultured in a $60 \mathrm{~mm}$ dish at a density of $5 \times 10^{5}$ cells/dish in RPMI 1640 medium with $10 \%$ FBS for $24 \mathrm{~h}$, followed by incubation with serum-free medium for $16 \mathrm{~h}$. Cells were switched to the medium in the presence or absence of $100 \mathrm{nM}$ insulin for $1 \mathrm{~h}$ as indicated. The total cellular protein extracts were prepared and subjected to immunoblot analysis using antibodies against phospho-AKT (Ser473) and $\beta$-actin. (B) Cells expressing siA1 or siSCR plasmid were cultured at a 
density of $5 \times 10^{5}$ cells/dish in RPMI 1640 medium with $10 \%$ FBS for $24 \mathrm{~h}$. RT-PCR analysis of AKT1 mRNA level and AKT2 mRNA level in OVCAR-3 cells expressing siA1 or siSCR was carried out as the method mentioned above. A single graph from triplicate determinations showing identical results is shown. The cells $\left(5 \times 10^{5}\right.$ cells $\left./ \mathrm{ml}\right)$ were cultured in normal medium and lysed, and $50 \mu \mathrm{g}$ of protein was analyzed by immunoblotting with the antibodies against AKT1, AKT2 and $\beta$-actin. (C) OVCAR-3 cells expressing siA1 or siSCR were cultured to $100 \%$ confluence. A sterile pipette tip was used to scratch the monolayer cells to form a wound. The cells were then cultured in $10 \%$ FBS medium for $24 \mathrm{~h}$ and fixed with formalin. The images were recorded using a microscope. (D) The wound-healing rate was quantified with measurements of the gap size over time. Three different areas in each assay were chosen to measure the distance of migrating cells. The wound-healing rate of cells expressing siA1 was normalized to that of the siSCR control cells. The mean values and the standard error were obtained from three individual experiments $(P<0.05$, Student's test). (E) The migration assay was conducted by transwell assay. The cells were split (1:2) the day before the assay. The cells were incubated in the transwells at $37^{\circ} \mathrm{C}$ in $5 \% \mathrm{CO}_{2}$ for $24 \mathrm{~h}$. Migrated cells were fixed and stained with hematoxylin. (F) The migrated cells in each well were counted in three different fields under the microscope. The mean values and the standard error were obtained from three independent experiments $(P<0.05$, Student's test). 
Fig. 5. SiA1 decreased OVCAR-3 cell invasion. (A) OVCAR-3 cells expressing siA1 or siSCR were cultured to near confluence in RPMI 1640 medium containing 10\% FBS. The invasion assay was carried out according to the method mentioned above. The representative fields were photographed. (B) The cells were enumerated by taking photographs at 200x magnification. The experiments were repeated three times. The cells in three different fields of each experiment were counted. The mean values and the standard error were obtained from three independent experiments $(P<0.05$, Student's test).

Fig. 6. SiA1 decreased OVCAR-3 cell proliferation. (A) Cell proliferation was measured by counting the number of OVCAR-3 cells expressing siA1 or siSCR. OVCAR-3 cells expressing siA1 or siSCR were seeded in a 12-well plate at a density of $2 \times 10^{5}$ cells $/ \mathrm{ml}$ in RPMI 1640 medium with $10 \%$ FBS for $24 \mathrm{~h}, 48 \mathrm{~h}$, and $72 \mathrm{~h}$. Cells were harvested and counted using a hemocytometer. The number of total cells was counted and normalized to the number obtained in the siSCR control at $0 \mathrm{~h}$. The data represented the mean and the standard error from three independent experiments. * indicates that the normalized cell number was significantly decreased when compared to the control at the same time point $(P<0.05$, Student's test). (B) SiA1 expression leads to a change of cell cycle regulatory proteins. Cells expressing siA1 or siSCR plasmid were cultured in a $60 \mathrm{~mm}$ dish at a density of $5 \times 10^{5}$ cells/dish in RPMI 1640 medium. The total cellular protein extracts were prepared and subjected to immunoblot analysis using 
specific antibodies against phospho-Rb (Ser795, Ser780 and Ser807/811), Rb C-terminal protein, cyclin D1, CDK4, CDK2, cyclin E, CDC25A, p2 $7^{\mathrm{KIP} 1}$, p21, PCNA, and $\beta$-actin. The experiments were carried out on three separate occasions. The bands were quantified by scanning densitometry using Eagleeye software. The relative mean densitometry between siRNA and siSCR was calculated. The mean ratio \pm SD was plotted on the graph.

Fig. 7. SiP2 and siA1 decreased p70S6K1 activation, and siRNA against p70S6K1 (sip70S6K1) expression decreased the expression of p70S6K1 protein in OVCAR-3 cells. (A) Cells expressing siP2, siA1 or siSCR plasmid were cultured in a $60 \mathrm{~mm}$ dish at a density of $5 \times 10^{5}$ cells/dish in RPMI 1640 medium, followed by incubation with serum-free medium for $16 \mathrm{~h}$. Cells were switched to the medium in the presence or absence of $100 \mathrm{nM}$ insulin for $1 \mathrm{~h}$ as indicated. The total cellular protein extracts were prepared and subjected to immunoblot analysis using antibodies against phospho-p70S6K1 (Thr421/Ser424) and $\beta$-actin. (B) Generation of cells stably expressing sip70S6K1. The oligonucleotides encoding 19-mer hairpin sequences specific to the p70S6K1 mRNA were designed using siRNA converter software. The oligonucleotides are synthesized, annealed, and ligated into the linearized pSilencer vector. The sip70S6K1 and siSCR plasmids were transfected into OVCAR-3 cells by Lipofectamine. After two weeks selection in medium containing $500 \mu \mathrm{g} / \mathrm{ml} \mathrm{G} 418$, the clones stably expressing the siRNA were picked and grown in fresh culture dishes. The 
cells $\left(5 \times 10^{5}\right.$ cells $\left./ \mathrm{ml}\right)$ were cultured in normal medium and lysed, and $50 \mu \mathrm{g}$ of protein was analyzed by immunoblotting with the antibodies against total p70S6K1, phospho-p70S6K1 (Thr421/Ser424) and $\beta$-actin. (C) The cells expressing p70S6K1 siRNA or siSCR were cultured and switched to serum-free medium for $16 \mathrm{~h}$ before treatment with $10 \% \mathrm{FBS}$ for $1 \mathrm{~h}$ at $37^{\circ} \mathrm{C}$. Aliquots $(50 \mu \mathrm{g})$ of total proteins were analyzed by immunoblotting using antibodies against total p70S6K1 and phopho-S6 ribosomal protein (Ser 235/236).

Fig. 8. Sip70S6K1 inhibited OVCAR-3 cell migration and invasion. (A) The migration assay was conducted by transwell assay. The cells were split at a ratio of 1:2 the day before the assay. The cells were incubated in the transwells at $37^{\circ} \mathrm{C}$ in $5 \% \mathrm{CO}_{2}$ for $24 \mathrm{~h}$. Migrated cells were fixed and stained with hematoxylin. The representative fields were photographed. (B) The migrated cells were counted in three different fields per assay under the microscope. The mean values and the standard error were obtained from three independent experiments $(P<0.05$, Student's test). (C) OVCAR-3 cells expressing sip70S6K1 or siSCR were cultured to near confluence in RPMI 1640 medium containing $10 \%$ FBS. The invasion assay was done according to the method mentioned above. The representative fields were photographed. (D) The cells were enumerated by taking photomicrographs at 200x magnification. The cells in three different fields in each experiment were counted. The mean values and the standard error were from three independent experiments $(P<0.05$, Student's test). 
Fig. 9. Sip70S6K1 decreased cell proliferation and cell cycle-associated protein expression. (A) Cell proliferation was measured by counting OVCAR-3 cells expressing sip70S6K1 or siSCR. OVCAR-3 cells expressing sip70S6K1 or siSCR were seeded in a 12-well plate at a density of $2 \times 10^{5}$ cells $/ \mathrm{ml}$ in RPMI 1640 medium with $10 \%$ FBS for $24 \mathrm{~h}, 48 \mathrm{~h}$, and $72 \mathrm{~h}$. Cells were harvested and counted using a hemocytometer. The number of total cells was counted and normalized to the number obtained in the siSCR control at $0 \mathrm{~h}$. The data represented the mean and the standard error from three independent experiments. * indicates that the cell number was significantly decreased when compared to the control at the same time point $(P<0.05$, Student's test $)$. (B) Cells expressing sip70S6K1 or siSCR were cultured in a $60 \mathrm{~mm}$ dish at a density of $5 \times 10^{5}$ cells/dish in RPMI 1640 medium with 10\% FBS for $24 \mathrm{~h}$. The total cellular protein extracts were prepared and subjected to immunoblot analysis using specific antibodies against phospho-RB (Ser795, Ser780, and Ser807/811), cyclin D1, CDK4, CDK2, cyclin E, CDC25A, p27 $7^{\mathrm{KIP} 1}, \mathrm{p} 21$, PCNA, and $\beta$-actin. The experiments were performed in triplicate. The bands were quantified by scanning densitometry using Eagleeye software. The relative mean densitometry between siRNA and siSCR was calculated. The mean ratio \pm SD was plotted on the graph. 
Fig. 1. SiP2 inhibited OVCAR-3 cell migration and wound-healing.
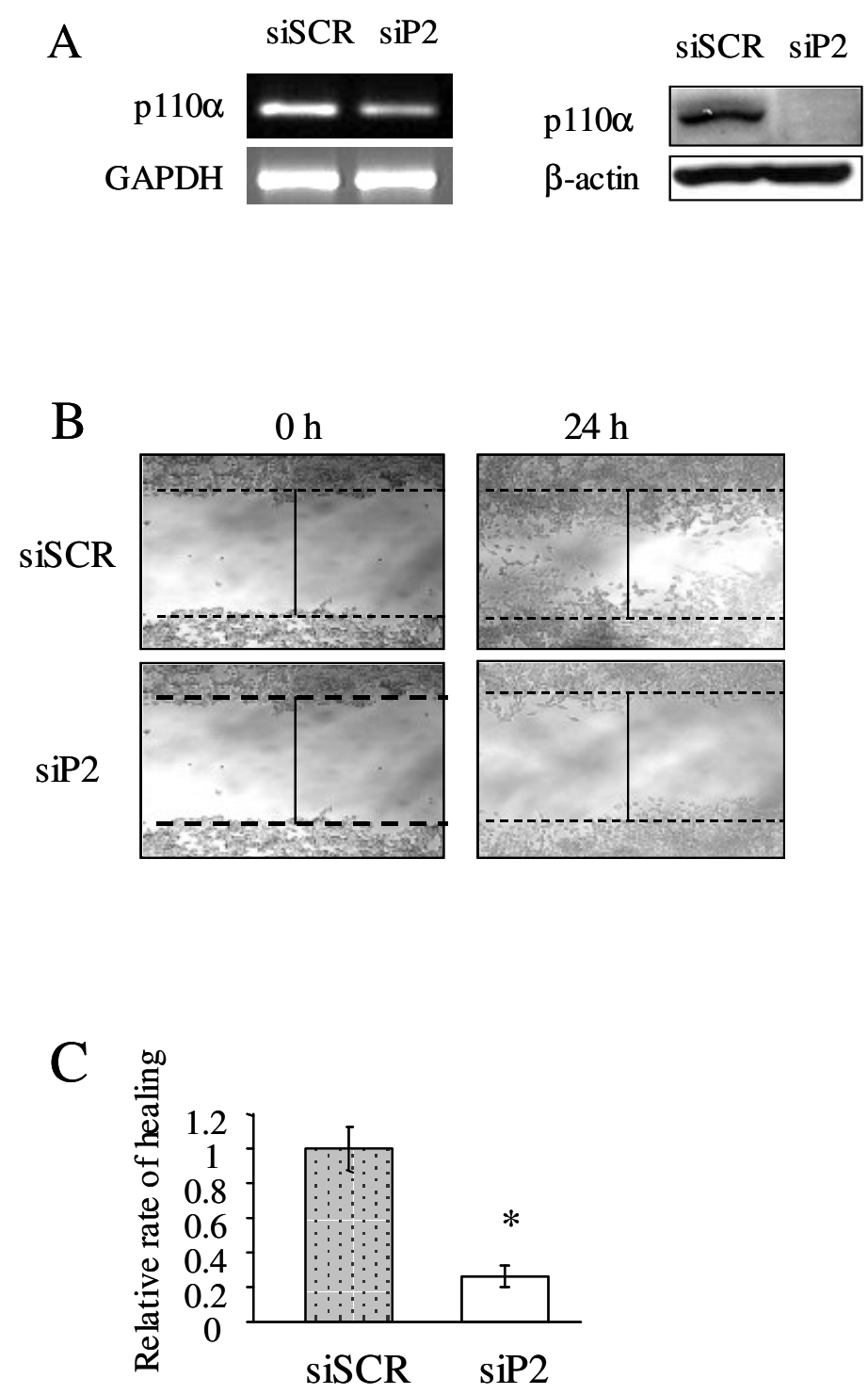
D
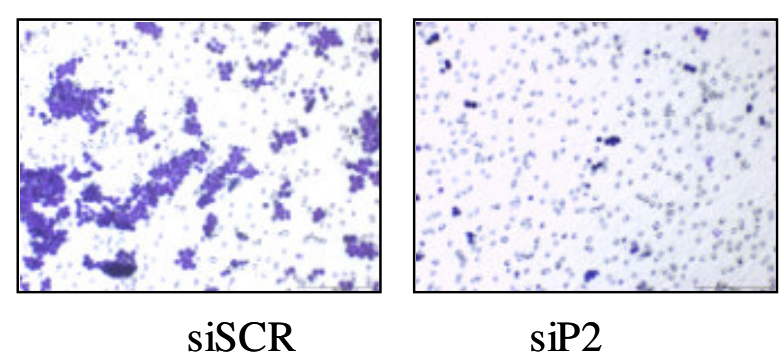

E

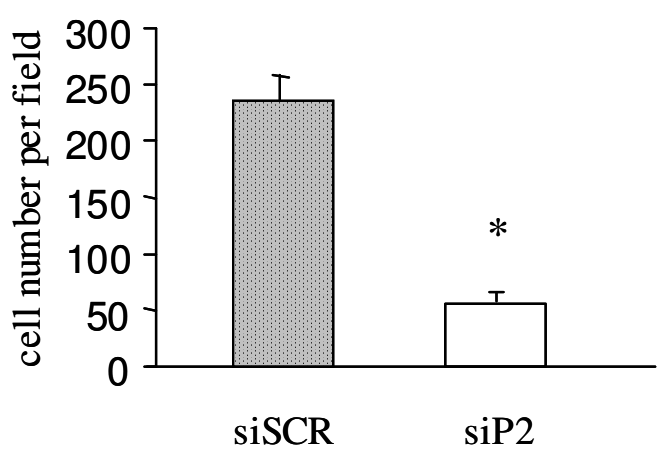


Fig. 2. SiP2 decreased OVCAR-3 cell invasion.

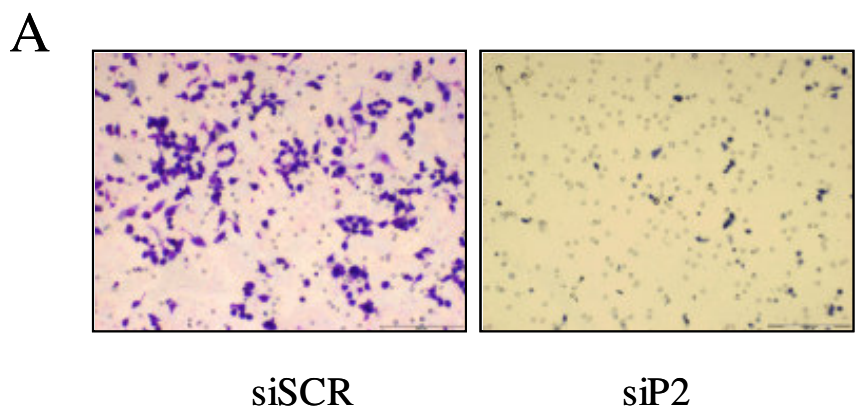

B

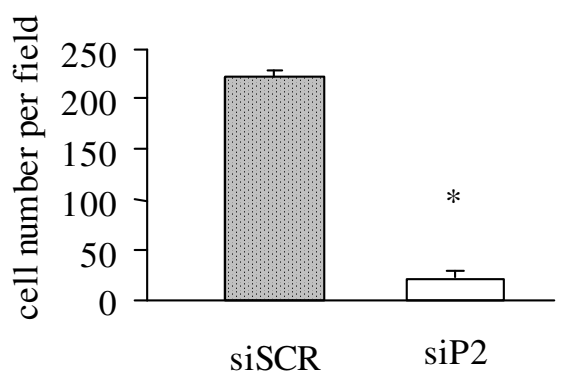


Fig. 3. SiP2 decreased OVCAR-3 cell proliferation.
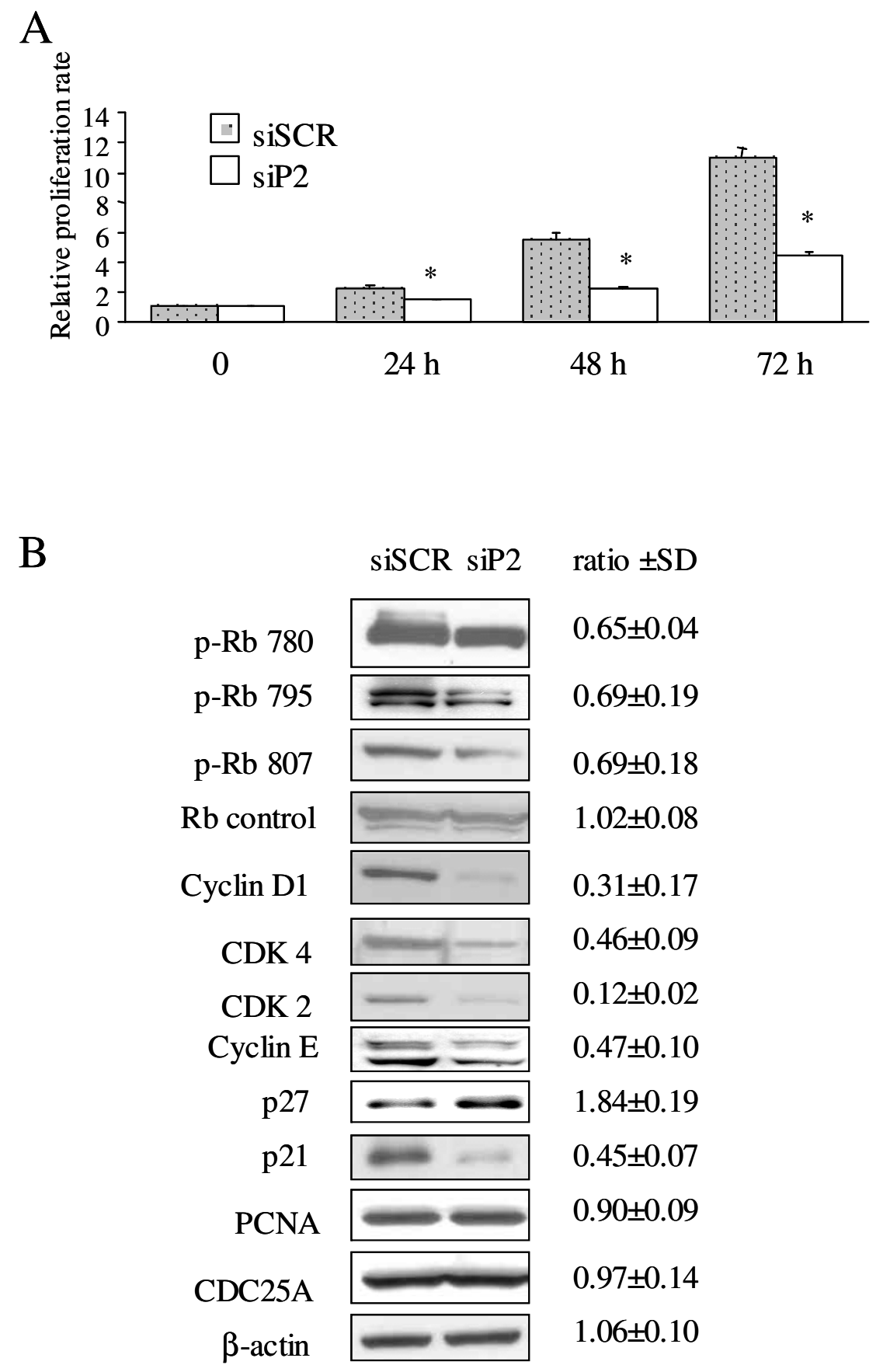
Fig. 4. SiRNA against AKT1 inhibited OVCAR-3 cell migration and wound healing.

A

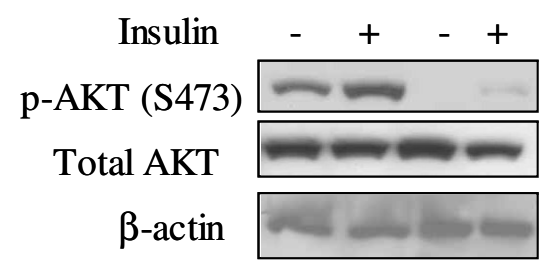

B

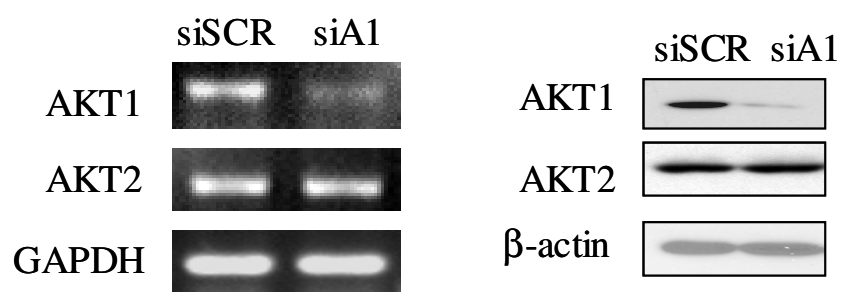

C

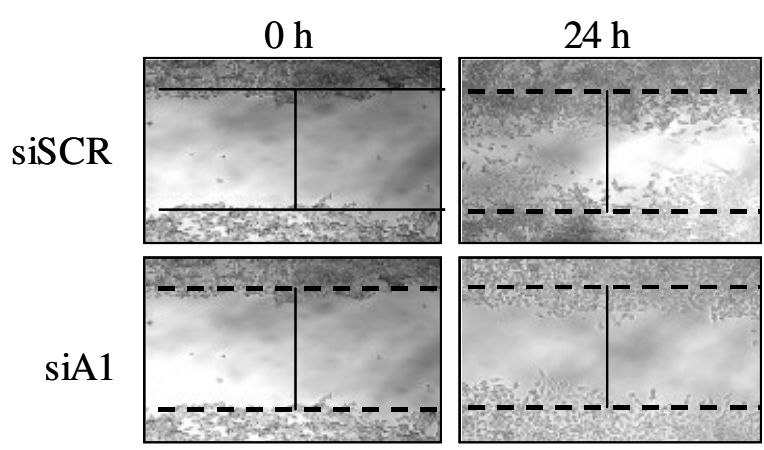


D

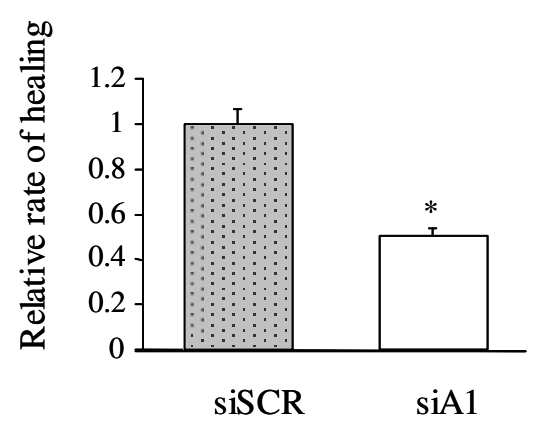

E

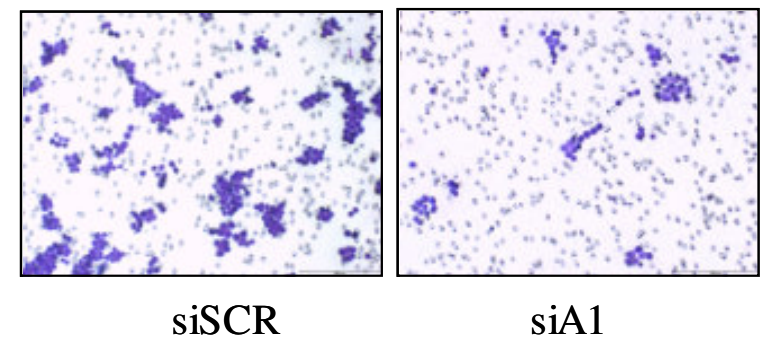

F

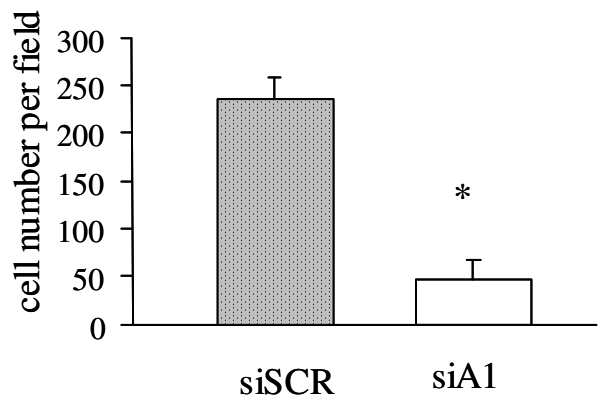


Fig. 5. SiA1 decreased OVCAR-3 cell invasion.

A

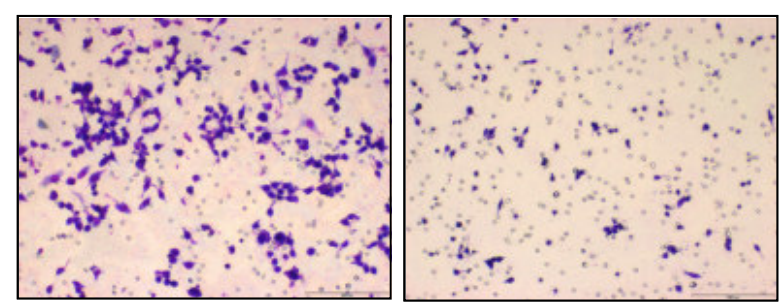

siSCR

siA1

B

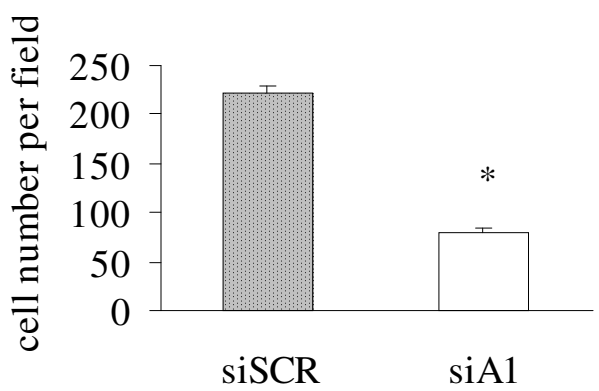


Fig. 6. SiA1 decreased OVCAR-3 cell proliferation.

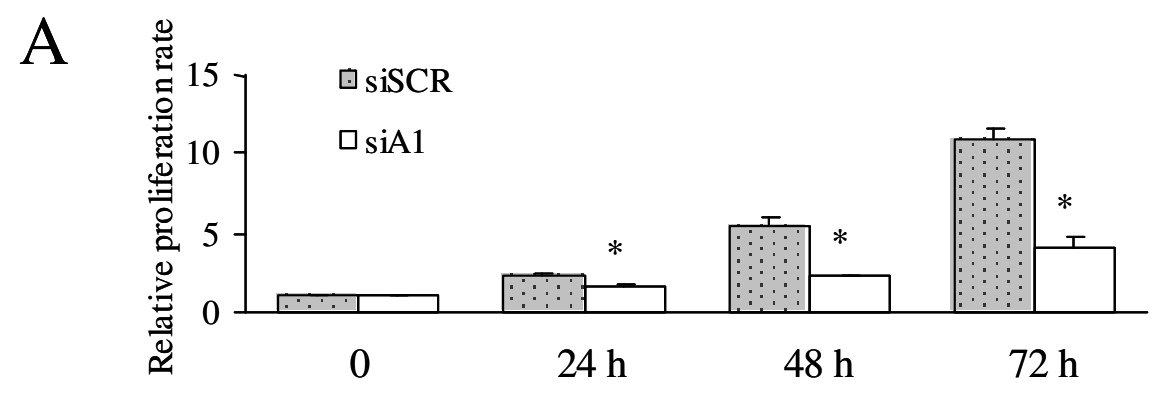

B

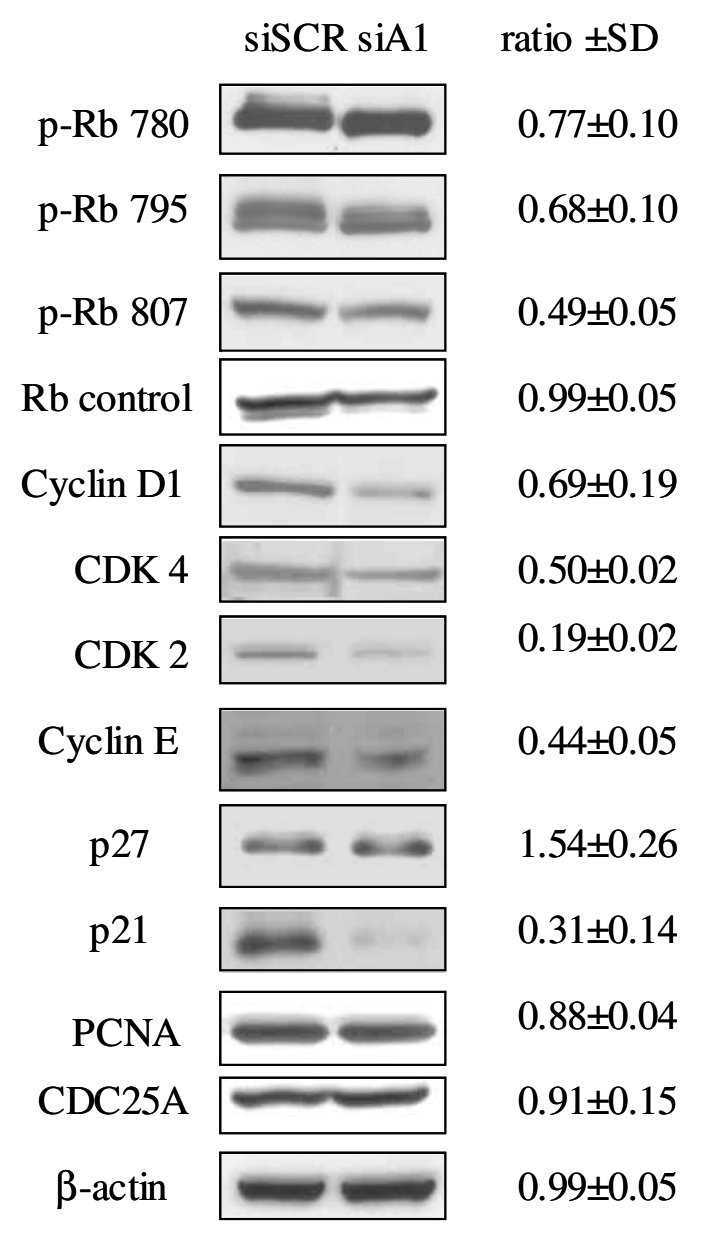


Fig. 7. SiP2 and siA1 decreased p70S6K1 activation, and siRNA against p70S6K1 (sip70S6K1) expression decreased the expression of p70S6K1 protein in OVCAR-3 cells.

A

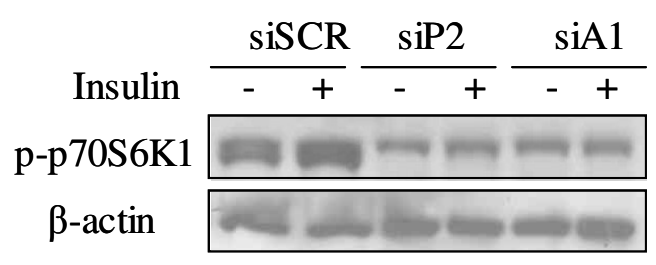

B siSCR $\operatorname{sip} 70 \mathrm{~S} 6 \mathrm{~K} 1$

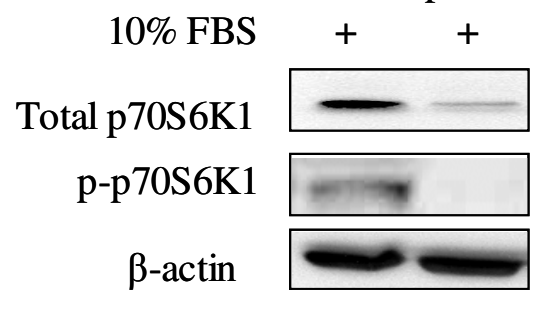

C

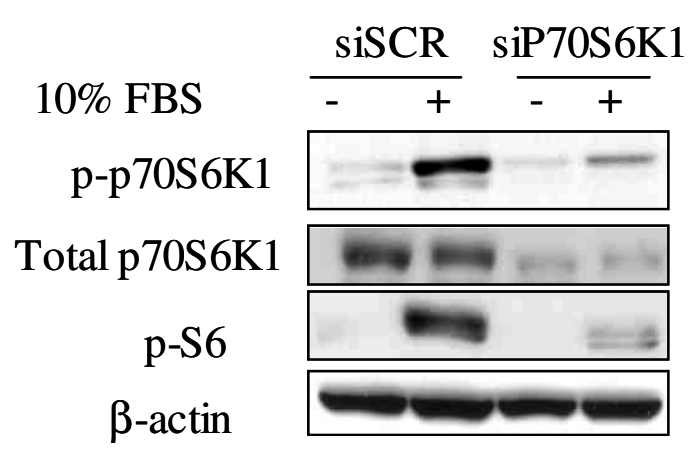


Fig. 8. Sip70S6K1 inhibited OVCAR-3 cell migration and invasion.

A

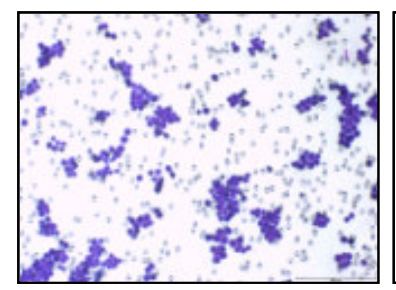

siSCR

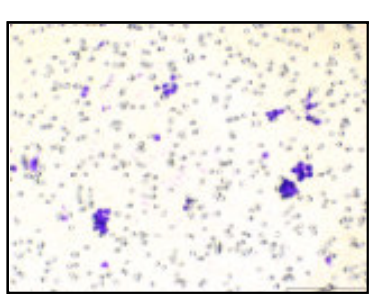

$\operatorname{sip} 70 \mathrm{~S} 6 \mathrm{~K} 1$

B

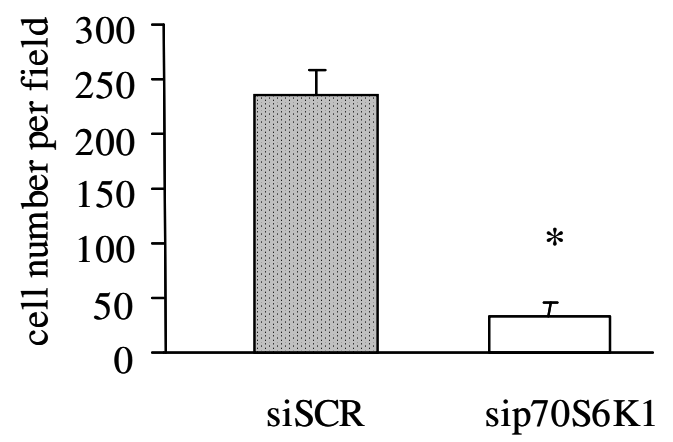

C
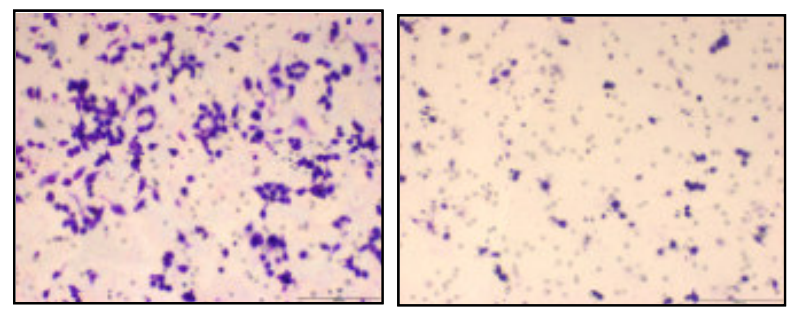

siSCR

sip70S6K1

$\mathrm{D}$

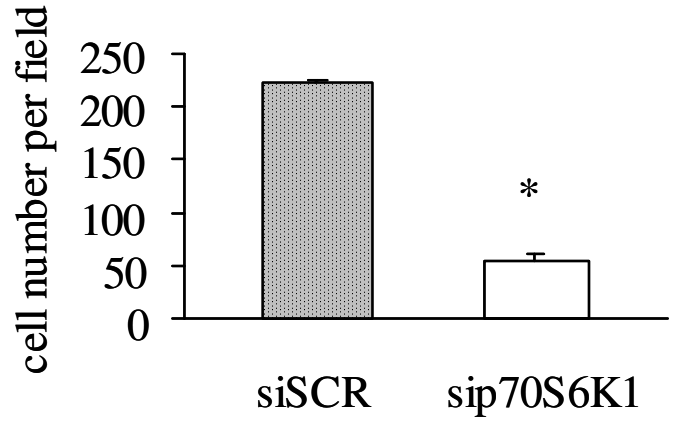


Fig. 9. Sip70S6K1 decreased cell proliferation and cell cycle-associated protein expression.

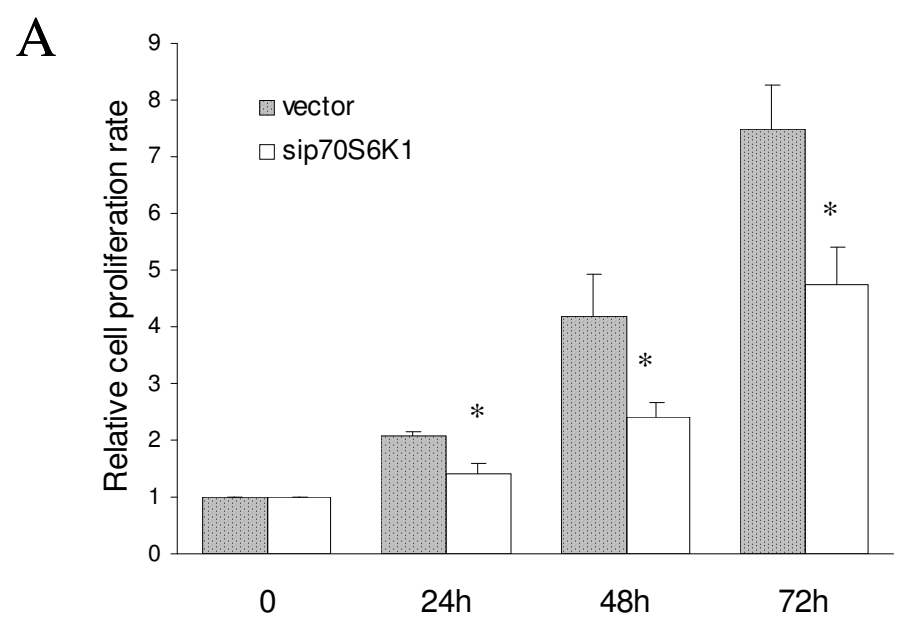

B

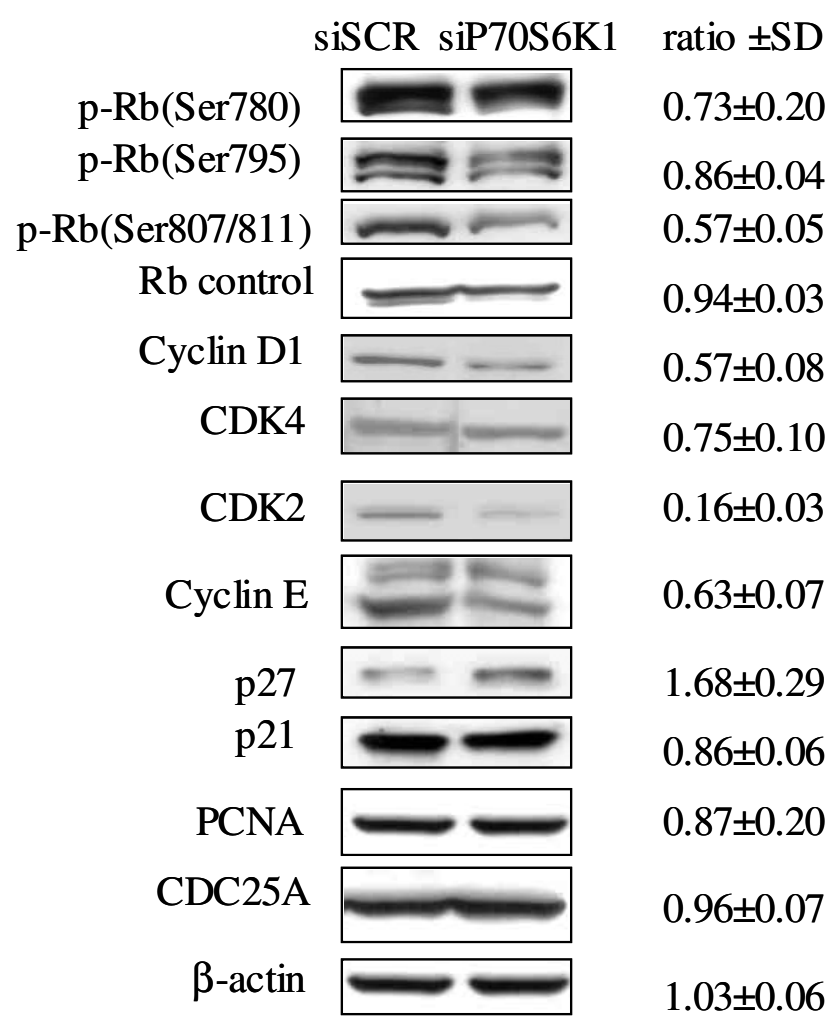




\section{CHAPTER III}

TSC2/p70S6K1 regulates tumor growth and angiogenesis through VEGF and

HIF-1 $\alpha$ expression 


\begin{abstract}
Tuberous sclerosis complex (TSC) is an autosomal dominant genetic disorder. To study the function of TSC in ovarian tumor angiogenesis, we established stable cell lines that expressed small interfering RNA (siRNA) specific to TSC1 or TSC2. Here, we show that inhibition of TSC1 and TSC2 induced the expression of HIF-1 $\alpha$ in ovarian cancer cells. Knock-down expression of TSC1 or TSC2 increased VEGF expression at both mRNA levels and protein levels. Lost function of TSC2 induced ovarian tumor angiogenesis and tumor growth through p70S6K1 activation. The 70kDa ribosomal S6 kinase 1 (p70S6K1) is regulated by TSC2/mTOR pathway. P70S6K1 is an important regulator of both cell proliferation and cell growth. However, the mechanism of p70S6K1 in tumorigenesis remains to be elucidated. In this study, we specifically inhibited p70S6K1 activity in ovarian cancer cells using vector-based siRNA against p70S6K1. We found that the expression of p70S6K1 siRNA significantly decreased VEGF protein expression and VEGF transcriptional activation through HIF-1 $\alpha$ binding site at VEGF promoter. The expression of p70S6K1 siRNA specifically inhibited HIF- $1 \alpha$, but not HIF-1 $\beta$ protein expression in ovarian cancer cells. We also found that p70S6K1 down-regulation decreased ovarian tumor growth and angiogenesis, and that p70S6K1 siRNA expression inhibited VEGF expression through decreasing HIF-1 $\alpha$ expression. Our data suggested that p70S6K1 might induce tumor angiogenesis by increasing HIF-1 $\alpha$ and VEGF expression. This study provides a novel mechanism of
\end{abstract}


human ovarian cancer induced by mutations of TSC and the activation of p70S6K1. 


\section{INTRODUCTION}

Tuberous sclerosis complex (TSC) is an autosomal dominant syndrome associated with the development of benign and occasional malignant tumors that occurs most notably in the central nervous system, kidney, heart, lung and skin ${ }^{1}$. Two genes are implicated in tuberous sclerosis: TSC $1^{2}$ and TSC2 ${ }^{3}$. TSC1 and TSC2 encode the protein hamartin and tuberin and are putative tumor suppressor genes ${ }^{4}$. Tuberous sclerosis results from mutations in either TSC1 or TSC2 gene. TSC2 forms a complex with TSC1 that inhibits mammalian target of rapamycin (mTOR) ${ }^{5}$. TSC2 has the function of GTPase activating protein towards the small Ras-like GTPase Rheb ${ }^{6}$. Rheb activates mTOR in its active GTP bound form ${ }^{7}$.

TSC complex is regulated by AMPK $^{8}$ and also by the tumor suppressor PTEN ${ }^{9}$. In the absence of PTEN, growth factors stimulate the production of PIP3 leading to the activation of AKT and PDK1. AKT phosphorylates TSC2, which leads to decreased TSC2 GAP activity ${ }^{10-12}$. Phosphorylated TSC 2 increases the activation of Rheb ${ }^{13}$ and activates $\mathrm{mTOR}^{14-16}$. Activated mTOR phosphorylates 4E-BP and S6 kinase, leading to an increase in the rates of protein translation ${ }^{17}$.

Several studies have implicated the role of VEGF in the TSC pathway in which the loss of TSC2 is accompanied by elevated levels of HIF-1 $\alpha$ and VEGF ${ }^{18}$. TSC2 loss results in the accumulation of HIF-1 $\alpha$ and increased expression of HIF-responsive genes including VEGF ${ }^{19}$. The regulation of HIF-1 by TSC2 involves mTOR. HIF-1 levels 
in TSC2-deficient cells are normalized by treatment with the mTOR inhibitor rapamycin

20. However, the role of $\mathrm{TSC} / \mathrm{mTOR} / \mathrm{p} 70 \mathrm{~S} 6 \mathrm{~K} 1$ pathway in regulating tumor angiogenesis still remains to be elucidated. In this study, the expression of tuberin and harmartin was inhibited by its specific siRNA against TSC1 or TSC2. The effect of downregulation of tuberin or harmartin on HIF-1 $\alpha$ and VEGF expression was determined. The role of TSC/mTOR/p70S6K1 pathway in ovarian tumor angiogenesis was studied.

P70S6K1 is activated through PI3K pathway ${ }^{21}$ and MAPK pathway ${ }^{22}$. Recent biochemical analyses determined that tuberin also regulates PI3K-dependent activation of p70S6K1. P70S6K1 is known to regulate cell growth by inducing protein synthesis components. Activated PI3K or AKT can induce cell transformation through the phosphorylation and activation of $\mathrm{p} 70 \mathrm{~S} 6 \mathrm{~K} 1^{23}$. P70S6K1 is involved in tumor progression. P70S6K1 is overactivated in the majority of human papillary cancer cells ${ }^{24}$, small cell lung cancer cells ${ }^{25}$ and pancreatic cancer cells ${ }^{26}$. Recent studies indicated the important role of p70S6K1 in phosphatase and tensin homologue (PTEN) negative and in AKT-overexpressing tumors ${ }^{27,28}$. It suggests that phosphorylation of p70S6K1 is correlated with PI3K induced tumorigenesis. P70S6K1 is well known to play an important role in cell proliferation, cell growth and cell cycle progression, but little is known about its role in angiogenesis.

Angiogenesis is the growth of new vascular endothelial cells and the development of new blood vessels. Tumor expansion cannot proceed beyond 1-2mm without $\operatorname{angiognesis}^{29}$. Angiogenesis is a crucial factor in the progression of solid tumors and 
metastasis $^{30-32}$. VEGF is expressed by many human solid tumors and has been implicated in tumor-associated angiogenesis ${ }^{33-37}$. VEGF has been found in ovarian tumor tissue, omental metastases, cystic and ascitic fluids, and the serum of patients with epithelial ovarian cancer $^{38-42}$. VEGF overexpression accelerated tumor growth and ascites formation, significantly enhanced tumor angiogenesis, and promoted the survival of tumor cells in mouse ovarian cancer model ${ }^{43}$. VEGF expression is regulated at the transcriptional level by hypoxia-inducible factor 1 (HIF-1) under hypoxia and in response to growth factor stimulation.

Hypoxia-inducible factor 1 (HIF-1) is a heterodimeric protein that consists of HIF- $1 \alpha$ and HIF- $1 \beta$ subunits $^{44}$. HIF- $1 \alpha$ is degraded during normoxia and HIF- $1 \beta$ is constitutively expressed. In normoxia, HIF- $1 \alpha$ is rapidly ubiquitinated by the von Hippel-Lindau tumor suppressor E3 ligase complex and subjected to proteasomal degradation ${ }^{45,46}$. Under hypoxic conditions, HIF- $1 \alpha$ is not degraded and accumulates to form an active complex with HIF-1 $\beta$. Under normal conditions, HIF-1 $\alpha$ protein synthesis is regulated by activation of the phosphatidylinositol 3-kinase (PI3K) ${ }^{47}$ and ERK mitogen-activated protein kinase (MAPK) pathways ${ }^{48,49}$. Recent studies suggest that amplified signaling through phosphoinositide 3-kinase and its downstream target, mTOR, increases HIF-1-dependent gene expression in certain cell types ${ }^{50,51}$. In mammals, mTOR is best known to regulate translation through the ribosomal protein S6 kinases (S6Ks) and the eukaryotic translation initiation factor 4E-binding proteins ${ }^{52}$.

The mTOR inhibitor rapamycin appears to be effective against tumors resulting 
from aberrantly high PI3K signaling ${ }^{53,54}$. Rapamycin has been shown to exert its effects on growth factor-induced cell proliferation, at least in part, by blocking the activation of the $\mathrm{p} 70 \mathrm{~S} 6 \mathrm{~K} 1^{55}$, thus preventing the downstream signaling process, such as the activation of the members of the cdk family ${ }^{56}$. Rapamycin showed antiangiogenesis activity by reducing VEGF protein production by tumor cells ${ }^{57}$. Rapamycin inhibits both stabilization of HIF-1 $\alpha$ and transcriptional activity of HIF-1 in hypoxic cancer cells ${ }^{58}$. Rapamycin interferes with HIF-1 activation in hypoxic cells by increasing the rate of HIF-1 $\alpha$ degradation ${ }^{59}$. Rapamycin can inhibit the mTOR activity, thus inhibiting the activity of S6K and 4E-BP1. The effect of rapamycin on angiogenesis suggested that p70S6K1 may play a role in tumor angiogenesis. However, rapamycin may have nonspecific effects on tumor angiogenesis. Thus, we want to specifically knockdown the expression of p70S6K1 to determine whether p70S6K1 regulates VEGF expression and transcriptional activation and whether p70S6K1 mediated VEGF expression is regulated by HIF-1 $\alpha$ expression in ovarian cancer cells. We further investigated the roles of p70S6K1 in tumor-associated angiogenesis in vivo. 


\section{MATERIALS AND METHODS}

Reagents and Cell Culture- The antibodies against total p70S6K1, phospho-p70S6K1 (Thr421/Ser424), phospho-AKT (Ser473), total AKT, phospho-GSK3ß (ser-9), total GSK3 $\beta$, phospho-p42/p44 MAPK, total mTOR and total TSC1 were from Cell Signaling Technology (Beverly, MA). Rapamycin and PD98059 were obtained from Calbiochem (La Jolla, CA). The antibodies against total TSC2, total ERK1, and total ERK2 were from Santa Cruz Biotechnology (Santa Cruz, CA). The mouse ABC staining system and the rabbit ABC staining system were from Santa Cruz Biotechnology (Santa Cruz, CA). The growth factor-reduced Matrigel and antibodies against HIF-1 $\alpha$ and HIF-1 $\beta$ were from BD Biosciences (Franklin Lakes, NJ). Recombinant human insulin and the antibody against $\beta$-actin were from Sigma (St. Louis, MO). The horseradish peroxidase (HRP)-conjugated anti-rabbit IgG and anti-mouse IgG were from Perkin Elmer Life

Sciences (Boston, MA). Factor VIII (Von Willebrand factor) antibody was from Biocare Medical (Concord, CA). The human ovarian cancer cell lines OVCAR-3 and A2780 were grown in RPMI 1640 (GIBCO BRL, Grand Island, NY) supplemented with 10\% heat inactivated fetal bovine serum, $2 \mathrm{mM} \mathrm{L}$-glutamine, $0.2 \%$ insulin, $100 \mathrm{U} / \mathrm{ml}$ penicillin, and $100 \mu \mathrm{g} / \mathrm{ml}$ streptomycin, and cultured at $37^{\circ} \mathrm{C}$ in humidified $5 \% \mathrm{CO}_{2}$ incubator.

siRNA and Plasmid Constructs - The siRNA constructs specific to TSC1, TSC2 or p70S6K1 were designed using siRNA converter software. The sequence of double 
strand small interfering RNA targeted to TSC1, TSC2 and p70S6K1 was as follows: TSC1, sense strand, CUGAACCACCACAAGCUACtt, and antisense strand, GUAGCUUGUGGUGGUUCAGtt; $\quad$ TSC2ab, sense strand, GAAAUUUGAAGAGCACGCAUU, and antisense strand, UGCGUGCUCUUCAAAUUUCUU; TSC2cd, sense strand, UGAGUCACAGUCCUUUGAGUU, and antisense strand, CUCAAAGGACUGUGACUCAUU; TSC2gh, sense strand, GGAUUACCCUUCCAACGAAUU, and antisense strand, UUCGUUGGAAGGGUAAUCCUU; p70S6K1, sense strand, GUUCAAGCUCAUCCAUUCUuu, and antisense strand, AGAAUGGAUGAGCUUGAACuu. A control siRNA that has scramble sequence without significant sequence homology to the known gene was also designed. The oligonucleotides were annealed, and ligated into the linearized pSilencer 2.1-U6 vector (Ambion, Austin, TX). The plasmid that expresses siRNA to TSC1, TSC2, p70S6K1 were named as siTSC1, siTSC2 or sip70S6K1. The scramble siRNA was named as siSCR. VEGF promoter reporter pGL-Stu1 containing a $2.65 \mathrm{~Kb}$ KpnI-BssHII fragment of the human VEGF gene promoter was cloned into the pGL2 basic luciferase vector. VEGF promoter reporter pMAP11wt, which contains the HIF-1 binding site of VEGF 5'-flanking sequence (from -985 to -939 ), was cloned into the pGL2 basic luciferase vector as described previously ${ }^{60}$. The mutant VEGF promoter reporter pMAP11mut was constructed by introducing a 3-bp substitution into pMAP11wt that abolishes the 
HIF-1 binding site. Human HIF-1 $\alpha$ gene was inserted into pCEP4 vector as described before $^{61}$.

Generation of siRNA-expressing cell lines- Cells were plated into 6 well plates. SiRNA $(2 \mu \mathrm{g})$ to TSC1 or siSCR was transfected into cells using Lipofectamine (Invitrogen), and cultured for $24 \mathrm{~h}$ without antibiotic selection. The cells were selected

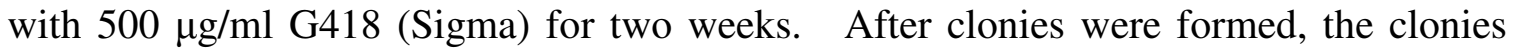
were removed and transfered to a fresh 96 well culture plate. When the cells reached confluency in a well of a 96 well culture dish, cells were moved to a well in a 24 well culture dish. When the cells reached confluency, they were split, and cultured with $250 \mu \mathrm{g} / \mathrm{ml} \mathrm{G} 418$ for selection. Three different clonies were selected and grown. The clonies were named as siTSC1-1, siTSC1-2 and siTSC1-3. $\operatorname{SiRNA}(2 \mu \mathrm{g})$ to TSC2, p70S6K1 or siSCR was transfected into cells using Lipofectamine (Invitrogen) according to the manufacturer's instructions, and cultured for $24 \mathrm{~h}$ without antibiotic selection. Then the cells were cultured in medium containing $500 \mu \mathrm{g} / \mathrm{ml} \mathrm{G} 418$ until all of the cells in the non-transfected control culture were killed. The antibiotic-resistant cells were pooled together and passaged as needed in medium containing 250 $\mathrm{g} / \mathrm{ml} \mathrm{G} 418$.

Transient transfection and luciferase(luc) assay- Cells were seeded in 12-well plates and cultured to 50-60\% confluence. Cells were transiently transfected with siRNA plasmid, VEGF reporter and pCMV- $\beta$-galactosidase plasmid using Lipofectamine from 
Invitrogen following the manufacturer's instructions. The transfected cells were cultured for $16 \mathrm{~h}$, washed once with phosphate-buffered saline (PBS), and lysed with 100 $\mu 1$ 1×Reporter Lysis Buffer from Promega (Madison, WI, USA). Luciferase substrate was added to protein samples $(10 \mu \mathrm{l})$ for the luciferase assay and measured by a monolight luminometer. $\quad \beta$-Galactosidase $(\beta$-gal) activity was measured by incubation in assay buffer (100 mM phosphate, pH 7.5, 2 mM $\mathrm{MgCl}_{2}, 100 \mathrm{mM} \beta$-mercaptoethanol, 1.33 $\mathrm{mg} / \mathrm{mL} o$-nitrophenyl $\beta$-D-galactopyranoside) at $37{ }^{\circ} \mathrm{C}$ for $1 \mathrm{~h}$. Relative Luc activity was calculated as the ratio of Luc/ $\beta$-gal activity and normalized to that from the control cells.

Immunoblotting Analysis - Cells were harvested and lysed in RIPA buffer [150 mM $\mathrm{NaCl}, 100 \mathrm{mM}$ Tris (pH 8.0), $1 \%$ Triton $\mathrm{X}-100,1 \%$ deoxycholic acid, 0.1\% SDS, $5 \mathrm{mM}$ EDTA, and $10 \mathrm{mM} \mathrm{NaF]}$, supplemented with protease inhibitors. Protein concentrations were determined by the Bradford assay (Bio-Rad). The total cellular protein extracts were separated by SDS-PAGE and transferred to nitrocellulose membrane. Membranes were blocked with 5\% nonfat dry milk in PBS containing $0.05 \%$ Tween 20, and incubated with the primary antibodies against total p70S6K1, phospho-p70S6K1 (Thr421/Ser424), phospho-AKT (Ser473), total AKT, phospho-GSK3ß (ser-9), total GSK3 $\beta$, phospho-p42/p44 MAPK, HIF-1 $\alpha$ and HIF-1 $\beta$, total mTOR, total TSC1, total TSC2, total ERK1, total ERK2 and $\beta$-actin. Bound antibodies were detected with an appropriate HRP-conjugated secondary antibody (Pierce) and chemiluminescence 
(Pierce). To use the same membrane to detect several proteins, the blots were incubated with gentle shaking in stripping buffer $(50 \mathrm{mM}$ glycine, $100 \mathrm{mM} \mathrm{KCl}, 0.5 \mathrm{mM}$ EDTA, 2-mercoptomethanol, 7M guandine hydrochloride) for $15 \mathrm{~min}$ at room temperature and washed three times with wash buffer for 15 min each time before reblotting the membranes using certain antibodies designed for the next experiment.

Quantification of VEGF protein- The levels of VEGF protein in the medium were determined by a VEGF ELISA kit (R\&D Systems). The cells were seeded in 12-well plates and cultured to $90-100 \%$ confluence. Cells were changed to fresh complete medium. The supernatants were collected and the cell numbers in each well were counted after $16 \mathrm{~h}$ incubation. VEGF in the supernatant $(100 \mu \mathrm{L})$ was determined and normalized to the cell numbers. A standard curve was obtained by a serial dilution of human recombinant VEGF. The data were presented as mean \pm SD from three different experiments.

Semi-Quantitative RT-PCR - Total RNAs were isolated from 1 x $10^{6}$ cultured cells with Trizol reagent (Invitrogen) according to the instruction of the manufacturer. First-strand cDNAs were synthesized from $1 \mu \mathrm{g}$ of total RNAs using AMV Reverse Transcriptase, an oligo(dT) primer and dNTP (Promega). Primers used for amplification were as follows: VEGF forward, 5'-TCGGGCCTCCGAAACCAT-3'; VEGF reverse, 5'-CCTGGTGAGAGATCTGGT-3'; GAPDH forward, 
5'-CCACCCATGGCAAATTCCATGGCA-3';

GAPDH

reverse

5'-TCTAGACGGCAGGTCAGGTCCACC-3'. Each RT-PCR reaction consisted of 30 cycles of $1 \mathrm{~min}$ at $94^{\circ} \mathrm{C}, 1 \mathrm{~min}$ at $60^{\circ} \mathrm{C}$ and $1 \mathrm{~min}$ at $72^{\circ} \mathrm{C}$. PCR products were run on $2 \%$ agarose gels, stained with ethidium bromide, and photographed using Eagleeye system.

Chicken Chorioallantoic Membrane (CAM) angiogenesis assay- White Leghorn chicken eggs were fertilized and incubated at $37^{\circ} \mathrm{C}$ with $70 \%$ humidity. An artificial air sac was created over a region containing small blood vessels in the chicken chorioallantoic membrane (CAM) as described previously ${ }^{62}$. Human ovarian cancer OVCAR-3 cells that expressed siRNA to TSC2, p70S6K1 or siSCR were trypsinized, washed, and resuspended at $10 \times 10^{7}$ cells/ml in serum-free RPMI 1640 medium and mixed with 10\% Matrigel (Collaborative Biomedical Products, Bedford, MA). Aliquots $(20 \mu \mathrm{l})$ of the mixture (two million cells) or the Matrigel alone were placed on the CAM of 9 days old chicken embryos. Five days after implantation, tumors in CAM were photographed using a Nikon digital camera. The experiments were repeated two times with five embryos for each treatment, and representative fields were photographed. The relative blood vessel density was determined by measuring the number of blood vessel branch points in a unit area on the CAM. Data were expressed as the mean \pm SD from replicate experiments. 
Immunohistochemistry-Tissues harvested from the CAMs were fixed in $10 \%$ formaldehyde, then embedded in paraffin (OCT; Miles Inc., IndianaB.C.). Tissue sections were deparaffinized in $3 \mathrm{x}$ xylene for $5 \mathrm{~min}$ each, in $2 \mathrm{x} 100 \%$ alcohol for $10 \mathrm{~min}$ each, in 2x 95\% alcohol for 10 min each, and then rinsed three times in deionized water. The slides were then boiled with antigen retrieval buffer $(10 \mathrm{mM}$ sodium citrate, $\mathrm{pH} 6.0)$ for $1 \mathrm{~min}$ at full power followed by 9 min at medium power using microwave, cooled for $20 \mathrm{~min}$, then rinsed in deionized water three times for 5 min each. The slides were incubated in $1 \%$ hydrogen peroxide for $10 \mathrm{~min}$ and washed in deionized water three times for 5 min each. The slides were incubated with $5 \%$ goat serum at room temperature for $1 \mathrm{~h}$, and then stained with antibodies against Factor VIII (1:100), VEGF (1:100) and HIF-1 $\alpha(1: 100)$. The sections were incubated in a humid chamber at $4^{\circ} \mathrm{C}$ overnight. After three washes in 1x PBS, the slides were incubated for $30 \mathrm{~min}$ with biotinylated secondary antibody, and detected by the incubation with $\mathrm{AB}$ enzyme reagent for $30 \mathrm{~min}$ at room temperature. Sections were rinsed several times in $1 \mathrm{x}$ PBS. One to three drops of peroxidase substrate were added to the slides for 5-10 min, and washed once with water. The slides were counterstained with hemotoxylin and washed several times with water. The sections were dehydrated as follows: 2 x $95 \%$ ethanol for 10 seconds each, 2x 100\% ethanol for 10 seconds each, 3x xylenes for 10 seconds each. After xylene goes off, the slides were immediately added with 1-2 drops of permanent mounting medium and covered with a glass coverslip. The slides were observed under light microscope and photographed. 
Statistical Analysis-The data were analyzed using SPSS statistics software package (SPSS, Chicago, IL). All of the results are expressed as mean \pm SD from three independent experiments except where that are specifically indicated, and the difference at $\mathrm{P}<0.05$ was considered significant. 


\section{RESULTS}

Expression of TSC1 or TSC2 siRNA induced HIF-1 $\alpha$ expression-TSC2 loss results in the accumulation of HIF-1 $\alpha$ and increased expression of HIF-responsive genes including VEGF in mouse embryo fibroblast cells. However the mechanism of regulation of HIF-1 expression by TSC1 and TSC2 is unknown. To determine whether TSC 1 and TSC2 regulate HIF-1 expression in ovarian cancer cells, we established the stable cell lines OVCAR-3 that expressed siRNA against siSCR, TSC1 or TSC2. To determine the effect of siTSC1 expression on HIF-1 $\alpha$ protein level, the ovarian cancer cells that stably expressed siTSC 1 or siSCR were cultured in complete medium for $24 \mathrm{~h}$ or in serum-free medium for $24 \mathrm{~h}$ and treated with insulin for $6 \mathrm{~h}$. Whole cell lysates were analyzed by immunoblotting using antibodies against HIF- $1 \alpha$ and HIF-1 $\beta$ proteins. SiTSC1 expression increased HIF-1 $\alpha$ protein level in complete medium compared to that in control cells (Fig. 1A). HIF-1 $\alpha$ protein level was induced in cells expressing siTSC2 in complete medium compared to that in control cells (Fig. 1B). SiTSC1 expression induced a higher level of HIF- $1 \alpha$ protein expression in serum-free medium than that in control cells (Fig. 1C). In contrast to siSCR cells, TSC2-knock down cells failed to downregulate HIF-1 $\alpha$ in response to growth factor deprivation (Fig. 1D).

Expression of siTSC1 or siTSC2 increased VEGF protein expression and mRNA level-VEGF plays an important role in human tumorigenesis and angiogenesis. 
However, the mechanism of its elevation in human cancer cells with TSC mutations still remains to be elucidated. To determine the role of TSC1 and TSC2 in regulating VEGF protein level, we established the stable cell lines OVCAR-3 that expressed siTSC1, siTSC2 or siSCR. The VEGF protein levels in the medium of cells expressing siTSC1, siTSC2 or siSCR were determined by ELISA. To exclude the effect of cell proliferation on the expression of VEGF protein, we normalized the VEGF protein concentration to the total cell number. As shown in Fig. 2A, siTSC1 or siTSC2 expression increased VEGF protein levels in OVCAR-3. To determine if siTSC1 or siTSC2 expression could regulate VEGF expression at the mRNA level, we performed semiquantitative RT-PCR. Expression of siTSC1 or siTSC2 induced the mRNA expression of VEGF compared to that in control cells (Fig. 2B).

Expression of TSC1 or TSC2 siRNA in the cells induced p70S6K1 and ERK1/2 activation, and decreased the phosphorylation of AKT and GSK3 $\beta$-To determine the signal pathway that TSC1 regulates HIF-1 expression in ovarian cancer cells, we established the stable cell lines OVCAR-3 that express siRNA to TSC1. Total TSC1 protein was reduced in cells expressing siTSC1 (Fig. 3A). The activity of p70S6K1 and ERK1/2 was induced in cells expressing siTSC1 compared to siSCR control in complete medium (Fig. 3B). Serum deprivation failed to block S6 phosphorylation and ERK1/2 phosphorylation in cells expressing siTSC1 (Fig. 3C). The AKT phosphorylation at Ser-473 and GSK3 $\beta$ phosporylation at Ser-9 were inhibited in cells expressing siTSC1 
compared to that in siSCR control in both complete medium (Fig. 3B) and serum-free medium in the presence or absence of insulin (Fig. 3C).

Loss of expression of tuberin plays a role in angiogenesis. To determine the signal pathway that TSC2 regulates HIF-1 expression in ovarian cancer cells, we established the stable cell lines OVCAR-3 that express siRNA to TSC2. Three different siRNA targeted to different region of TSC2 gene were utilized and three stable cell line that express siRNA to TSC2 were established. They were named as siTSC2ab, siTSC2cd and siTSC2gh. In contrast to a scrambled siRNA, total TSC2 protein was markedly reduced by expression of siTSC2 (Fig. 4A). The level of phosphorylated p70S6K1 and phosphorylated ERK1/2 was higher in cells expressing siTSC2 than that in siSCR control cells under the condition of complete medium (Fig. 4A) or serum-free medium treated with or without insulin (Fig. 4B). The expression of siTSC2 inhibited the activity of AKT and GSK3 $\beta$ in both complete medium (Fig. 4A) and serum-free medium in the presence or absence of insulin (Fig. 4B). The results suggested that loss of TSC1 or TSC2 might regulate HIF-1 and VEGF expression through p70S6K1 and ERK1/2 and not through AKT in ovarian cancer cells.

siTSC2 expression induced ovarian tumor angiogenesis and tumor growth through $m T O R / p 70 S 6 K 1$ - To determine whether tuberin regulated tumor-induced angiogenesis through mTOR/p70S6K1 in vivo, cells expressing siTSC2 treated with DMSO or $10 \mathrm{nM}$ rapamycin, and cells expressing siTSC2 infected with adenovirus vector or with 
adenovirus expressing p70S6K1(K100R) were mixed with Matrigel, and implanted onto the CAM of 9-day-old embryos. The cells expressing siSCR were used as the control. The relative blood vessel numbers were increased in tumors generated from the cells that expressed siTSC2 when compared to the siSCR control group (Fig. 5). This result showed that loss of TSC2 induced tumor angiogenesis. The number of blood vessels was decreased in siTSC2 treated with $10 \mathrm{nM}$ rapamycin in contrast to that in siTSC2 treated with DMSO. The group of siTSC2 infected with adenovirus expressing p70S6K1 (K100R) has less blood vessel formation when compared to the cells expressing siTSC2 infected with adenovirus vector (Fig. 5).

To test the effect of siTSC2 expression on tumor growth, OVCAR-3 cells stably expressing siTSC2 or siSCR were mixed with Matrigel, and implanted onto the CAMs as described above. The cells were incubated in the CAMs for 9 days at $37^{\circ} \mathrm{C}$. Tumor weight generated from the cells with siTSC2 expression was two times that in the control suggesting the loss of TSC2 induced tumor growth (Fig. 6B). Tumors from cells expressing siTSC2 pretreated with rapamycin have a significantly decreased tumor weight compared to that of cells expressing siTSC2. Tumor weight from cells expressing siTSC2 infected with adenovirus expressing p70S6K1 (K100R) was 50\% of that in the cells expressing siTSC2 infected with adenovirus vector (Fig. 6B). This result demonstrated that TSC2 induced tumor growth through p70S6K1 activation. 
P70S6K1 was a downstream molecule that mediated the effect of TSC1 or TSC2 on VEGF transcriptional activation - To determine the mechanism through which TSC2 regulates VEGF expression, OVCAR-3 cells were transiently transfected with a VEGF promoter reporter containing 2.6-kb human VEGF promoter with or without presence of siTSC1 or siTSC2 construct. SiTSC1 expression or siTSC2 expression induced VEGF transcriptional activation in a dose-dependent manner (Fig. 7A). Overexpression of sip70S6K1 reduced the VEGF reporter activity induced by expression of siTSC1 or siTSC2 to normal (Fig. 7B). Expression of TSC1 or TSC2 inhibited VEGF transcriptional activation in a dose-dependent manner (Fig. 7C). Overexpression of the p70S6K1 active form reversed the VEGF reporter activity inhibited by expression of TSC2 or TSC1 (Fig. 7D).

To determine the role of p70S6K1 in regulating VEGF protein level, we established the stable cell lines OVCAR-3 and A2780 cells that expressed siRNA against p70S6K1 (sip70S6K1) or siSCR. The VEGF protein levels in the medium of cells expressing sip70S6K1 or siSCR were detected by ELISA assay. As shown in Fig. 8A and 8B, sip70S6K1 expression significantly decreased VEGF protein levels in OVCAR-3 and A2780 cells.

To further determine the mechanism through which p70S6K1 regulates VEGF expression, A2780 or OVCAR-3 cells were transiently transfected with a VEGF promoter reporter containing 2.6-kb human VEGF promoter with or without presence of sip70S6K1 construct. Sip70S6K1 expression inhibited VEGF transcriptional activation 
in a dose-dependent manner (Fig. 8C). The results showed that p70S6K1 regulated VEGF expression at the transcriptional level. To test whether the HIF-1 binding site at the VEGF promoter is important for p70S6K1- mediated transcriptional activation, we analyzed the effect of sip70S6K1 expression on a short form of VEGF promoter reporter, pMAP11WT which contained a functional promoter fragment with the HIF-1 binding site. The OVCAR-3 and A2780 cells were cotransfected with pMAP11wt reporter and sip70S6K1 construct. The cells cotransfected with pMAP11wt reporter and siSCR were used as a control. Sip70S6K1 expression significantly decreased pMAP11wt reporter activity $(p<0.05)$ (Fig. 8D). Overexpression of HIF-1 $\alpha$ reversed the pMAP11wt reporter activity inhibited by expression of sip70S6K1 (Fig. 8D), suggesting that sip70S6K1 inhibited VEGF transcriptional activation via HIF-1 $\alpha$ DNA binding site and HIF-1 $\alpha$ protein expression. To test whether the inhibitory effect of sip70S6K1 on VEGF transcriptional activity required the HIF-1 binding site, we employed a mutant pMAP11mut VEGF promoter reporter that had 3 bp substitutions at the HIF-1 binding site. The cells were cotransfected with pMAP11mut VEGF promoter reporter and sip70S6K1. We found that sip70S6K1 expression did not inhibit the pMAP11mut VEGF reporter activity (Fig. 8E), further confirming that p70S6K1 regulates VEGF transcriptional activation through HIF-1 $\alpha$ DNA binding site.

Sip70S6K1 expression inhibited HIF-1 $\alpha$ expression-To determine the effect of sip70S6K1 expression on HIF-1 $\alpha$ protein level, the ovarian cancer cells that stably 
expressed sip70S6K1 or siSCR were cultured in complete medium for $24 \mathrm{~h}$ or in serum-free medium for $24 \mathrm{~h}$ and treated with insulin for $6 \mathrm{~h}$. Whole cellular lysates were analyzed by immunoblotting using antibodies against HIF-1 $\alpha$ and HIF-1 $\beta$ proteins. Sip70S6K1 expression decreased HIF-1 $\alpha$ protein level in complete medium compared to that in vector control cells (Fig. 9A). Insulin induced HIF-1 $\alpha$, but not HIF-1 $\beta$ expression in the control cells. Sip70S6K1 expression abolished insulin-induced HIF-1 $\alpha$ protein expressions, showing that p70S6K1 may activate VEGF transcription specifically through HIF-1 $\alpha$ expression in the ovarian cancer cells (Fig. 9B).

Sip70S6K1 expression inhibited tumor induced angiogenesis and tumor growth in vivoTo test whether specific inhibition of p70S6K1 affected tumor-induced angiogenesis in vivo, OVCAR-3 cells stably expressing sip70S6K1 or siSCR were mixed with Matrigel, and implanted onto the CAM of 9-day-old embryos, and then incubated for 5 days at $37^{\circ} \mathrm{C}$. OVCAR-3 cells induced angiogenesis, which was inhibited by sip70S6K1 expression with a $60 \%$ reduction of angiogenesis when compared to the Matrigel alone in the CAM (Fig. 10B). To determine whether sip70S6K1 expression inhibited angiogenesis in the tumors, tumor sections were stained using antibodies against Factor VIII, which reacts specifically with the endothelial cells of blood vessels. We found that sip70S6K1 expression greatly decreased angiogenesis in tumors $(p<0.05)$ (Fig. 10C). To test the effect of sip70S6K1 expression on tumor growth, OVCAR-3 cells stably expressing sip70S6K1 or siSCR were mixed with Matrigel, and implanted onto the 
CAMs as described above. The cells were incubated in the CAMs for 9 days at $37^{\circ} \mathrm{C}$. Tumor weight generated from the cells with sip70S6K1 expression was only $25 \%$ of that in the control (Fig. 10E). We also determined the expression of sip70S6K1 on affecting phospho-p70S6K1 and total p70S6K1 levels in the tumor tissues. Total proteins were extracted from three tumors in each group, and phospho-p70S6K1 and total p70S6K1 proteins were detected by immunoblotting. Sip70S6K1 expression significantly inhibited phospho-p70S6K1 and total p70S6K1 expression (Fig. 10F).

Sip70S6K1 Expression Decreased VEGF and HIF-1 $\alpha$ expression in tumors- To determine whether sip70S6K1 expression inhibits VEGF and HIF-1 $\alpha$ expression in vivo, tumor sections were stained using antibodies against VEGF or HIF-1 $\alpha$. We found that sip70S6K1 expression significantly decreased the signals of VEGF or HIF-1 $\alpha$ in tumor sections (Fig. 11A). We also determined the effect of sip70S6K1 expression on HIF-1 $\alpha$ and HIF-1 $\beta$ protein levels by immunoblotting in tumors. Sip70S6K1 expression significantly decreased the expression of HIF- $1 \alpha$. HIF-1 $\beta$ protein expression was not changed (Fig. 11B). This result showed that sip70S6K1 specifically regulated HIF-1 $\alpha$, but not HIF-1 $\beta$ expression in vivo. 


\section{DISCUSSION}

The tumor-suppressor proteins TSC1 and TSC2 are associated with an autosomal dominant disorder known as tuberous sclerosis complex (TSC). TSC1/TSC2 complex is known to play a role in regulating VEGF through mTOR dependent pathway in mouse embryo fibroblasts cells. In this study, we showed that downregulation of TSC1 or TSC2 with their siRNA constructs upregulated HIF-1 $\alpha$ in ovarian cancer epithelial cells. The activation of p70S6K1 and ERK1/2 was induced in cells expressing siTSC1 or siTSC2. It suggests that TSC1/TSC2 complex may regulate the expression of HIF-1 $\alpha$ through MAPK or p70S6K1. Activated p70S6K1 may inhibit AKT activation through a negative feedback loop from mTOR/S6K to the adaptor molecule IRS-1. A similar negative feedback involving S6K repression of AKT activation has also been described in Drosophila ${ }^{63}$. The increase in HIF-1 $\alpha$ levels in cells expressing siTSC1 or siTSC2 is functionally important as it is accompanied by increased expression of VEGF. VEGF has a very important role in tumor growth and angiogenesis. To determine the effect of siTSC2 in tumor progression, we performed tumor angiogenesis and tumor assay using CAM model. Expression of siRNA to TSC2 in tumor cells induced tumor growth and angiogenesis (Fig. 6B and Fig. 10B). The increased tumor growth and angiogenesis can be inhibited by rapamycin and p70S6K1 (K100R) expression. These data are consistent with a model that downregulation of TSC2 results in activation of mTOR/p70S6K1, which increases HIF-1 $\alpha$ and VEGF and leads to increased tumor 
growth and angiogenesis.

P70S6K1 is known to play an important role in cell proliferation and cell cycle progression. Growth factors activate p70S6K1 through the activation of PI3K and mTOR. PI3K activation is necessary and sufficient for the activation of p70S6K1 which specifically phosphorylates the ribosomal protein S6 which is required for cells to enter the $\mathrm{S}$ phase after mitogenic stimulation ${ }^{64}$. Rapamycin is implicated in tumor growth. Inhibition of mTOR activity with rapamycin resulted in G1 arrest in ovarian cancer cells with increased AKT activity ${ }^{65,66}$. Rapamycin effectively inhibits tumor growth that depend on AKT signaling for proliferation in a genetically defined mouse ovarian carcinoma model ${ }^{67}$. Rapamycin has demonstrated antiangiogenic effects in in vivo mouse model ${ }^{68}$. However, there is no direct evidence in the role of p70S6K1 in angiogenesis. In this study we showed that specifically knockdown of p70S6K1 expression decreased ovarian cancer tumor growth and angiogenesis in vivo (Fig. 10). We also showed that p70S6K1 played an important role in the regulation of VEGF and HIF-1 $\alpha$ expression (Fig. 8). VEGF is overexpressed in most human tumors including ovarian cancer. VEGF stimulates angiogenesis and tumor growth. VEGF is becoming an important target for cancer treatment. In this paper we have demonstrated that inhibition of p70S6K1 expression decreased VEGF expression at the transcriptional level in ovarian cancer cells (Fig. 8). It suggested that p70S6K1 might regulate ovarian cancer angiogenesis through VEGF expression. VEGF expression is regulated through at least three mechanisms including gene transcription, gene translation level, and mRNA 
stabilization. To investigate the mechanism of p70S6K1-mediated VEGF expression, we used a VEGF promoter-reporter gene construct and demonstrated that p70S6K1 down-regulation decreased VEGF expression at the transcriptional level.

The transcriptional regulation of VEGF is mainly mediated by HIF-1. Recently, growth factors were shown to increase expression of HIF-1 $\alpha$ and HIF-1 $\alpha$ mediated VEGF transcriptional activation via a PI3K mechanism ${ }^{69-72}$. In this study we demonstrated that p70S6K1 regulates VEGF transcriptional activation through HIF-1 $\alpha$, but not HIF-1 $\beta$ subunit. We also showed that p70S6K1 is required for VEGF and HIF-1 $\alpha$ expression in tumor tissues. This study provides strong evidence to suggest that p70S6K1 may regulate ovarian cancer angiogenesis through VEGF and HIF-1 $\alpha$ expression.

In summary, these results suggest that downregulation of TSC2 increased tumor growth and angiogenesis through mTOR/p70S6K1 pathway. We demonstrate here for the first time that p70S6K1 down-regulation inhibits expression of VEGF at the transcriptional level through HIF-1 $\alpha$ expression and inhibition of p70S6K1 expression decreased ovarian tumor growth and angiogenesis in vivo. This novel finding provides a mechanism for potentially targeting p70S6K1 for human ovarian cancer therapy in the future. 


\section{ACKNOWLEDGEMENTS}

We thank Dr. John Blenis for kindly providing p70S6K1 construct and Dr. Zong-Xian Cao for kindly providing p70S6K1 (K100R) adenovirus and adenovirus vector. 


\section{Reference List}

1. Mak, B. C. and Yeung, R. S. The tuberous sclerosis complex genes in tumor development. Cancer Invest, 22: 588-603, 2004.

2. van Slegtenhorst, M., de Hoogt, R., Hermans, C., Nellist, M., Janssen, B., Verhoef, S., Lindhout, D., van den, O. A., Halley, D., Young, J., Burley, M., Jeremiah, S., Woodward, K., Nahmias, J., Fox, M., Ekong, R., Osborne, J., Wolfe, J., Povey, S., Snell, R. G., Cheadle, J. P., Jones, A. C., Tachataki, M., Ravine, D., Sampson, J. R., Reeve, M. P., Richardson, P., Wilmer, F., Munro, C., Hawkins, T. L., Sepp, T., Ali, J. B., Ward, S., Green, A. J., Yates, J. R., Kwiatkowska, J., Henske, E. P., Short, M. P., Haines, J. H., Jozwiak, S., and Kwiatkowski, D. J. Identification of the tuberous sclerosis gene TSC1 on chromosome 9q34. Science, 277: 805-808, 1997.

3. Identification and characterization of the tuberous sclerosis gene on chromosome 16. The European Chromosome 16 Tuberous Sclerosis Consortium. Cell, 75: 1305-1315, 1993.

4. Green, A. J., Johnson, P. H., and Yates, J. R. The tuberous sclerosis gene on chromosome 9q34 acts as a growth suppressor. Hum.Mol.Genet., 3: 1833-1834, 1994.

5. Tee, A. R., Fingar, D. C., Manning, B. D., Kwiatkowski, D. J., Cantley, L. C., and Blenis, J. Tuberous sclerosis complex-1 and -2 gene products function together to 
inhibit mammalian target of rapamycin (mTOR)-mediated downstream signaling. Proc.Natl.Acad.Sci.U.S.A, 99: 13571-13576, 2002.

6. Zhang, Y., Gao, X., Saucedo, L. J., Ru, B., Edgar, B. A., and Pan, D. Rheb is a direct target of the tuberous sclerosis tumour suppressor proteins. Nat.Cell Biol., 5: 578-581, 2003.

7. Saucedo, L. J., Gao, X., Chiarelli, D. A., Li, L., Pan, D., and Edgar, B. A. Rheb promotes cell growth as a component of the insulin/TOR signalling network. Nat.Cell Biol., 5: 566-571, 2003.

8. Inoki, K., Zhu, T., and Guan, K. L. TSC2 mediates cellular energy response to control cell growth and survival. Cell, 115: 577-590, 2003.

9. Ma, L., Teruya-Feldstein, J., Behrendt, N., Chen, Z., Noda, T., Hino, O., Cordon-Cardo, C., and Pandolfi, P. P. Genetic analysis of Pten and Tsc2 functional interactions in the mouse reveals asymmetrical haploinsufficiency in tumor suppression. Genes Dev., 19: 1779-1786, 2005.

10. Inoki, K., Li, Y., Zhu, T., Wu, J., and Guan, K. L. TSC2 is phosphorylated and inhibited by Akt and suppresses mTOR signalling. Nat.Cell Biol., 4: 648-657, 2002.

11. Manning, B. D., Tee, A. R., Logsdon, M. N., Blenis, J., and Cantley, L. C. Identification of the tuberous sclerosis complex-2 tumor suppressor gene product 
tuberin as a target of the phosphoinositide 3-kinase/akt pathway. Mol.Cell, 10: 151-162, 2002.

12. Potter, C. J., Pedraza, L. G., and $\mathrm{Xu}, \mathrm{T}$. Akt regulates growth by directly phosphorylating Tsc2. Nat.Cell Biol., 4: 658-665, 2002.

13. Zhang, Y., Gao, X., Saucedo, L. J., Ru, B., Edgar, B. A., and Pan, D. Rheb is a direct target of the tuberous sclerosis tumour suppressor proteins. Nat.Cell Biol., 5: 578-581, 2003.

14. Hanrahan, J. and Blenis, J. Rheb Activation of mTOR and S6K1 Signaling. Methods Enzymol., 407: 542-555, 2005.

15. Inoki, K., Li, Y., Xu, T., and Guan, K. L. Rheb GTPase is a direct target of TSC2 GAP activity and regulates mTOR signaling. Genes Dev., 17: 1829-1834, 2003.

16. Manning, B. D. and Cantley, L. C. Rheb fills a GAP between TSC and TOR. Trends Biochem.Sci., 28: 573-576, 2003.

17. Fingar, D. C. and Blenis, J. Target of rapamycin (TOR): an integrator of nutrient and growth factor signals and coordinator of cell growth and cell cycle progression. Oncogene, 23: 3151-3171, 2004.

18. El Hashemite, N., Walker, V., Zhang, H., and Kwiatkowski, D. J. Loss of Tsc1 or Tsc2 induces vascular endothelial growth factor production through mammalian 
target of rapamycin. Cancer Res., 63: 5173-5177, 2003.

19. Liu, M. Y., Poellinger, L., and Walker, C. L. Up-regulation of hypoxia-inducible factor 2alpha in renal cell carcinoma associated with loss of Tsc-2 tumor suppressor gene. Cancer Res., 63: 2675-2680, 2003.

20. Brugarolas, J. B., Vazquez, F., Reddy, A., Sellers, W. R., and Kaelin, W. G., Jr. TSC2 regulates VEGF through mTOR-dependent and -independent pathways. Cancer Cell, 4: 147-158, 2003.

21. Chung, J., Grammer, T. C., Lemon, K. P., Kazlauskas, A., and Blenis, J. Nature, 370: 71-75, 1994.

22. Martin, K. A. and Blenis, J. Coordinate regulation of translation by the PI 3-kinase and mTOR pathways. Adv.Cancer Res, 86: 1-39, 2002.

23. Aoki, M., Blazek, E., and Vogt, P. K. A role of the kinase mTOR in cellular transformation induced by the oncoproteins P3k and Akt. Proc.Natl.Acad.Sci.U.S.A, 98: 136-141, 2001.

24. Miyakawa, M., Tsushima, T., Murakami, H., Wakai, K., Isozaki, O., and Takano, K. Increased expression of phosphorylated p70S6 kinase and Akt in papillary thyroid cancer tissues. Endocr.J, 50: 77-83, 2003.

25. Seufferlein, T. and Rozengurt, E. Rapamycin inhibits constitutive p70s6k 
phosphorylation, cell proliferation, and colony formation in small cell lung cancer cells. Cancer Res, 56: 3895-3897, 1996.

26. Shah, S. A., Potter, M. W., Ricciardi, R., Perugini, R. A., and Callery, M. P. FRAP-p70s6K signaling is required for pancreatic cancer cell proliferation. $\mathrm{J}$ Surg.Res, 97: 123-130, 2001.

27. Neshat, M. S., Mellinghoff, I. K., Tran, C., Stiles, B., Thomas, G., Petersen, R., Frost, P., Gibbons, J. J., Wu, H., and Sawyers, C. L. Enhanced sensitivity of PTEN-deficient tumors to inhibition of FRAP/mTOR. Proc.Natl.Acad.Sci.U.S.A, 98: 10314-10319, 2001.

28. Podsypanina, K., Lee, R. T., Politis, C., Hennessy, I., Crane, A., Puc, J., Neshat, M., Wang, H., Yang, L., Gibbons, J., Frost, P., Dreisbach, V., Blenis, J., Gaciong, Z., Fisher, P., Sawyers, C., Hedrick-Ellenson, L., and Parsons, R. An inhibitor of mTOR reduces neoplasia and normalizes p70/S6 kinase activity in Pten+/- mice. Proc.Natl.Acad.Sci.U.S.A, 98: 10320-10325, 2001.

29. Folkman, J. What is the evidence that tumors are angiogenesis dependent? J Natl.Cancer Inst., 82: 4-6, 1990.

30. Folkman, J., Watson, K., Ingber, D., and Hanahan, D. Induction of angiogenesis during the transition from hyperplasia to neoplasia. Nature, 339: 58-61, 1989. 
31. Folkman, J. What is the evidence that tumors are angiogenesis dependent? J Natl.Cancer Inst., 82: 4-6, 1990.

32. Sharma, R. A., Harris, A. L., Dalgleish, A. G., Steward, W. P., and O'Byrne, K. J. Angiogenesis as a biomarker and target in cancer chemoprevention. Lancet Oncol., 2: 726-732, 2001.

33. Claffey, K. P., Brown, L. F., del Aguila, L. F., Tognazzi, K., Yeo, K. T., Manseau, E. J., and Dvorak, H. F. Expression of vascular permeability factor/vascular endothelial growth factor by melanoma cells increases tumor growth, angiogenesis, and experimental metastasis. Cancer Res., 56: 172-181, 1996.

34. Plate, K. H., Breier, G., Millauer, B., Ullrich, A., and Risau, W. Up-regulation of vascular endothelial growth factor and its cognate receptors in a rat glioma model of tumor angiogenesis. Cancer Res., 53: 5822-5827, 1993.

35. Rak, J., Mitsuhashi, Y., Sheehan, C., Tamir, A., Viloria-Petit, A., Filmus, J., Mansour, S. J., Ahn, N. G., and Kerbel, R. S. Oncogenes and tumor angiogenesis: differential modes of vascular endothelial growth factor up-regulation in ras-transformed epithelial cells and fibroblasts. Cancer Res., 60: 490-498, 2000.

36. Takahashi, Y., Kitadai, Y., Bucana, C. D., Cleary, K. R., and Ellis, L. M. Expression of vascular endothelial growth factor and its receptor, KDR, correlates with vascularity, metastasis, and proliferation of human colon cancer. Cancer Res., 55: 
3964-3968, 1995.

37. Yoshiji, H., Gomez, D. E., Shibuya, M., and Thorgeirsson, U. P. Expression of vascular endothelial growth factor, its receptor, and other angiogenic factors in human breast cancer. Cancer Res., 56: 2013-2016, 1996.

38. Santin, A. D., Hermonat, P. L., Ravaggi, A., Cannon, M. J., Pecorelli, S., and Parham, G. P. Secretion of vascular endothelial growth factor in ovarian cancer. Eur.J Gynaecol.Oncol., 20: 177-181, 1999.

39. Li, L., Wang, L. M., Zhang, W., Zhang, J. Q., Song, H. L., Yao, D. S., Tang, Y., Chen, X. Q., and Yang, Z. H. [Study on serum vascular endothelial growth factor level in ovarian malignant tumors]. Zhonghua Fu Chan Ke.Za Zhi., 38: 72-76, 2003.

40. Li, L., Wang, L., Zhang, W., Tang, B., Zhang, J., Song, H., Yao, D., Tang, Y., Chen, X., Yang, Z., Wang, G., Li, X., Zhao, J., Ding, H., Reed, E., and Li, Q. Q. Correlation of serum VEGF levels with clinical stage, therapy efficacy, tumor metastasis and patient survival in ovarian cancer. Anticancer Res, 24: 1973-1979, 2004.

41. Chen, C. A., Cheng, W. F., Lee, C. N., Chen, T. M., Kung, C. C., Hsieh, F. J., and Hsieh, C. Y. Serum vascular endothelial growth factor in epithelial ovarian neoplasms: correlation with patient survival. Gynecol.Oncol., 74: 235-240, 1999. 
42. Ghosh, S. and Maity, P. Isolation and purification of vascular endothelial growth factor (VEGF) from ascitic fluid of ovarian cancer patients. Pathol Oncol.Res, 10: 104-108, 2004.

43. Byrne, A. T., Ross, L., Holash, J., Nakanishi, M., Hu, L., Hofmann, J. I., Yancopoulos, G. D., and Jaffe, R. B. Vascular endothelial growth factor-trap decreases tumor burden, inhibits ascites, and causes dramatic vascular remodeling in an ovarian cancer model. Clin Cancer Res, 9: 5721-5728, 2003.

44. Wang, G. L. and Semenza, G. L. Purification and characterization of hypoxia-inducible factor 1. J Biol.Chem., 270: 1230-1237, 1995.

45. Maxwell, P. H., Wiesener, M. S., Chang, G. W., Clifford, S. C., Vaux, E. C., Cockman, M. E., Wykoff, C. C., Pugh, C. W., Maher, E. R., and Ratcliffe, P. J. The tumour suppressor protein VHL targets hypoxia-inducible factors for oxygen-dependent proteolysis. Nature, 399: 271-275, 1999.

46. Salceda, S. and Caro, J. Hypoxia-inducible factor 1alpha (HIF-1alpha) protein is rapidly degraded by the ubiquitin-proteasome system under normoxic conditions. Its stabilization by hypoxia depends on redox-induced changes. J Biol.Chem., 272: 22642-22647, 1997.

47. Jiang, B. H., Jiang, G., Zheng, J. Z., Lu, Z., Hunter, T., and Vogt, P. K. Phosphatidylinositol 3-kinase signaling controls levels of hypoxia-inducible factor 
1. Cell Growth Differ., 12: 363-369, 2001.

48. Laughner, E., Taghavi, P., Chiles, K., Mahon, P. C., and Semenza, G. L. HER2 (neu) signaling increases the rate of hypoxia-inducible factor 1alpha (HIF-1alpha) synthesis: novel mechanism for HIF-1-mediated vascular endothelial growth factor expression. Mol.Cell Biol., 21: 3995-4004, 2001.

49. Zhong, H., Chiles, K., Feldser, D., Laughner, E., Hanrahan, C., Georgescu, M. M., Simons, J. W., and Semenza, G. L. Modulation of hypoxia-inducible factor 1alpha expression by the epidermal growth factor/phosphatidylinositol 3-kinase/PTEN/AKT/FRAP pathway in human prostate cancer cells: implications for tumor angiogenesis and therapeutics. Cancer Res, 60: 1541-1545, 2000.

50. Hudson, C. C., Liu, M., Chiang, G. G., Otterness, D. M., Loomis, D. C., Kaper, F., Giaccia, A. J., and Abraham, R. T. Regulation of hypoxia-inducible factor 1alpha expression and function by the mammalian target of rapamycin. Mol.Cell Biol., 22: 7004-7014, 2002.

51. Mayerhofer, M., Valent, P., Sperr, W. R., Griffin, J. D., and Sillaber, C. BCR/ABL induces expression of vascular endothelial growth factor and its transcriptional activator, hypoxia inducible factor-1alpha, through a pathway involving phosphoinositide 3-kinase and the mammalian target of rapamycin. Blood, 100: 3767-3775, 2002. 
52. Fingar, D. C., Richardson, C. J., Tee, A. R., Cheatham, L., Tsou, C., and Blenis, J. mTOR controls cell cycle progression through its cell growth effectors S6K1 and 4E-BP1/eukaryotic translation initiation factor 4E. Mol.Cell Biol., 24: 200-216, 2004.

53. Altomare, D. A., Wang, H. Q., Skele, K. L., De Rienzo, A., Klein-Szanto, A. J., Godwin, A. K., and Testa, J. R. AKT and mTOR phosphorylation is frequently detected in ovarian cancer and can be targeted to disrupt ovarian tumor cell growth. Oncogene, 23: 5853-5857, 2004.

54. Frost, P., Moatamed, F., Hoang, B., Shi, Y., Gera, J., Yan, H., Frost, P., Gibbons, J., and Lichtenstein, A. In vivo antitumor effects of the mTOR inhibitor CCI-779 against human multiple myeloma cells in a xenograft model. Blood, 104: 4181-4187, 2004.

55. Jefferies, H. B., Fumagalli, S., Dennis, P. B., Reinhard, C., Pearson, R. B., and Thomas, G. Rapamycin suppresses 5'TOP mRNA translation through inhibition of p70s6k. EMBO J, 16: 3693-3704, 1997.

56. Dumont, F. J. and Su, Q. Mechanism of action of the immunosuppressant rapamycin. Life Sci., 58: 373-395, 1996.

57. Guba, M., von Breitenbuch, P., Steinbauer, M., Koehl, G., Flegel, S., Hornung, M., Bruns, C. J., Zuelke, C., Farkas, S., Anthuber, M., Jauch, K. W., and Geissler, E. K. 
Rapamycin inhibits primary and metastatic tumor growth by antiangiogenesis: involvement of vascular endothelial growth factor. Nat.Med, 8: 128-135, 2002.

58. Zhong, H., Chiles, K., Feldser, D., Laughner, E., Hanrahan, C., Georgescu, M. M., Simons, J. W., and Semenza, G. L. Modulation of hypoxia-inducible factor 1alpha expression by the epidermal growth factor/phosphatidylinositol 3-kinase/PTEN/AKT/FRAP pathway in human prostate cancer cells: implications for tumor angiogenesis and therapeutics. Cancer Res, 60: 1541-1545, 2000.

59. Hudson, C. C., Liu, M., Chiang, G. G., Otterness, D. M., Loomis, D. C., Kaper, F., Giaccia, A. J., and Abraham, R. T. Regulation of hypoxia-inducible factor 1alpha expression and function by the mammalian target of rapamycin. Mol.Cell Biol., 22: 7004-7014, 2002.

60. Forsythe, J. A., Jiang, B. H., Iyer, N. V., Agani, F., Leung, S. W., Koos, R. D., and Semenza, G. L. Activation of vascular endothelial growth factor gene transcription by hypoxia-inducible factor 1. Mol.Cell Biol., 16: 4604-4613, 1996.

61. Jiang, B. H., Rue, E., Wang, G. L., Roe, R., and Semenza, G. L. Dimerization, DNA binding, and transactivation properties of hypoxia-inducible factor 1. J.Biol.Chem., 271: 17771-17778, 1996.

62. Eliceiri, B. P., Klemke, R., Stromblad, S., and Cheresh, D. A. Integrin alphavbeta3 requirement for sustained mitogen-activated protein kinase activity during 
angiogenesis. J Cell Biol., 140: 1255-1263, 1998.

63. Radimerski, T., Montagne, J., Hemmings-Mieszczak, M., and Thomas, G. Lethality of Drosophila lacking TSC tumor suppressor function rescued by reducing dS6K signaling. Genes Dev., 16: 2627-2632, 2002.

64. Sekulic, A., Hudson, C. C., Homme, J. L., Yin, P., Otterness, D. M., Karnitz, L. M., and Abraham, R. T. A direct linkage between the phosphoinositide 3-kinase-AKT signaling pathway and the mammalian target of rapamycin in mitogen-stimulated and transformed cells. Cancer Res, 60: 3504-3513, 2000.

65. Altomare, D. A., Wang, H. Q., Skele, K. L., De Rienzo, A., Klein-Szanto, A. J., Godwin, A. K., and Testa, J. R. AKT and mTOR phosphorylation is frequently detected in ovarian cancer and can be targeted to disrupt ovarian tumor cell growth. Oncogene, 23: 5853-5857, 2004.

66. Frost, P., Moatamed, F., Hoang, B., Shi, Y., Gera, J., Yan, H., Frost, P., Gibbons, J., and Lichtenstein, A. In vivo antitumor effects of the mTOR inhibitor CCI-779 against human multiple myeloma cells in a xenograft model. Blood, 104: 4181-4187, 2004.

67. Frost, P., Moatamed, F., Hoang, B., Shi, Y., Gera, J., Yan, H., Frost, P., Gibbons, J., and Lichtenstein, A. In vivo antitumor effects of the mTOR inhibitor CCI-779 against human multiple myeloma cells in a xenograft model. Blood, 104: 
4181-4187, 2004.

68. Guba, M., von Breitenbuch, P., Steinbauer, M., Koehl, G., Flegel, S., Hornung, M., Bruns, C. J., Zuelke, C., Farkas, S., Anthuber, M., Jauch, K. W., and Geissler, E. K. Rapamycin inhibits primary and metastatic tumor growth by antiangiogenesis: involvement of vascular endothelial growth factor. Nat.Med, 8: 128-135, 2002.

69. Burroughs, K. D., Oh, J., Barrett, J. C., and DiAugustine, R. P. Phosphatidylinositol 3-kinase and mek1/2 are necessary for insulin-like growth factor-I-induced vascular endothelial growth factor synthesis in prostate epithelial cells: a role for hypoxia-inducible factor-1? Mol.Cancer Res, 1: 312-322, 2003.

70. Fukuda, R., Hirota, K., Fan, F., Jung, Y. D., Ellis, L. M., and Semenza, G. L. Insulin-like growth factor 1 induces hypoxia-inducible factor 1-mediated vascular endothelial growth factor expression, which is dependent on MAP kinase and phosphatidylinositol 3-kinase signaling in colon cancer cells. J Biol.Chem., 277: 38205-38211, 2002.

71. Laughner, E., Taghavi, P., Chiles, K., Mahon, P. C., and Semenza, G. L. HER2 (neu) signaling increases the rate of hypoxia-inducible factor 1alpha (HIF-1alpha) synthesis: novel mechanism for HIF-1-mediated vascular endothelial growth factor expression. Mol.Cell Biol., 21: 3995-4004, 2001.

72. Mayerhofer, M., Valent, P., Sperr, W. R., Griffin, J. D., and Sillaber, C. BCR/ABL 
induces expression of vascular endothelial growth factor and its transcriptional activator, hypoxia inducible factor-1alpha, through a pathway involving phosphoinositide 3-kinase and the mammalian target of rapamycin. Blood, 100: 3767-3775, 2002. 


\section{FIGURE LEGENDS}

Figure 1. SiTSC1 or siTSC2 expression induced HIF-1 $\alpha$ expression in both complete medium and serum-free medium. (A) OVCAR-3 cells expressing siSCR or siTSC1 were split at the density of $5 \times 10^{5}$ cells/dish and cultured in complete medium for $24 \mathrm{~h}$. Aliquots $(30 \mu \mathrm{g})$ of total cellular proteins were analyzed by immunoblotting using antibodies against HIF-1 $\alpha$ and HIF-1 $\beta$. (B) OVCAR-3 cells expressing siSCR or siTSC2 were split at the density of $5 \times 10^{5}$ cells/dish and cultured in complete medium for $24 \mathrm{~h}$. The HIF- $1 \alpha$ and HIF-1 $\beta$ protein levels were analyzed by immunoblotting analysis. (C) OVCAR-3 cells expressing siSCR or siTSC 1 were split at the density of $5 \times 10^{5}$ cells/dish, followed by the treatment with serum-free medium for $24 \mathrm{~h}$. The cells were incubated in the absence or presence of $100 \mathrm{nM}$ insulin for $6 \mathrm{~h}$. Protein levels of HIF-1 $\alpha$ and HIF-1 $\beta$ within the cellular lysates were determined by immunoblotting assay using HIF-1 $\alpha$ and HIF-1 $\beta$ antibody. (D) OVCAR-3 cells expressing siSCR or siTSC2 were split at the density of $5 \times 10^{5}$ cells/dish, followed by the treatment with serum-free medium for $24 \mathrm{~h}$. Cells were switched to the serum-free medium in the presence or absence of $100 \mathrm{nM}$ insulin for $6 \mathrm{~h}$. Aliquots $(30 \mu \mathrm{g})$ of total cellular proteins were analyzed by immunoblotting using antibodies specific for HIF-1 $\alpha$ and HIF-1 $\beta$.

Figure 2. SiTSC1 or siTSC2 expression induced VEGF protein expression and VEGF mRNA level in ovarian cancer cells. (A) OVCAR-3 cells stably expressing 
siTSC1, siTSC 2 or siSCR were cultured to $100 \%$ confluence. The cells were changed to fresh complete medium overnight. Aliquots of cell supernatants were collected and analyzed for VEGF protein levels by ELISA. (B) OVCAR-3 cells stably expressing siTSC1, siTSC2 or siSCR were seeded at the density of $5 \times 10^{5}$ cells/dish. After cells were grown to $70 \%$ confluence, cells were collected and total RNAs were extracted using Trizol reagent. The total RNAs were prepared and first strand cDNAs were synthesized using AMV Reverse Transcriptase and oligo(dT) primer. VEGF mRNA in OVCAR-3 cells expressing siTSC1, siTSC2 or siSCR was assayed by semiquantitative RT-PCR. The products of PCR were resolved on 2\% agrose gel and photographed using Eagle-eye system.

Figure 3. Expression of siTSC1 induced p70S6K1 and ERK1/2 activation, and decreased levels of AKT and GSK3 $\beta$ phosphorylation. (A) OVCAR-3 cells stably expressing siTSC 1 or siSCR were seeded at a density of $5 \times 10^{5}$ cells/dish. The total cellular protein extracts were prepared and subjected to immunoblotting analysis using antibodies against total mTOR, phospho-p70S6K1 (Thr421/Ser424), phospho-AKT (Ser473), total AKT and $\beta$-actin. (B) OVCAR-3 cells stably expressing siTSC1 or siSCR plasmid were cultured in a $60 \mathrm{~mm}$ dish at a density of $5 \times 10^{5}$ cells/dish overnight, followed by the incubation with serum-free medium for $24 \mathrm{~h}$. Cells were stimulated with or without $100 \mathrm{nM}$ insulin for $1 \mathrm{~h}$ as indicated. Cellular extracts were subjected to immunoblotting analysis with phospho-specific antibodies to compare levels of p70S6K1 
phosphorylation at Thr-421 and Ser-424, AKT phosphorylation at Ser-473, GSK3 $\beta$ phosporylation at Ser-9, and ERK1/2 phosphorylation at Thr-202 and Tyr-204. Levels of total AKT, total p70S6K1, total ERK1/2 and $\beta$-actin were used as a control.

Figure 4. Expression of siTSC2 induced p70S6K1 and ERK1/2 activation, and decreased levels of AKT and GSK3ß phosphorylation. (A) OVCAR-3 cells stably expressing siTSC2 or siSCR were seeded at a density of $5 \times 10^{5}$ cells/dish, cultured for 24 h at $37{ }^{\circ} \mathrm{C}$ in $5 \% \mathrm{CO}_{2}$. Aliquots $(30 \mu \mathrm{g})$ of total cellular proteins were analyzed by immunoblotting using antibodies specific to total TSC2, phospho-p70S6K1 (Thr421/Ser424), total p70S6K1, phospho-AKT (Ser473), total AKT, p-GSK3ß (Ser9), total GSK3 $\beta$, phospho p42/p44 MAPK, total ERK1/2 and $\beta$-actin. (B) OVCAR-3 cells stably expressing siTSC2 or siSCR were cultured in a $60 \mathrm{~mm}$ dish at a density of $5 \times 10^{5}$ cells/dish overnight, followed by the treatment with serum-free medium for $24 \mathrm{~h}$. Cells were switched to the serum-free medium in the presence or absence of $100 \mathrm{nM}$ insulin for $1 \mathrm{~h}$. Protein $(30 \mu \mathrm{g})$ of total cellular lysate was used for detection of p70S6K1 phospho-Thr-421/Se-r424, AKT phospho-Ser-473, GSK3 $\beta$ phospho-Ser-9, and ERK1/2 phospho-Thr-202 /Tyr-204. Levels of total AKT, total p70S6K1, total ERK1/2 and $\beta$-actin were used as a control.

Figure 5. SiTSC2 expression induced ovarian tumor angiogenesis through mTOR/p70S6K1 pathway. (A) OVCAR-3 cells stably expressing siTSC2 were treated 
with $10 \mathrm{nM}$ rapamycin or the solvent for $12 \mathrm{~h}$. OVCAR-3 cells stably expressing siTSC2 were infected with $15 \mathrm{MOI}$ adenovirus vector or adenovirus expressing p70S6K1 (K100R) for $24 \mathrm{~h}$. Cells were collected in serum-free medium at the concentration of 10 x $10^{7}$ cells/ml in serum-free RPMI 1640, which contained 5\% Matrigel without growth factor. Aliquots $(20 \mu \mathrm{l})$ of the mixture (two million cells) were implanted onto the CAM of 9-day-old chicken embryos. Tumors in the CAM were photographed 5 days after implantation. The experiments were repeated two times with five embryos for each group, and representative fields were photographed. (B) The relative blood vessel density was determined by measuring the number of blood vessel branch points in a unit area on Day 5. Data are expressed as mean $\pm \mathrm{SD}$ from replicate experiments, and normalized to results obtained with the CAMs implanted by the cells expressing siSCR.

* indicates a significant difference from the siSCR control group $(p<0.05)$. \# indicates a significant difference in tumor weight from the siTSC2 group $(p<0.05)$. (C) Tumor sections were stained by Factor VIII (Von Willebrand factor) antibody. The signals were detected using the rabbit $\mathrm{ABC}$ staining system. The pictures were taken under Olympus microscope at the magnification of 160x. Negative control was set that the section was incubated in the presence of the primary antibody without the secondary antibody.

Figure 6. SiTSC2 expression induced tumor growth in vivo. (A) OVCAR-3 cells stably expressing siTSC2 were treated with DMSO or with $10 \mathrm{nM}$ rapamycin for $12 \mathrm{~h}$. 
OVCAR-3 cells stably expressing siTSC2 were infected with $15 \mathrm{MOI}$ adenovirus vector or adenovirus expressing p70S6K1 (K100R) for $24 \mathrm{~h}$. Cells were collected in serum-free medium and mixed with the equal volume of Matrigel without growth factor. The mixture was placed on the CAM of 9-day-old chicken embryos. The tumors were harvested after 9-day incubation. The tumors were weighed and fixed in $10 \%$ formalin. Representative tumor pictures from different treatments were taken. (B) Tumor weight was obtained from four different embryos for each treatment with two replicate

experiments. The mean $\pm \mathrm{SD}$ were obtained from eight replicate tumors. * indicates a significant difference from the siSCR control group $(p<0.05)$. \# indicates a significant difference when compared to the siTSC2 group $(p<0.05)$.

\section{Figure 7. P70S6K1 was a downstream molecule that mediated siTSC2-induced} VEGF transcriptional activation. (A) Cells were seeded in 12 well plates and cultured to $40-50 \%$ confluence. Cells were transiently transfected with VEGF promoter reporter pGL-Stu1, pCMV- $\beta$-galactosidase plasmid, siTSC1 and siTSC 2 at the concentrations as indicated. The empty vector was added to make total transfected DNA to $1.15 \mu \mathrm{g}$. The relative luciferase activity was determined as described above. ${ }^{*}$ indicates a significant difference when compared to the control $(p<0.05)$. (B) Cells were transiently transfected with VEGF promoter reporter pGL-Stu1, pCMV- $\beta$-galactosidase plasmid, siTSC1, siTSC2 and sip70S6K1 plasmid at the concentrations as indicated. The empty vector was added to make total transfected DNA to $1.25 \mu \mathrm{g}$. The relative luciferase 
activity was determined as described above. * indicates a significant difference when compared to the siTSC1 group $(p<0.05)$. \# indicates a significant difference when compared to the siTSC2 group $(p<0.05)$. (C) Cells were transiently transfected with VEGF promoter reporter pGL-Stu1, pCMV- $\beta$-galactosidase plasmid, TSC1 and TSC2 plasmid at the concentrations as indicated. The empty vector pRK7 was added to make total transfected DNA to $1.15 \mu \mathrm{g}$. The relative luciferase activity was determined. * indicates a significant difference when compared to the control $(p<0.05)$. (D) Cells were transiently transfected with VEGF promoter reporter pGL-Stu1, pCMV- $\beta$-galactosidase plasmid, TSC1, TSC2 and p70S6K1 active form plasmid at the concentrations as indicated. The empty vector was added to make total transfected DNA to $1.25 \mu \mathrm{g}$. The relative luciferase activity was determined. Statistical analysis was performed by ANOVA software at a significance level of $P<0.05$. Data are mean \pm SD from 3 independent experiments. Each experiment was performed with triplicate cultures. * indicates a significant difference when compared to the control $(p<0.05)$. \# indicates a significant difference when compared to the TSC1 group $(p<0.05) . \Delta$ indicates a significant difference when compared to the TSC2 group $(p<0.05)$.

\section{Figure 8. Sip70S6K1 expression inhibited VEGF protein expression and VEGF} transcriptional activation via HIF-1 $\alpha$ DNA binding site. (A) OVCAR-3 cells stably expressing sip70S6K1 or siSCR were cultured to $100 \%$ confluence. The cells were changed to fresh complete medium. Aliquots of cell supernatants were collected and 
analyzed for VEGF protein levels by ELISA. (B) A2780 cells stably expressing sip70S6K1 or siSCR were cultured to $100 \%$ confluence. The cells were changed to fresh complete medium. Aliquots of cell supernatant were collected and analyzed for VEGF protein levels by ELISA. Data are mean \pm SD from 3 independent experiments. Statistical analysis was performed by Student's $t$ test at a significance level of $P<0.05$. *Significantly decreased VEGF when compared to that of control, $P<0.05$. (C) Cells were seeded in 12 well plates and cultured to $40-50 \%$ confluence. Cells were transiently transfected with VEGF promoter reporter pGL-Stu1, pCMV- $\beta$-galactosidase plasmid, sip70S6K1 and wild-type HIF-1 $\alpha$ plasmid at the concentrations as indicated. The empty vector was added to make total transfected DNA to $1.15 \mu \mathrm{g}$. (D) Cells were transfected with pMAP11wt reporter, $\beta$-gal plasmid, sip70S6K1 and wild-type HIF-1 $\alpha$ plasmid at the concentrations as indicated. (E) Cells were transfected with pMAP11 mutant reporter, $\beta$-gal plasmid and sip70S6K1 at the concentrations as indicated. Statistical analysis was performed by ANOVA software at a significance level of $P<0.05$. * indicates a significant difference when compared to the control $(p<0.05)$.

\section{Figure 9. Sip70S6K1 expression inhibited HIF-1 $\alpha$ protein expression in ovarian}

cancer cells. (A) OVCAR-3 cells or A2780 cells stably expressing sip70S6K1 or siSCR were seeded in $60 \mathrm{~mm}$ plates in RPMI 1640 medium with 10\% FBS for $24 \mathrm{~h}$. The total cellular protein extracts were prepared, and subjected to immunoblotting analysis using specific antibodies against HIF-1 $\alpha$ and HIF-1 $\beta$. (B) OVCAR-3 cells or A2780 cells 
stably expressing sip70S6K1 or siSCR plasmid were cultured in a $60 \mathrm{~mm}$ dish at a density of $5 \times 10^{5}$ cells/dish in RPMI 1640 medium with $10 \%$ FBS for $24 \mathrm{~h}$ at $37^{\circ} \mathrm{C}$ in $5 \%$ $\mathrm{CO}_{2}$ incubator, followed by the incubation with serum-free medium for $24 \mathrm{~h}$. Cells were switched to the medium in the presence or absence of $100 \mathrm{nM}$ insulin for $6 \mathrm{~h}$ as indicated. The total cellular protein extracts were prepared and subjected to immunoblotting analysis using antibodies against HIF-1 $\alpha$ and HIF-1 $\beta$.

\section{Figure 10. Sip70S6K1 expression inhibited ovarian tumor angiogenesis and tumor}

growth. (A) Two million OVCAR-3 cells expressing siSCR or sip70S6K1 were collected in serum-free medium and mixed with the equal volume of Matrigel. The mixture or the Matrigel alone was placed on the CAM of 9-day-old chicken embryos. Tumors in the CAMs were photographed 5 days after the implantation. The experiments were repeated two times with five embryos per each treatment and representative fields were photographed. (B) The relative blood vessel density was determined by measuring the number of blood vessel branch points in a unit area on Day 5. Data are expressed as mean \pm SD from replicate experiments, and normalized to results obtained from the CAMs implanted by Matrigel alone. (C) Tumor sections were stained by Factor VIII (Von Willebrand factor) antibody. The signals were detected using the rabbit $\mathrm{ABC}$ staining system. Negative control was the data from the sections without the primary antibody. The pictures were taken with an Olympus microscope at the magnification of $160 \times$. (D) Two million OVCAR-3 cells expressing siSCR or sip70S6K1 were collected in 
serum-free medium, and mixed with the equal volume of Matrigel. The mixture or the Matrigel alone was placed on the CAMs of 9-day-old chicken embryos. The tumors were harvested after 9 days' incubation. The tumors were weighed, fixed in $3.7 \%$ formalin in PBS, and frozen in liquid nitrogen. Tumor sections were formalin-fixed and paraffin-embedded. Representative tumor pictures were taken. (E) Tumor weight was obtained from ten different tumors. The mean $\pm \mathrm{SD}$ were obtained from the ten tumors per treatments. (F) Tumor tissues from chicken embryos were frozen in liquid nitrogen and the total proteins were extracted. Immunoblotting analysis was performed using antibodies against phospho-p70S6K1 (Thr421/Ser424), total p70S6K1 and $\beta$-actin.

\section{Figure 11. Sip70S6K1 expression inhibited HIF-1 $\alpha$ and VEGF expression in tumors.}

(A) Tumor sections from cells expressing siSCR or sip70S6K1 were stained using VEGF antibodies. The signals were detected using the ABC staining system. Tumor sections were processed for immunohistochemical staining using monoclonal antibody against

HIF-1 $\alpha$. (B) Tumor tissues from chicken embryos were frozen in liquid nitrogen and the total proteins were extracted. Immunoblotting analysis was performed using antibodies against HIF1- $\alpha$ and HIF-1 $\beta$. 
Figure 1. SiTSC1 or siTSC2 expression induced HIF-1 $\alpha$ expression in both complete medium and serum-free medium.

A siSCR siTSC1-1 23 pool

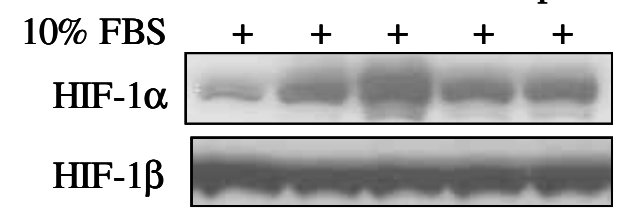

B

$$
\text { siSCR siTSC2ab cd gh }
$$

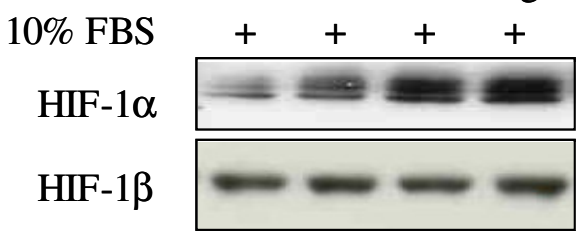

$\mathrm{C}$

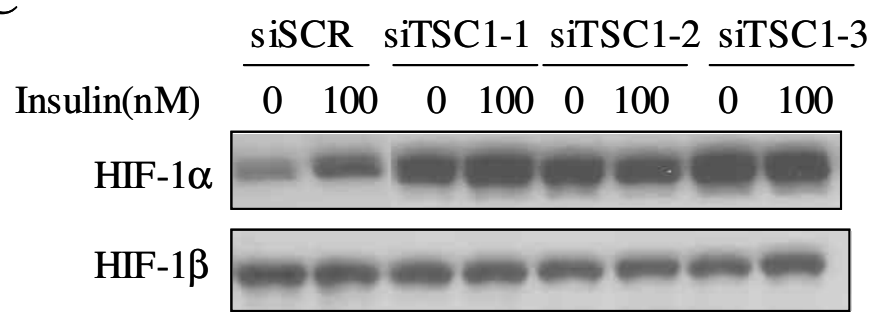

$\mathrm{D}$

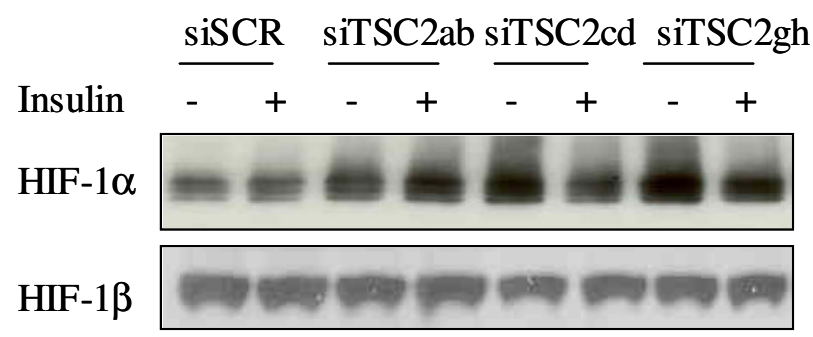


Figure 2. SiTSC1 or siTSC2 expression induced VEGF protein expression and VEGF mRNA level in ovarian cancer cells.

A

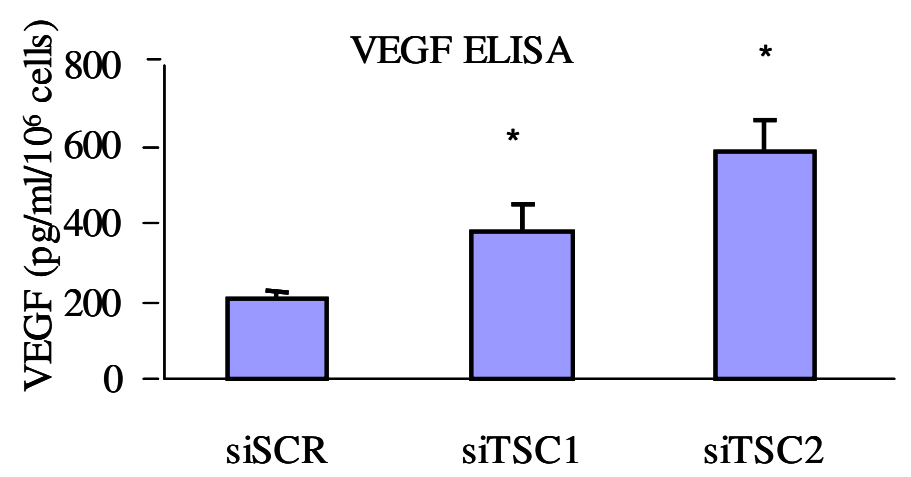

B M siSCR siTSC1 siTSC2ab siTSC2cd

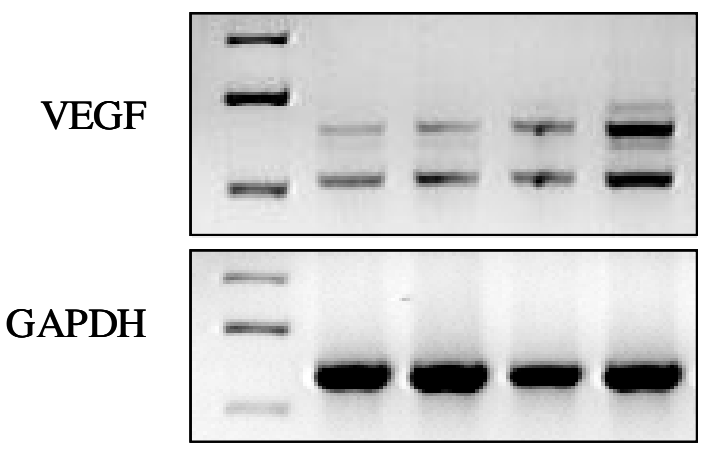

VEGF165

VEGF145

VEGF121 
Figure 3. Expression of siTSC1 induced p70S6K1 and ERK1/2 activation, and decreased levels of AKT and GSK3ß phosphorylation.

A siSCR siTSC1-1 23 pool

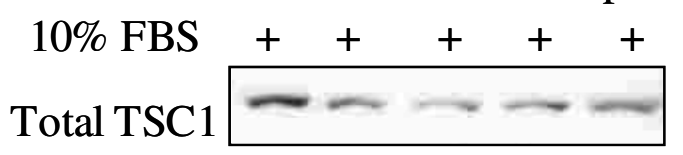
$\beta$-actin

B siSCR siTSC1-1 23 pool

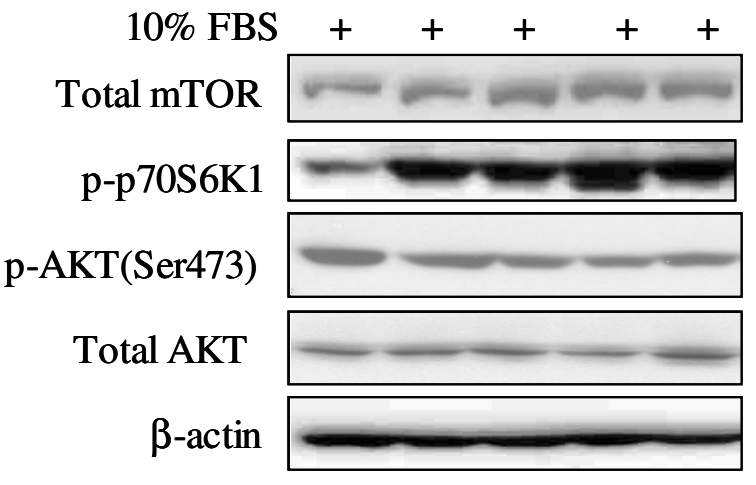

C

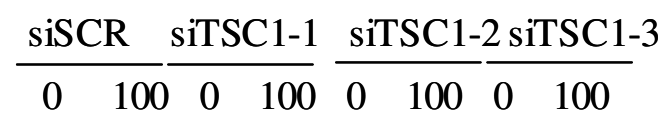

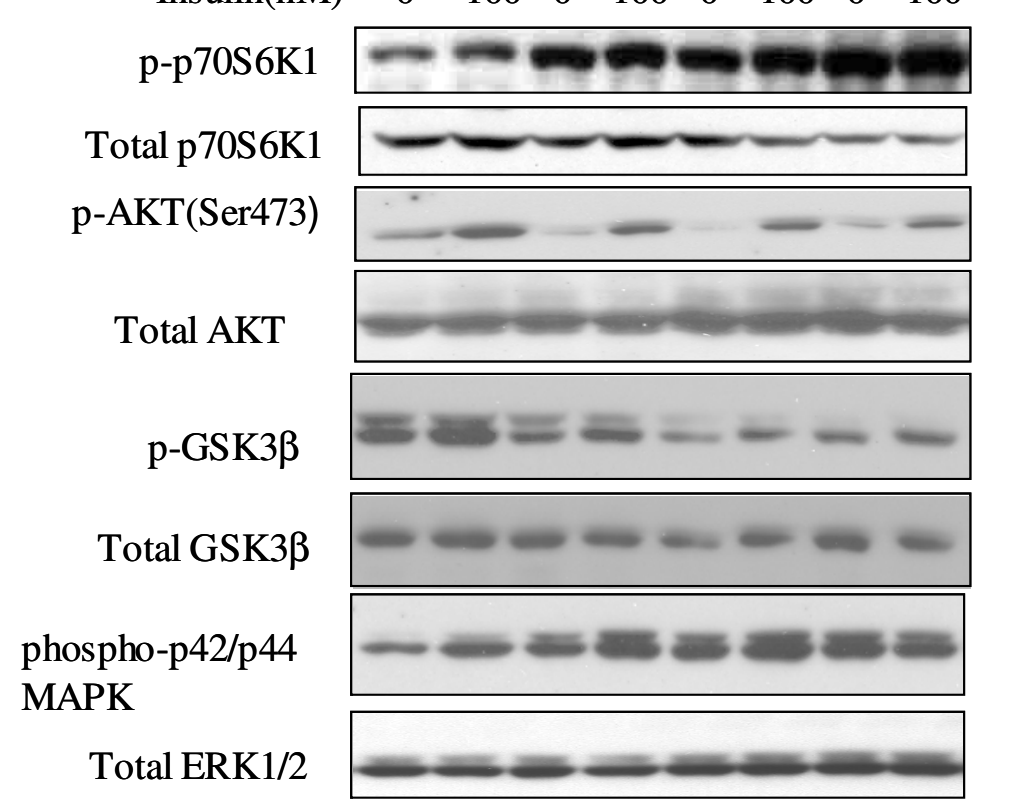


Figure 4. Expression of siTSC2 induced p70S6K1 and ERK1/2 activation, and decreased levels of AKT and GSK3ß phosphorylation.

A

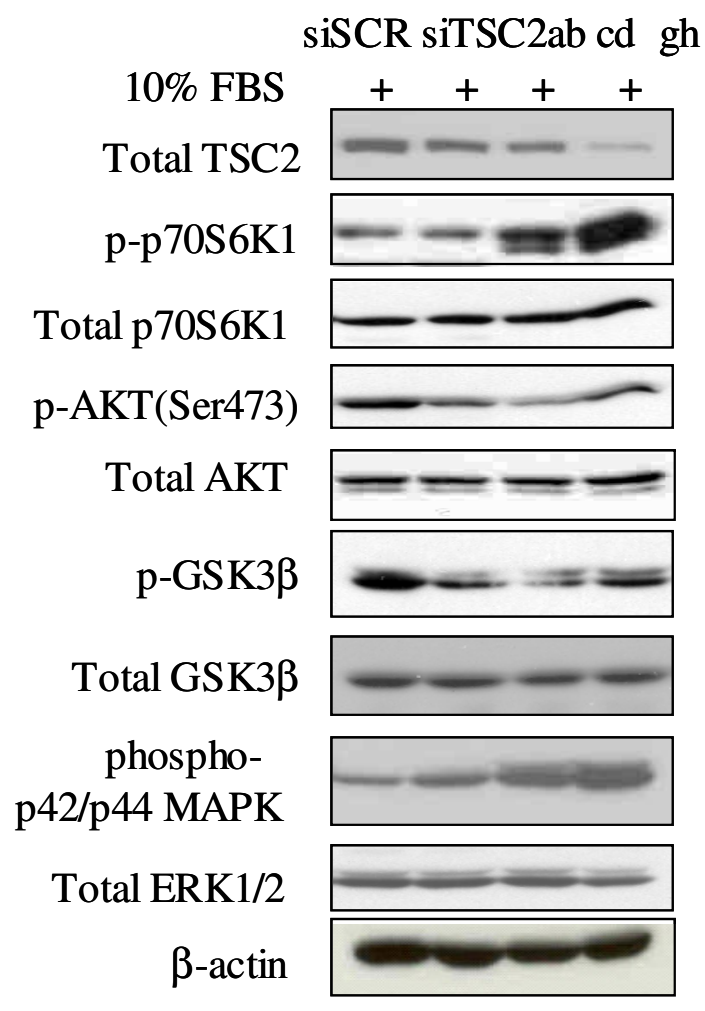

B

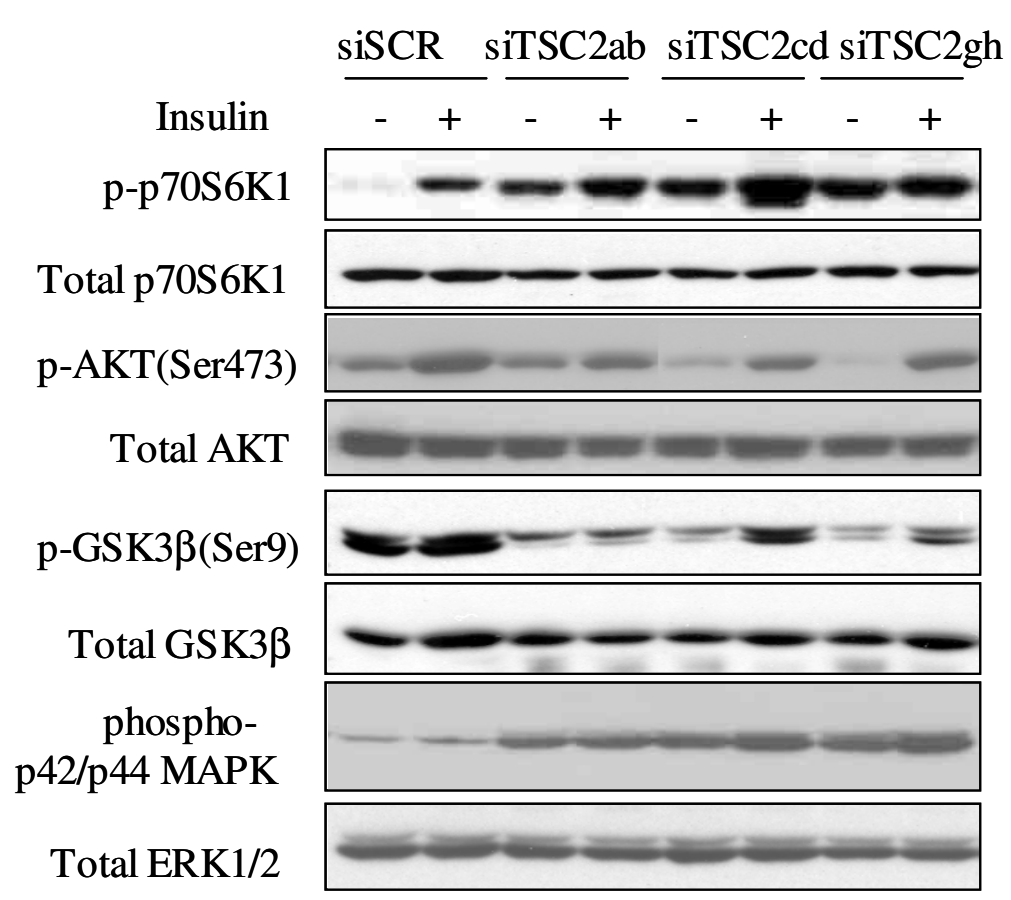


Figure 5. SiTSC2 expression induced ovarian tumor angiogenesis through mTOR/p70S6K1 pathway.

A

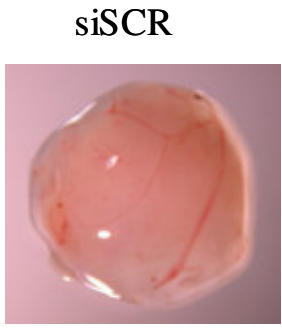
siTSC2+DMSO siTSC2+Rapamycin
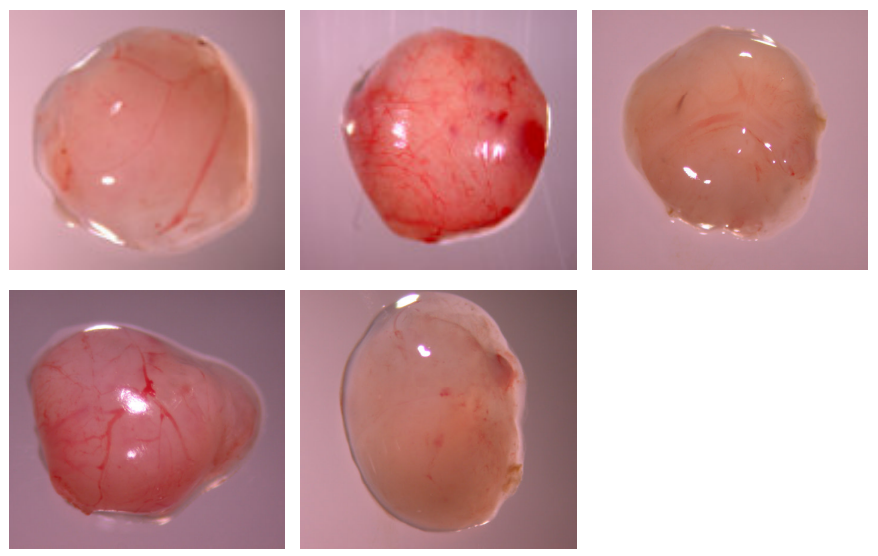

siTSC2+Ad-Vector siTSC2+Ad-K100R

B

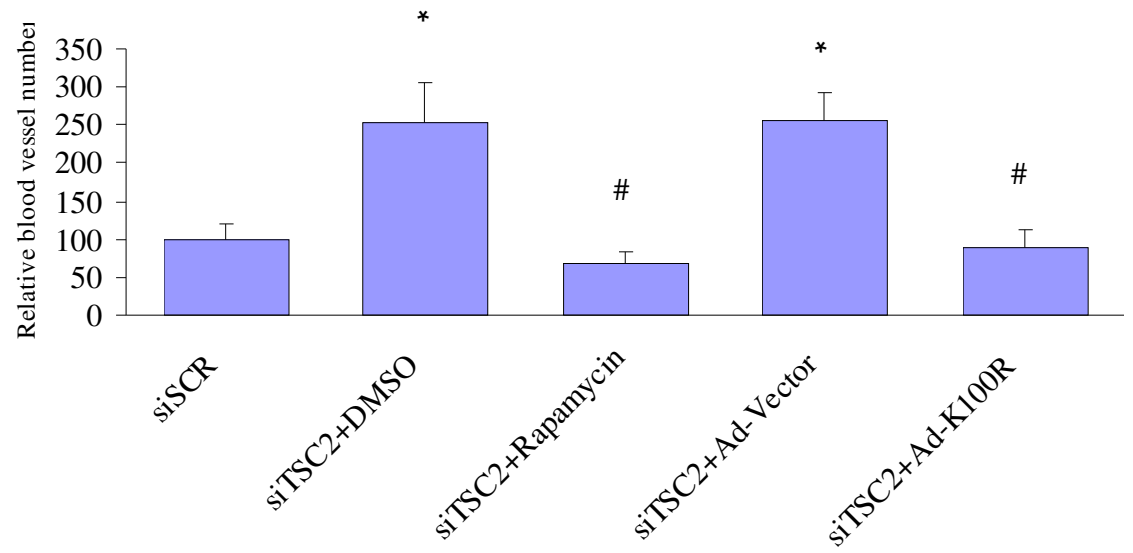


C
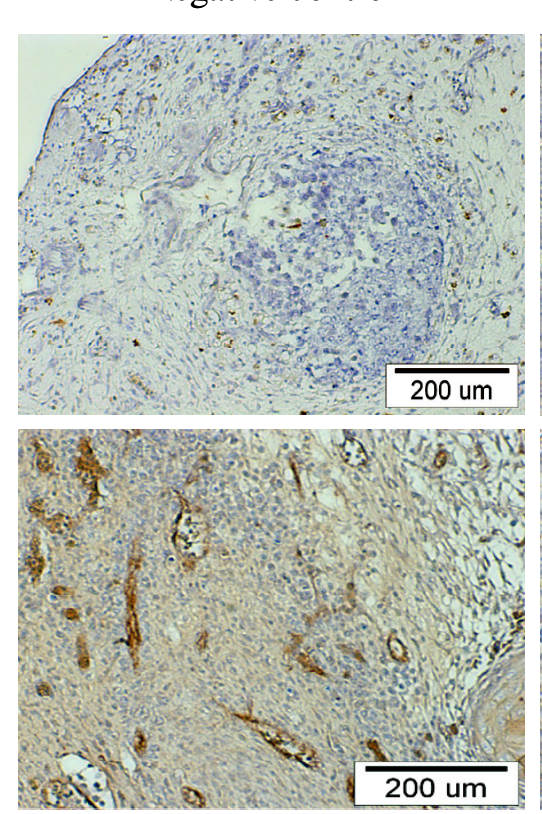

siTSC2+DMSO

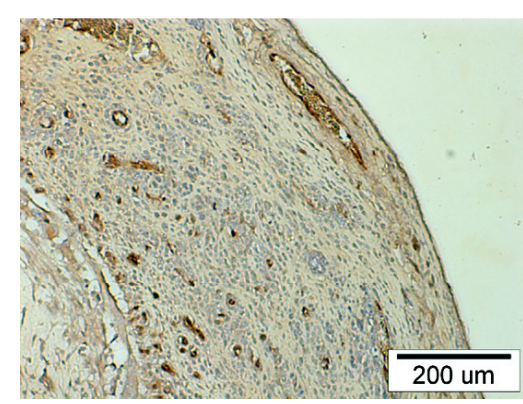

siTSC2+Ad-vector
siSCR
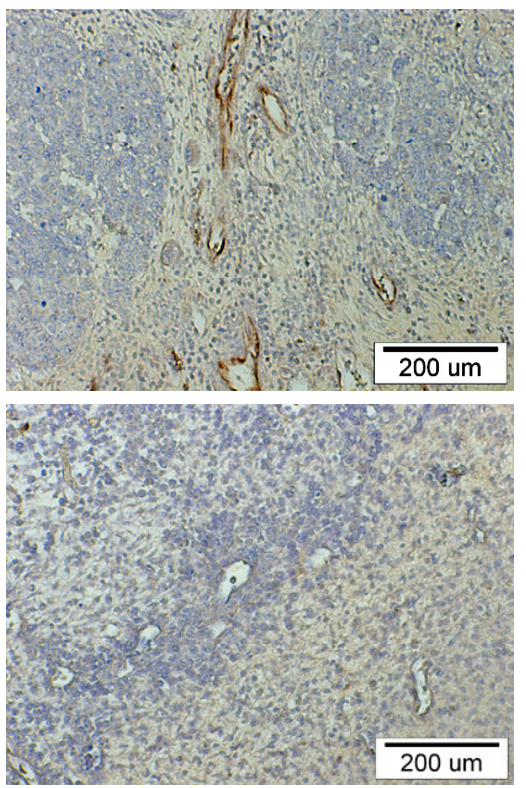

siTSC2+Rapamycin

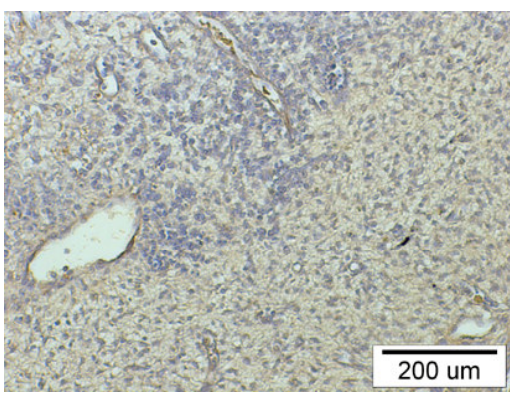

siTSC2+Ad-K100R 
Figure 6. SiTSC2 expression induced tumor growth in vivo.

A

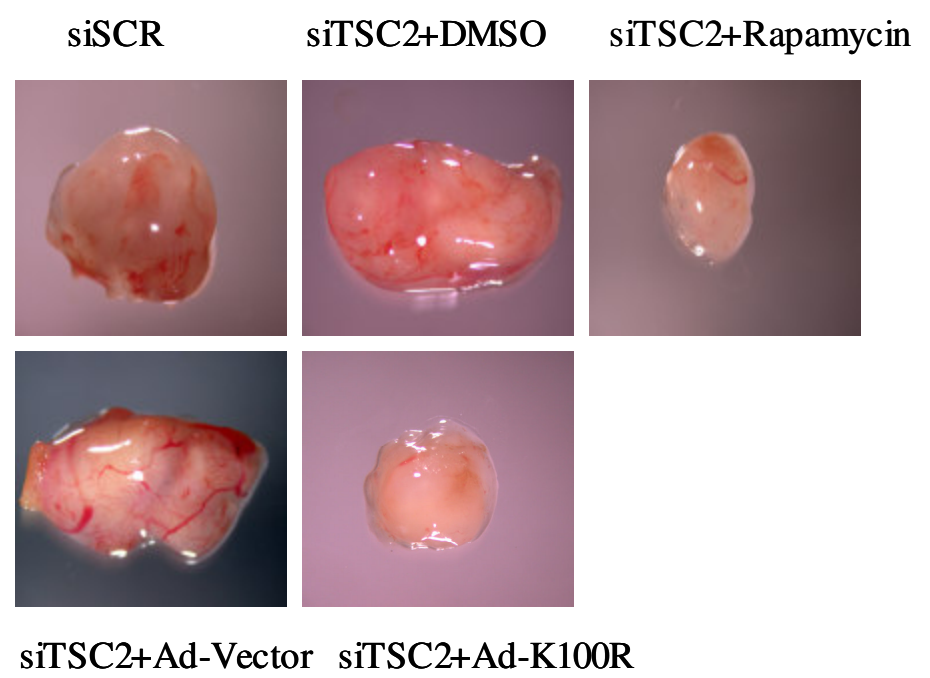

B

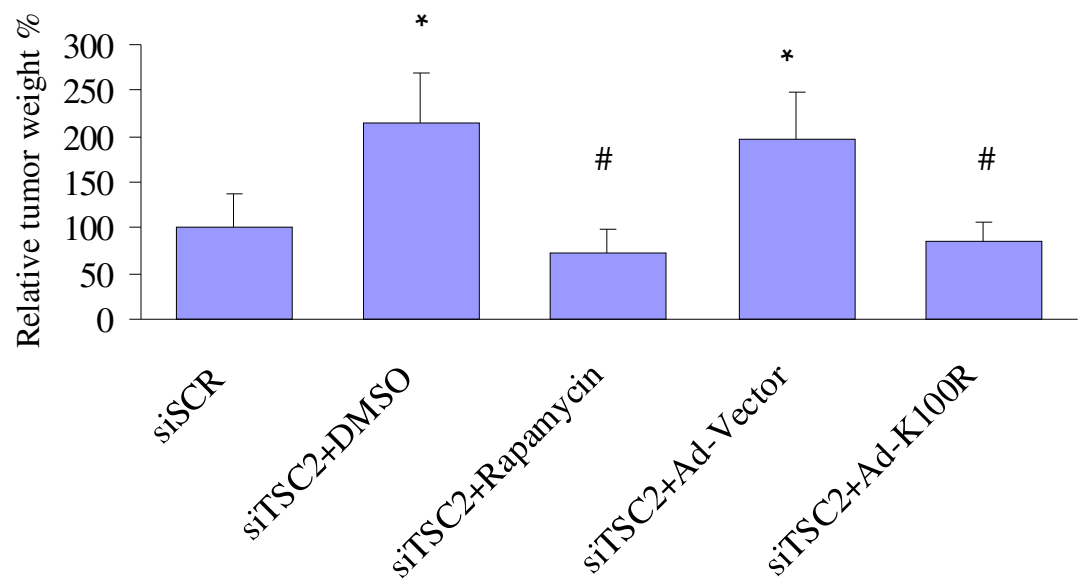


Figure 7. P70S6K1 was a downstream molecule that mediated siTSC2-induced VEGF transcriptional activation.

A

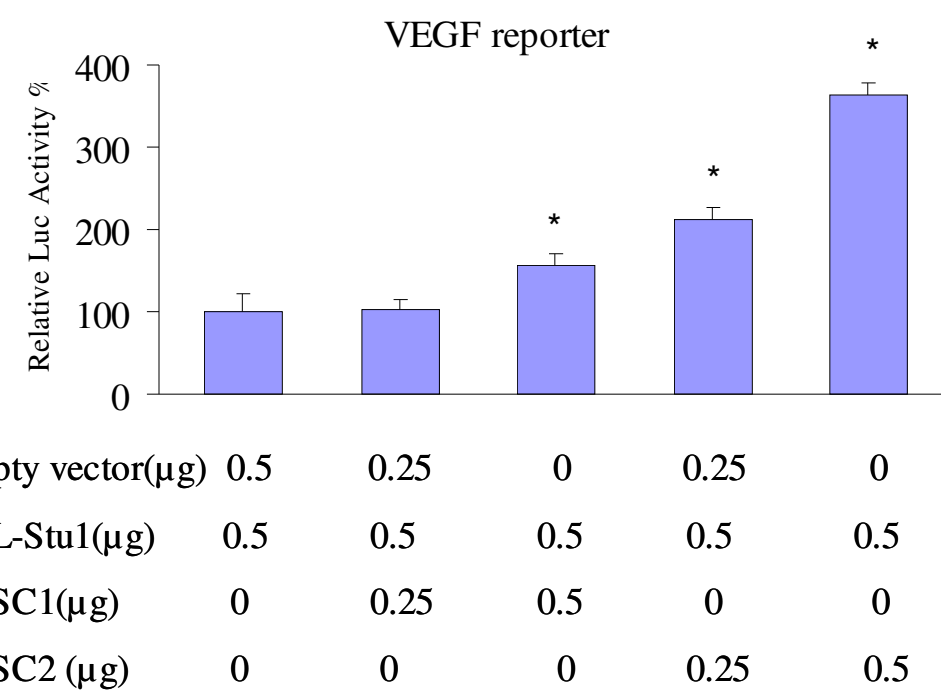

B

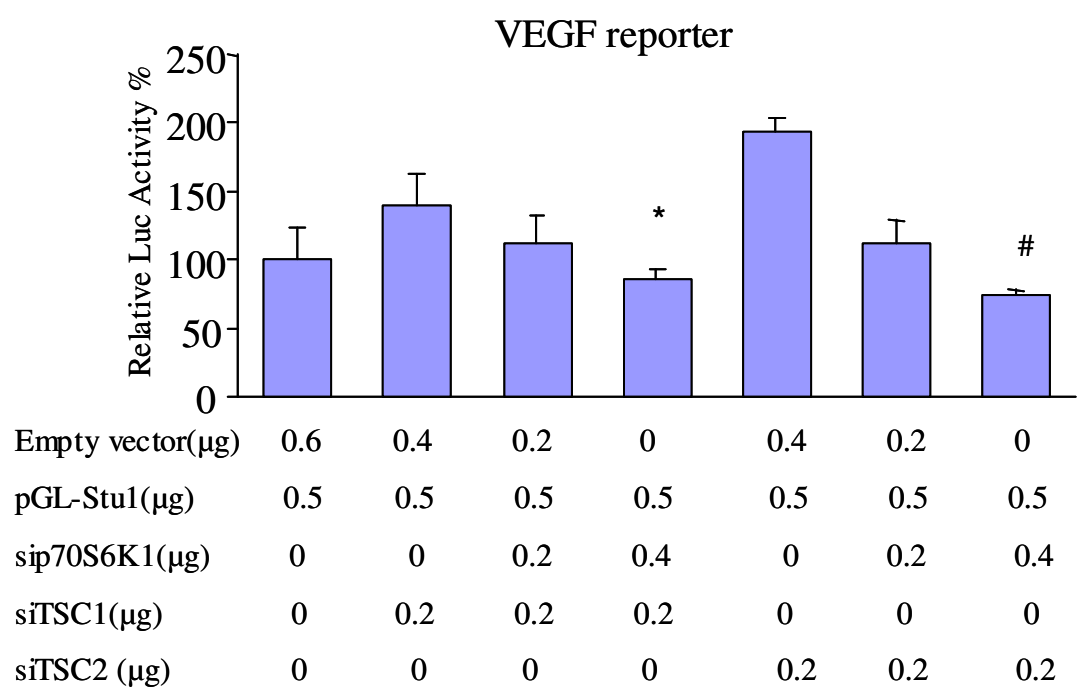


C

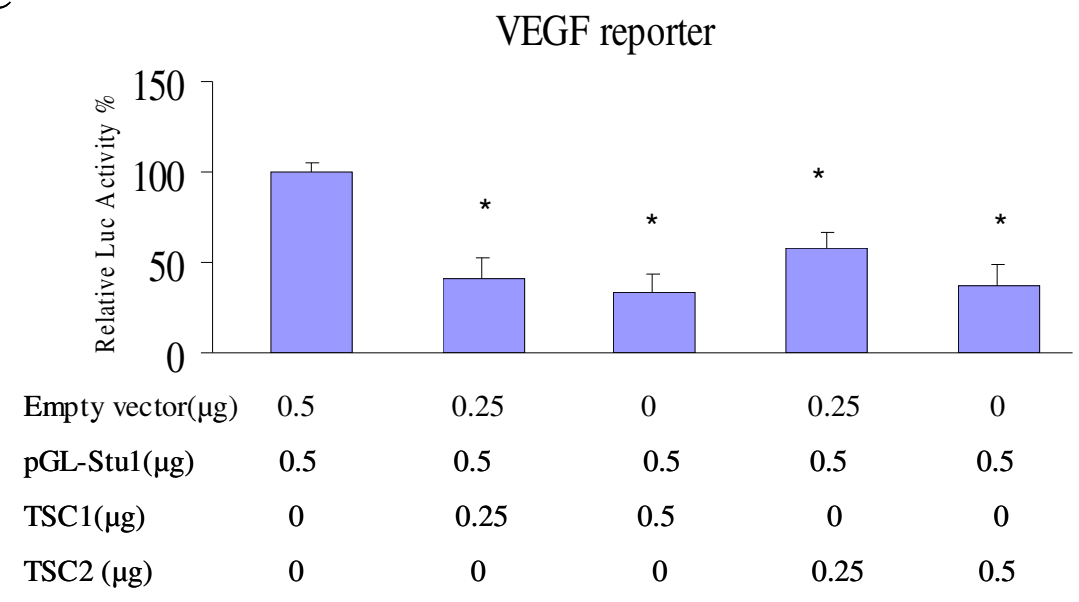

D

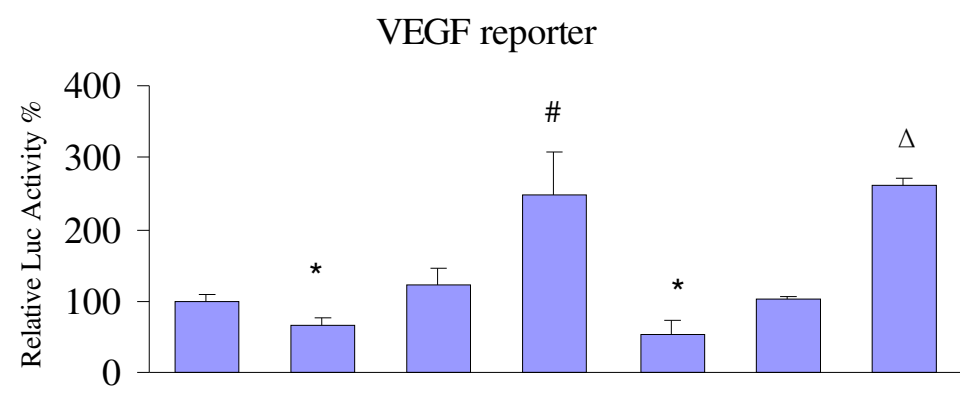

$\begin{array}{lccccccc}\text { Empty vector }(\mu \mathrm{g}) & 0.75 & 0.5 & 0.25 & 0 & 0.5 & 0.25 & 0 \\ \text { pGL-Stu1 }(\mu \mathrm{g}) & 0.5 & 0.5 & 0.5 & 0.5 & 0.5 & 0.5 & 0.5 \\ \operatorname{p70S6K1}(\mu \mathrm{g}) & 0 & 0 & 0.25 & 0.5 & 0 & 0.25 & 0.5 \\ \operatorname{TSC} 1(\mu \mathrm{g}) & 0 & 0.25 & 0.25 & 0.25 & 0 & 0 & 0 \\ \operatorname{TSC} 2(\mu \mathrm{g}) & 0 & 0 & 0 & 0 & 0.25 & 0.25 & 0.25\end{array}$


Figure 8. Sip70S6K1 expression inhibited VEGF protein expression and VEGF transcriptional activation via HIF-1 $\alpha$ DNA binding site.

A

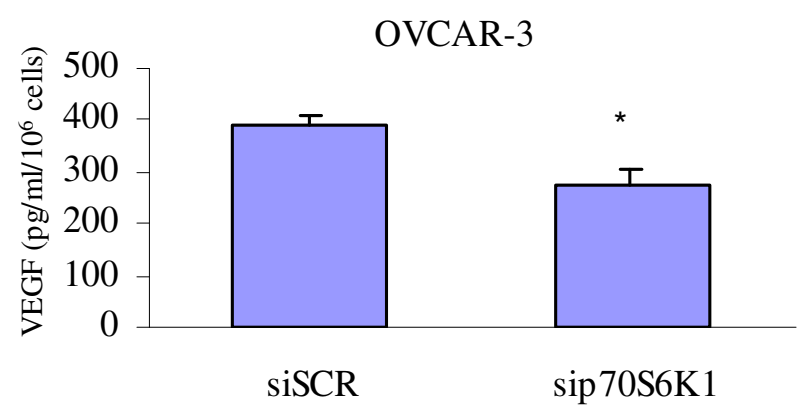

B

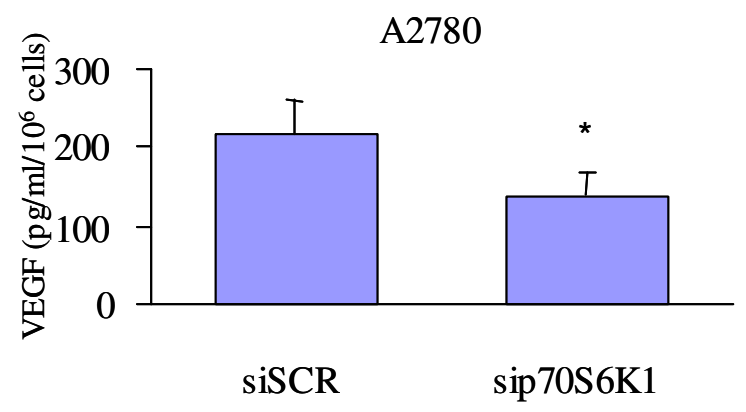

$\mathrm{C}$

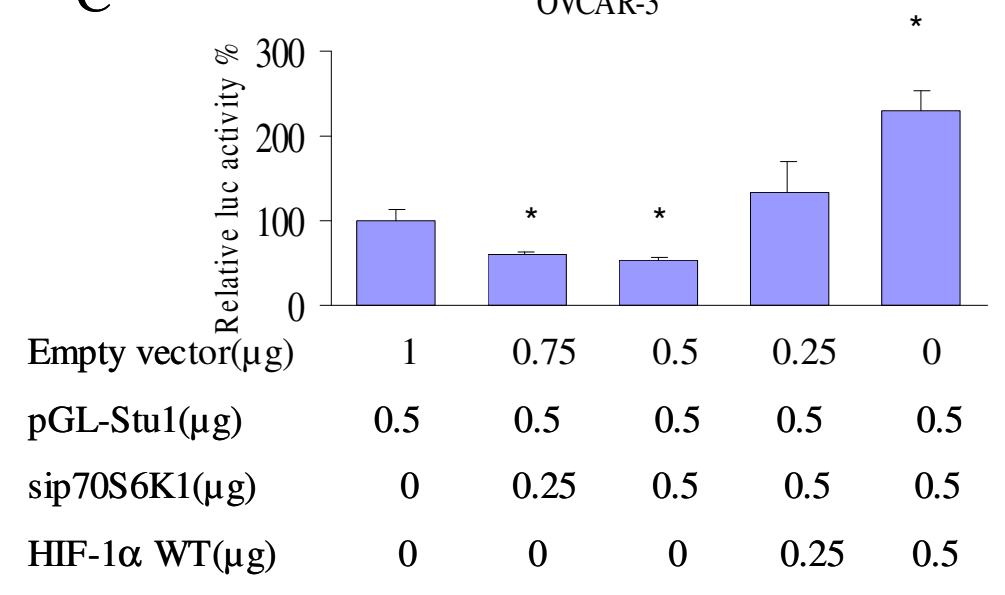


A2780

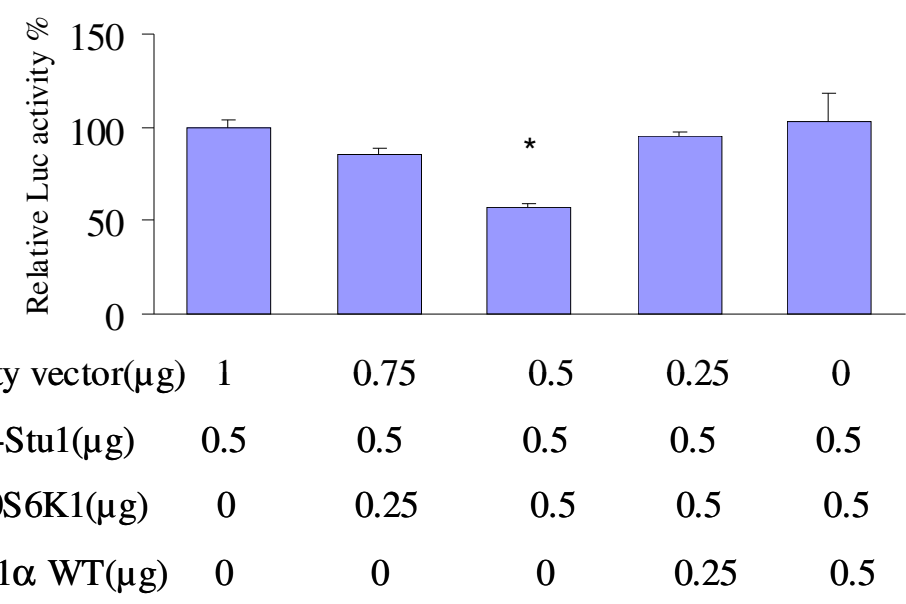

D

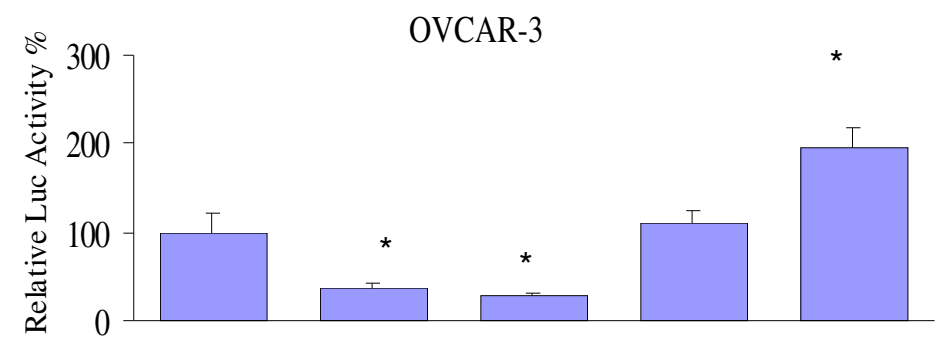

$\begin{array}{lccccc}\text { Empty vector }(\mu \mathrm{g}) & 1 & 0.75 & 0.5 & 0.25 & 0 \\ \text { pMAP11WT }(\mu \mathrm{g}) & 0.5 & 0.5 & 0.5 & 0.5 & 0.5 \\ \operatorname{sip} 70 \mathrm{~S} 6 \mathrm{~K} 1(\mu \mathrm{g}) & 0 & 0.25 & 0.5 & 0.5 & 0.5 \\ \mathrm{HIF}-1 \alpha \mathrm{WT}(\mu \mathrm{g}) & 0 & 0 & 0 & 0.25 & 0.5\end{array}$

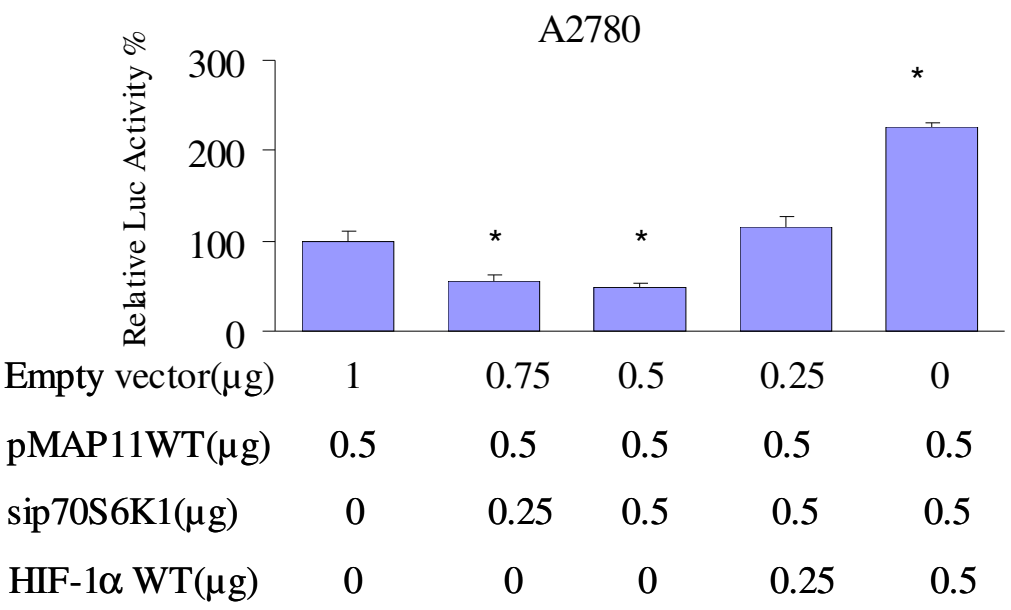


E

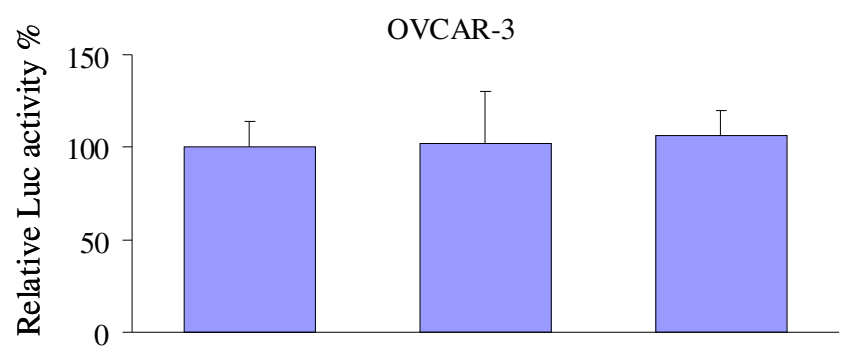

$\begin{array}{cclc}\text { Empty vector }(\mu \mathrm{g}) & 0.5 & 0.25 & 0 \\ \operatorname{pMAP11MT}(\mu \mathrm{g}) & 0.5 & 0.5 & 0.5 \\ \operatorname{sip} 70 \mathrm{~S} 6 \mathrm{~K} 1(\mu \mathrm{g}) & 0 & 0.25 & 0.5\end{array}$

A2780

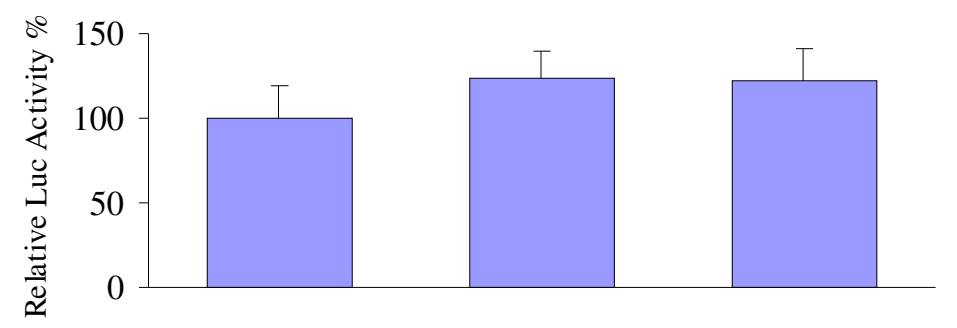

$\begin{array}{rclc}\text { Empty vector }(\mu \mathrm{g}) & 0.5 & 0.25 & 0 \\ \operatorname{pMAP11MT}(\mu \mathrm{g}) & 0.5 & 0.5 & 0.5 \\ \operatorname{sip70S6K1}(\mu \mathrm{g}) & 0 & 0.25 & 0.5\end{array}$


Figure 9. Sip70S6K1 expression inhibited HIF-1 $\alpha$ protein expression in ovarian cancer cells.

A

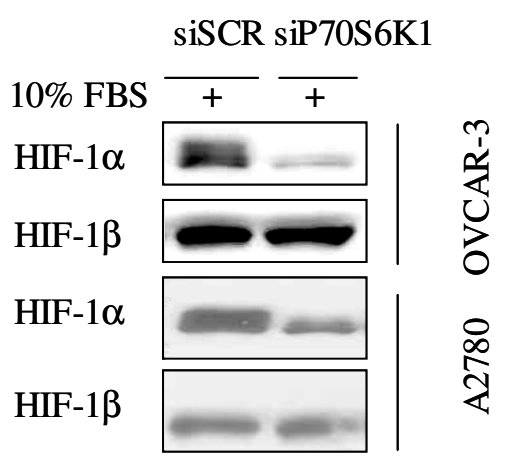

B

\begin{tabular}{|c|c|c|}
\hline & siSCR & siP70S6K \\
\hline Insulin(nM) & -100 & $\begin{array}{l}-\quad 100 \\
\end{array}$ \\
\hline HIF- $1 \alpha$ & ma & 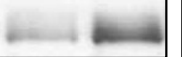 \\
\hline HIF-1 $\beta$ & 5 & $\omega$ \\
\hline HIF- $1 \alpha$ & 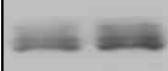 & \\
\hline HIF-1 $\beta$ & $=$ & 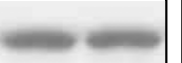 \\
\hline
\end{tabular}


Figure 10. Sip70S6K1 expression inhibited ovarian tumor angiogenesis and tumor growth in CAM model.

A
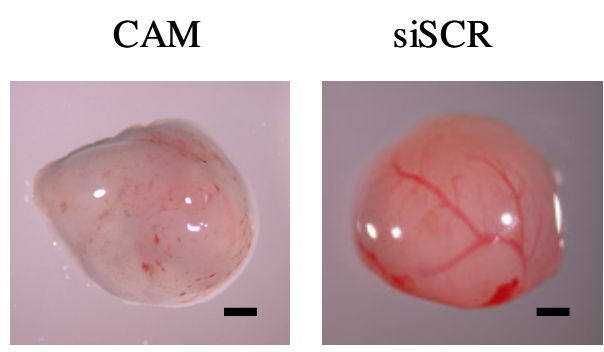

$\operatorname{sip} 70 \mathrm{~S} 6 \mathrm{~K} 1$

B
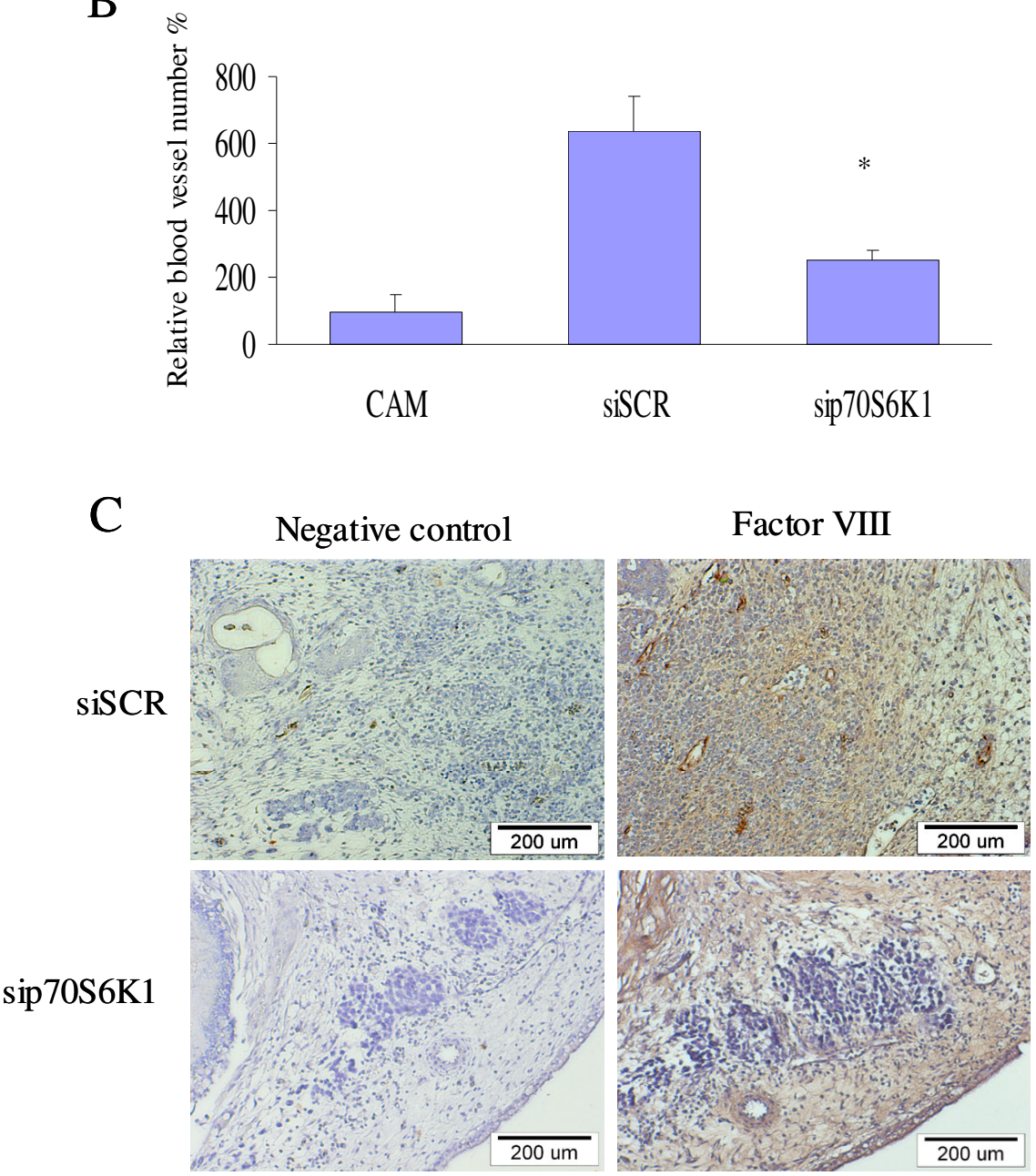
D

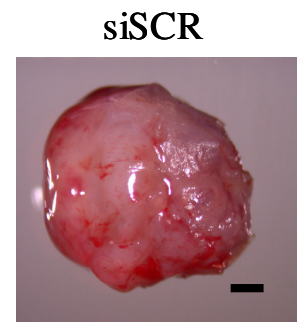

$\operatorname{sip} 70 S 6 K 1$

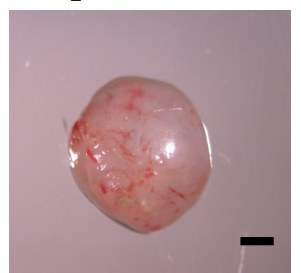

E

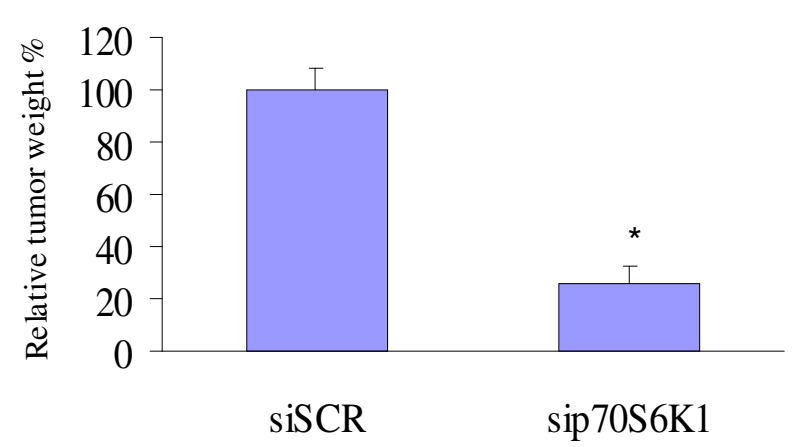

F

siSCR $\operatorname{sip} 70 \mathrm{~S} 6 \mathrm{~K} 1$

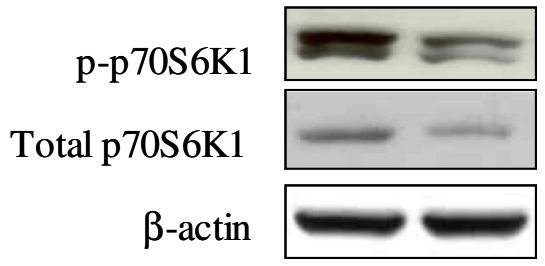


Figure 11. Sip70S6K1 expression inhibited HIF-1 $\alpha$ and VEGF expression in tumor sections.

A
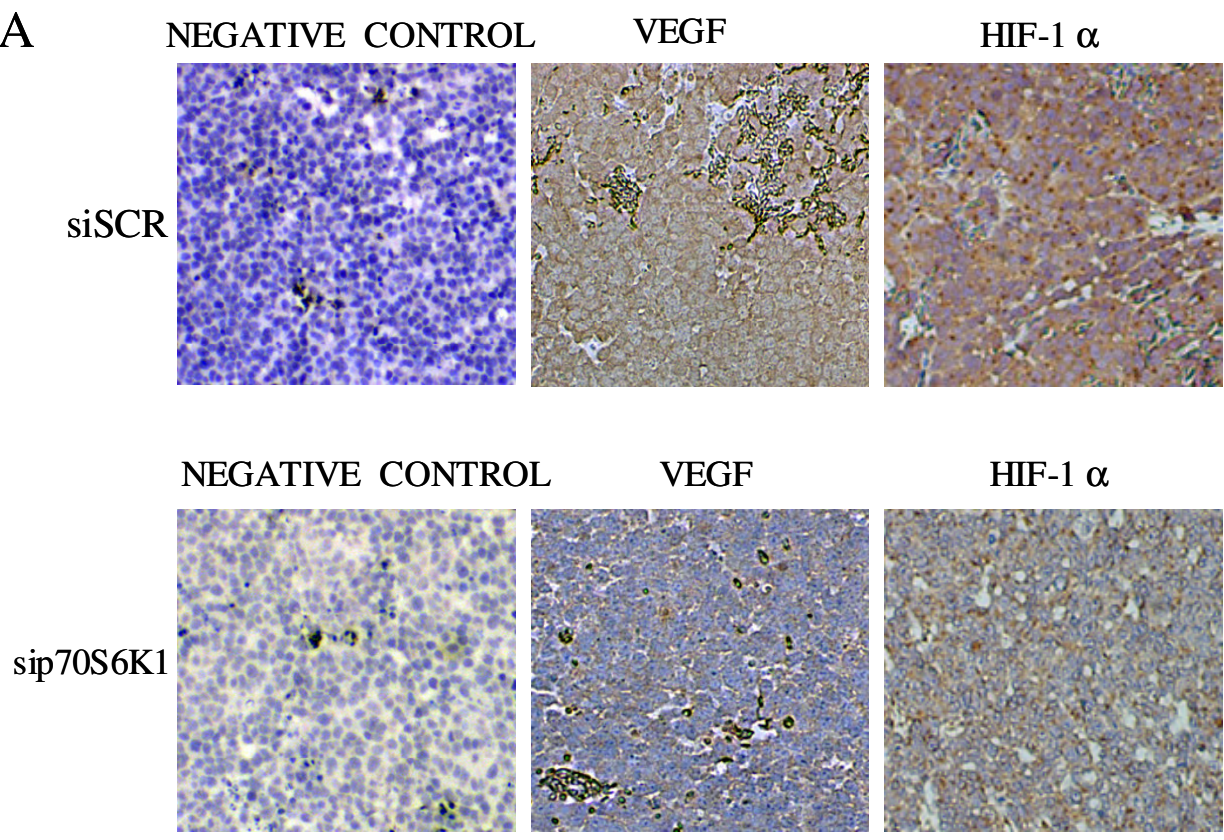

B

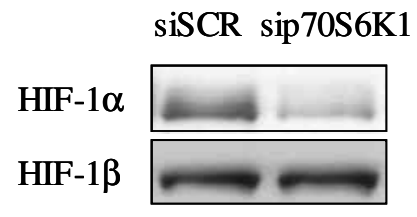




\section{CHAPTER IV}

Regulation of Survivin by PI3K/AKT /p70S6K1 Pathway and Role of Survivin in Ovarian Cancer 


\begin{abstract}
The survivin gene is highly expressed in ovarian cancer cell lines and is a potential target of gene therapy for ovarian cancer. To investigate the role of PI3K pathway in the regulation of survivin mRNA, we used the oncoprotein v-P3k and tumor suppressor gene PTEN to investigate the effects of PI3K on survivin expression. Overexpression of PI3K induced the expression level of survivin mRNA. Inhibition of PI3K by LY294002 or overexpression of PTEN suppressed the level of survivin mRNA. Expression of a constitutively active form of AKT was sufficient to induce the expression of survivin mRNA. To test whether p70S6K1 is a downstream target for regulating survivin expression, we generated a constitutively active p70S6K1 (E389D3E) construct by RCAS. We found that expression of p70S6K1 increased the mRNA expression of survivin and rapamycin treatment decreased the survivin mRNA expression. This study demonstrates that survivin mRNA is regulated by PI3K/AKT/p70S6K1 pathway. To study the role of survivin in ovarian cancer cells, we established a stable cell line that expressed siRNA against survivin. Expression of survivin siRNA in ovarian cancer cells induced apoptosis when combined with LY294002 or taxol treatment. Survivin is an important downstream molecule of PI3K/AKT/p70S6K1 pathway that plays a role in antiapoptosis in ovarian cancer cells.
\end{abstract}




\section{INTRODUCTION}

Apoptosis is an important process for cell and tissue homeostasis. Apoptotic effector molecules and disordered apoptosis are involved in various diseases. The inhibitor of apoptosis protein (IAP) inhibits apoptosis by inactivating several caspases ${ }^{1-4}$. Survivin is a newly described member of the IAP family ${ }^{5}$. Survivin can inhibit apoptosis by blocking a common step downstream of mitochondrial cytochrome $c$ release by inhibiting terminal effector caspase- 3 and caspase- 7 , and interfering with caspase- 9 activity and processing ${ }^{6-8}$. Overexpression of survivin can lead to resistance to apoptotic stimuli.

Survivin is expressed primarily in fetal, but not adult tissues. Survivin is constitutively expressed in most cancers, including carcinomas of the $\operatorname{lung}^{9}$, colon ${ }^{10,11}$,

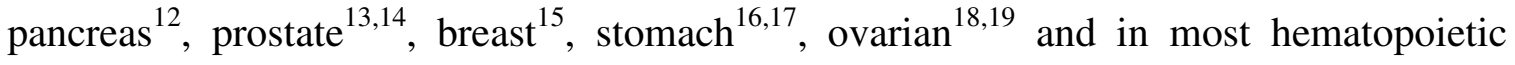
malignancies ${ }^{20-23}$. The expression of survivin is cell-cycle dependent ${ }^{24}$. It is selectively expressed at the G2/M phase of the cell cycle in a cell cycle-regulated manner and localized with caspase-3 to mitotic spindle microtubules ${ }^{25}$. Hematopoietic and vascular remodeling cytokines, STAT3-dependent signaling and PI3K activity influence survivin expression through non-cell-cycle-dependent mechanisms ${ }^{26}$. PI3K/AKT activation has been implicated in the upregulation of survivin induced by Ang- $1^{27,28}$, VEGF and GM-CSF ${ }^{29}$. Angiopoietin-1 inhibits endothelial cell apoptosis via the AKT/survivin pathway ${ }^{28}$. VEGF binding to VEGF-R2 activates the PI3K survival 
pathway and induces the expression of survivin in endothelial cells ${ }^{30-32}$. Exposure of human neuroblastoma cells to exogenous VEGF results in an increased expression of survivin protein and phosphorylated AKT, and inhibition of PI3-kinase abrogates those effects ${ }^{33}$. LY294002, the inhibitor of the PI3K pathway, inhibited survivin expression on GM-CSF stimulation of acute myeloid leukemia cells ${ }^{29}$. Inhibition of PI3K pathway down-regulates survivin expression and enhances TRAIL-mediated apoptosis in neuroblastomas ${ }^{34}$. Geranylgeranyltransferase I inhibitors (GGTIs) induce apoptosis in both cisplatin-sensitive and -resistant human ovarian epithelial cancer cells by inhibition of PI3K/AKT and survivin pathways ${ }^{35}$. Survivin expression is upregulated by coexpression of human epidermal growth factor receptor 2 (HER2) and epidermal growth factor receptor (EGFR) through PI3K/AKT signaling pathway in breast cancer cells ${ }^{36}$. We hypothesize that the transcriptional regulation of survivin is regulated by PI3K/AKT/mTOR pathway. In this study, we use chicken embryo fibroblast cells as a model to test the effect of PI3K, AKT and p70S6K1 on survivin expression.

The targeting of survivin by antisense or dominant-negative strategies leads to the induction of apoptosis. Ovarian cancer cells have a high expression of survivin. High levels of survivin protein were detected in advanced ovarian carcinomas ${ }^{37}$ and correlated with taxol resistance in human ovarian cancer ${ }^{38}$. In this study, we want to test whether knock-down expression of survivin by siRNA combined with PI3K inhibitor or taxol can regulate the apoptosis rate of ovarian cancer cells. 


\section{MATERIALS AND METHODS}

Reagents and Cell Culture- Total RNAs were isolated using the Trizol reagent from Invitrogen (Carlsbad, CA, USA). The primers for the survivin and GAPDH were from Gene Scrip Inc (Piscataway, NJ). The antibody against survivin was from Santa Cruz Biotechnology (Santa Cruz, CA) and the antibodies against phospho-Akt (Ser473), total Akt, p70S6K1, and phospho-p70S6K1 (Thr421/Ser424) were from Cell Signaling Technology (Beverly, MA). The antibody against $\beta$-actin was from Sigma (St. Louis, MO). The horseradish peroxidase (HRP)-conjugated anti-rabbit IgG and anti-mouse IgG were from Perkin Elmer Life Sciences (Boston, MA). The human ovarian cancer cell line OVCAR-3 (American Type Culture Collection, Manassas, VA) was maintained in RPMI 1640 (GIBCO BRL, Grand Island, NY) supplemented with 10\% FBS, 0.2\% insulin and antibiotics at $37^{\circ} \mathrm{C}$ with $95 \%$ air and $5 \% \mathrm{CO}_{2}$.

Plasmid Constructs - SiRNA was designed using siRNA converter software (Ambion, Austin, TX) and the sequence was searched for homology with Basic Local Alignment Search Tool (BLAST) software. The 21-mer oligonucleotides specific to survivin were sense strand siRNA: UGGCGUGAACCCAGGAGGCtt and antisense strand: GCCUCCUGGGUUCACGCCAtt. Two annealed sense and antisense DNA oligonucleotides containing the 21-mer sequences directed against survivin were ligated into a pSilencer 2.1-U6 vector (Ambion, Austin, TX). DNA oligonucleotides containing 
the scramble sequence having no homology to any human genomes were also ligated into the vector and used as a control. The plasmid that expresses siRNA against human survivin was named as si-survivin. The negative control plasmid was named as siSCR. The plasmid constructs used are v-P3k, Myr-Akt, PTEN and PTEN mutant (C124S) expressed by the avian retrovirus vector RCAS as previously described ${ }^{39-41}$. P70S6K1 (E389D3E) was subcloned into an adaptor vector pBSFI and then inserted into a modified avian retrovirus vector RCAS.Sfi. Chicken embryo fibroblasts (CEF) were plated at $2 \times 10^{5}$ cells/well in six-well plates, cultured for overnight and transfected with $2 \mu \mathrm{g}$ of plasmid DNA using Lipofectamine reagent (Life Technologies, Gaithersburg, MD) per the instruction of the manufacturer. After transfection, the cells were passaged for two weeks to ensure that the actively replicating retroviral vector spreads through the culture.

Selecting a population of cells that stably express siRNA to survivin or siSCR-OVCAR-3 cells were plated into 6 well plates. After cells were grown to 50-60\% confluence, $2 \mu \mathrm{g}$ of si-survivin or siSCR was transfected into OVCAR-3 cells using Lipofectamine and cultured for $24 \mathrm{~h}$ in complete medium. Then the cells were switched to medium containing $500 \mu \mathrm{g} / \mathrm{ml} \mathrm{G} 418$ (Sigma) and cultured for two weeks. The resistant cells were pooled and passaged in medium containing $250 \mu \mathrm{g} / \mathrm{ml} \mathrm{G} 418$ as needed.

RNA Isolation and RT-PCR - Total RNAs were extracted with Trizol reagent 
(Invitrogen). RNA was quantitated by measuring absorbance at $260 \mathrm{~nm}$. cDNAs were prepared by incubating $1 \mu \mathrm{g}$ of total RNA in $25 \mu \mathrm{l}$ reaction buffer that has AMV Reverse Transcriptase, an oligo(dT) primer, RNase inhibitors and dNTP (Promega) for $60 \mathrm{~min}$ at $37^{\circ} \mathrm{C}$. The cDNA fragment was amplified by PCR using following specific primers: survivin forward, 5'-GAG CTG CAG GTT CCTTAT C-3'; survivin reverse, 5'-ACA GCA TCG AGC CAA GTC AT-3’; GAPDH forward, 5'-CCACCCATGGCAAATTCCATGGCA-3'; $\quad$ GAPDH reverse 5'-TCTAGACGGCAGGTCAGGTCCACC-3'. PCR was carried out in a thermal cycle programmed at $94^{\circ} \mathrm{C}$ for $1 \mathrm{~min}, 55^{\circ} \mathrm{C}$ for $1 \mathrm{~min}$, and $72^{\circ} \mathrm{C}$ for $1 \mathrm{~min}$ and amplified for 30 cycles. The amplified PCR products were visualized on $2 \%$ agarose gels.

Northern Blot analysis - Total RNAs were extracted using Trizol reagent according to manufacturer's instruction. Aliquots of total RNAs $(10 \mu \mathrm{g})$ per lane were separated by formaldehyde gel and transferred to nylon membranes by capillary transfer with a downward transfer system (Schleicher \& Schuell). After UV crosslinking, the membranes were prehybridized for $1 \mathrm{~h}$ at $42^{\circ} \mathrm{C}$ in $10 \mathrm{ml}$ of Ultrahyb buffer (Ambion). Then the membrane was hybridized to $\mathrm{dCTP}_{-}{ }^{32} \mathrm{P}$ labeled chicken survivin cDNA fragment, which was labeled with $\left[\alpha-{ }^{32} \mathrm{P}\right] \mathrm{dCTP}$ by random priming using the RadPrime DNA labeling system (Invitrogen) and purified with the ProbeQuant G-50 Micro Columns (Amersham Biosciences, Piscataway, NJ). Signals were visualized by film autoradiography with an intensifying screen. To monitor the loading of RNA and the 
integrity of RNA, total RNAs $(10 \mu \mathrm{g})$ were loaded on the formaldehyde gel and stained with ethidium bromide.

Western Blotting - Cells were washed with cold PBS and collected by scraping. They were lysed in ice-cold lysis buffer [150 mM NaCl, $100 \mathrm{mM}$ Tris (pH 8.0), 1\% Triton $\mathrm{X}-100,1 \%$ deoxycholic acid, $0.1 \%$ SDS, $5 \mathrm{mM}$ EDTA, and $10 \mathrm{mM} \mathrm{NaF}$ ] which was supplemented with $1 \mathrm{mM}$ sodium vanadate, $2 \mathrm{mM}$ leupeptin, $2 \mathrm{mM}$ aprotinin, $1 \mathrm{mM}$ phenylmethylsulfonylfluoride, $1 \mathrm{mM}$ dithiothreitol, and $2 \mathrm{mM}$ pepstatin A. After centrifuging at 12,000 rpm for $15 \mathrm{~min}$, the supernatant was used for protein determination using Bio-Rad protein assay reagent (Richmond, CA). The proteins were resolved on 8\% SDS-PAGE, transferred onto nitrocellulose membrane and incubated with antibodies against total AKT, phospho-AKT (Ser473), total p70S6K1, phospho-p70S6K1 (Thr421/Ser424) and $\beta$-actin. The membranes were washed with PBS buffer containing $0.05 \%$ Tween 20 , followed by incubation with the appropriate HRP-linked secondary antibodies. The levels of specific proteins were detected with the enhanced chemiluminescence reagent (NEN, Boston, MA).

Tunnel assay-Cells were washed 3 times in PBS and adjusted to $2 \times 10^{7}$ cells $/ \mathrm{ml}$. Cells (100 $\mu \mathrm{l} /$ well) were transferred to a V-bottomed 96-well microplate. A freshly prepared fixation solution $(100 \mu \mathrm{l} /$ well $)$ was added to cell suspension. Cells were resuspended and incubated $60 \mathrm{~min}$ at $15-25^{\circ} \mathrm{C}$. Fixative solution was removed by flicking off the 
microplate. Cells were washed once with PBS. The microplate was centrifuged at $300 \times \mathrm{g}$ for $10 \mathrm{~min}$. Cells were resuspended in $100 \mu \mathrm{l} /$ well permeabilisation solution for 2 min on ice. Cells were washed twice with PBS and resuspended in Tunnel reaction mixture. The microplate was incubated for $30 \mathrm{~min}$ at $37^{\circ} \mathrm{C}$ in a humidified atmosphere in the dark. Samples were washed twice in PBS. Cells were transferred in a tube to a final volume of $250-500 \mu \mathrm{l}$ in PBS. Samples were analyzed by flow cytometry using an excitation wavelength at $540 \mathrm{~nm}$ and detection wavelength at $620 \mathrm{~nm}$.

Statistical Analysis-The data were analyzed using SPSS statistics software package (SPSS, Chicago, IL). All of the results are expressed as mean \pm SD from three independent experiments. The difference with $\mathrm{P}<0.05$ was considered significant. 


\section{RESULTS}

PI3K is sufficient to induce survivin mRNA expression- Among the inhibitors of apoptosis proteins (IAPs), survivin is an especially attracted target. The mechanism of tumor-associated survivin expression is not clear. PI3K pathway has been implicated in the regulation of survivin induced by growth factors. The oncogene v-P3k codes for a constitutively active form of PI3K catalytic subunit. To investigate the direct role of PI3K pathway in the regulation of survivin, we used the oncoprotein v-P3k to investigate the effects of PI3K on survivin expression. We used the RCAS vector carrying v-P3k or RCAS vector to transfect CEF cells. Overexpression of v-P3k increased the expression of p-Akt (Ser473) in serum starvation condition and PI3K inhibitor LY294002 treatment decreased the level of p-Akt (Ser473) (Fig. 1A). Northern blot analysis demonstrated that v-P3k increased the level of survivin mRNA and PI3K inhibitor LY294002 inhibited the mRNA expression of survivin (Fig. 1B). The tumor suppressor phosphatase and tensin homologue deleted on chromosome 10 (PTEN) is a phosphoinositide 3-specific phosphatase that dephosphorylates $\operatorname{Ptd} \operatorname{Ins}(3,4,5) P 3$ and $\operatorname{PtdIns}(3,4) P 2$ to $\operatorname{PtdIns}(4,5) P 2$ and PtdIns(4)P, respectively. The mRNA expression of survivin was reduced by the PTEN expression and the level of survivin was not changed by the expression of PTEN kinase dead mutant (C124S) (Fig. 1C). Overexpression of PTEN decreased the expression of p-Akt (Ser473) protein and PTEN mutant did not change the expression of p-Akt (Ser473) protein (Fig. 1D). LY294002 treatment also decreased the survivin 
mRNA expression in complete medium (Fig. 1E).

AKT and p70S6K1 are downstream signaling molecules of PI3K that regulate survivin $m R N A$ expression- AKT is a very important downstream target of PI3K. Next, we asked whether PI3K-induced survivin expression was mediated by the activation of AKT. To determine whether overexpression of a constitutively active form of AKT was sufficient to induce the survivin mRNA, CEF cells were transfected with a constitutively active form of Akt (Myr-Akt) or empty vector. Overexpression of Myr-Akt increased the mRNA expression of survivin. PI3K inhibitor treatment decreased the expression of survivin induced by Myr-Akt expression (Fig. 2A). Compared to vector control, overexpression of Myr-Akt increased the expression of p-Akt (Ser473) in serum free condition and the increased level of p-Akt (Ser473) protein was inhibited by LY294002 (Fig. 2B). This result suggested that Myr-Akt is a downstream molecule of PI3K that regulate survivin mRNA expression. P70S6K1 is another downstream signaling molecule of PI3K and is implicated as a target of Akt. To test whether p70S6K1 was involved in PI3K- and Akt-mediated survivin expression, CEF cells expressing v-P3k and Myr-Akt were used to test the level of p70S6K1 phosphorylation, which correlated to the activation of p70S6K1. Rapmycin is an inhibitor of mTOR/p70S6K1. The phosphorylation of p70S6K1 was analyzed in the absence or the presence of rapamycin. The induced activity of p70S6K1 by active forms of PI3K and Akt was inhibited by rapamycin in serum starvation condition (Fig. 3B and Fig. 3D). Rapamycin treatment 
inhibited the mRNA expression of survivin induced by v-P3k (Fig. 3A) or Myr-Akt (Fig. 3C). Overexpression of p70S6K1 (E389D3E) increased the expression of phosphorylated p70S6K1 when compared to that of RCAS control in serum-starvation condition. The phosphorylation of p70S6K1 was decreased by rapamycin treatment (Fig. 3F). The expression of p70S6K1 (E389D3E) in CEF cells increased the mRNA expression of survivin and rapamycin decreased the survivin mRNA expression (Fig. 3E). These results suggested that survivin mRNA expression was regulated by PI3K /Akt/p70S6K1 pathway.

Expression of siRNA against survivin (si-survivin) in ovarian cancer cells induced apoptosis when combined with LY294002 or taxol treatment- Increased survivin expression is a negative prognostic marker in many tumors, including ovarian cancer. To investigate the role of survivin in ovarian cancer, we generated the ovarian cancer cells that stably expressed si-survivin. Cells expressing si-survivin had a decreased expression of survivin mRNA when compared to that of cells expressing siSCR (Fig. 4A). Expression of si-survivin also decreased the expression of survivin protein (Fig. 4B). PI3K plays an important role in cell survival and cell growth. It was reported that taxol-mediated mitotic arrest of cancer cells is associated with survivin induction, which preserves a survival pathway and results in resistance to taxol ${ }^{38,42}$. To test the effect of PI3K inhibitor or taxol on the cell survival of ovarian cancer cells, we treated OVCAR-3 cells expressing si-survivin or si-SCR with PI3K inhibitor or taxol in $0.5 \%$ FBS medium 
for $24 \mathrm{~h}$. The percentage of apoptosis cells induced by PI3K inhibitor LY294002 treatment was higher in cells expressing si-survivin than that of apoptosis cells expressing siSCR control cells (Fig. 4C). Treatment with taxol increased apoptosis of OVCAR-3 cells expressing si-survivin when compared to the cells expressing siSCR (Fig. 4D). It suggested that increased levels of survivin were associated with increased resistance to apoptosis in ovarian cancer. 


\section{DISCUSSION}

Recent studies demonstrated that PI3K/AKT activation has been involved in the upregulation of survivin induced by GM-CSF ${ }^{29}$, Ang- $1^{27,28}$ and VEGF VE,31,43 $^{30, H o w e v e r, ~}$ there is no report on the direct effect of PI3K on survivin expression. Our study demonstrated that survivin mRNA level is regulated by PI3K signaling pathway. We used CEF cells as a cell model. To determine if over-expression of PI3K can increase survivin mRNA expression, we transfected the CEF cells with v-P3k and Myr-Akt constructs by RCAS vector. CEF cells over expressing v-P3k or Myr-Akt had a high expression of survivin mRNA when compared to RCAS vector control. The expression of survivin was inhibited by inactivation of PI3K through PI3K inhibitor LY294002 or PTEN expression. Overexpression of constitutively activated p70S6K1 (E389D3E) induced the expression of survivin. The mRNA level of survivin was repressed by inhibition of mTOR activity by rapamycin. This suggests that survivin mRNA level is regulated by PI3K/AKT/p70S6K1 pathway. This is the first report that suvivin mRNA is regulated by PI3K/AKT/p70S6K1 pathway.

In recent years researchers have made considerable efforts to develop strategies for modulating apoptosis in cancer. In this context, approaches to inhibit survivin in tumor cells have been proposed with the dual aim to inhibit tumor growth through an increase in spontaneous apoptosis, and to enhance tumor cell response to apoptosis-inducing agents. Considering that apoptosis is the primary mode of cell death 
induced by several classes of anticancer agents and ionizing radiation, a possible general role of survivin in determining the chemo- and radio-sensitivity profiles of tumor cells has been hypothesized ${ }^{38,42,44,45}$. Moreover, since survivin is associated with microtubules and with the mitotic spindle it is likely that this protein can specifically contribute to the response of cells to microtubule-interacting agents. It is recently reported that transfection of wild-type survivin efficiently protected murine NIH3T3 fibroblasts from apoptosis induced by the microtubule-stabilizing agent taxol ${ }^{25}$. In agreement with this observation, infection of HeLa cells with an adenoviral vector expressing survivin suppressed apoptosis induced by taxol ${ }^{46}$. Based on this finding, our laboratory performed a parallel investigation on an ovarian cancer cell lines to determine whether survivin is involved in regulating cell sensitivity to taxol. Our finding is that expression of siRNA specific to survivin in ovarian cancer cells induces more apoptosis when combined with LY294002 or taxol treatment than cells expressing siSCR alone treated with LY294002 or taxol. Treatment with survivin siRNA and inhibitors of PI3K or taxol may provide potential novel therapeutic options to treat ovarian cancer. 


\section{Reference List}

1. Deveraux, Q. L., Takahashi, R., Salvesen, G. S., and Reed, J. C. X-linked IAP is a direct inhibitor of cell-death proteases. Nature, 388: 300-304, 1997.

2. Riedl, S. J., Renatus, M., Schwarzenbacher, R., Zhou, Q., Sun, C., Fesik, S. W., Liddington, R. C., and Salvesen, G. S. Structural basis for the inhibition of caspase-3 by XIAP. Cell, 104: 791-800, 2001.

3. Scott, F. L., Denault, J. B., Riedl, S. J., Shin, H., Renatus, M., and Salvesen, G. S. XIAP inhibits caspase-3 and -7 using two binding sites: evolutionarily conserved mechanism of IAPs. EMBO J., 24: 645-655, 2005.

4. Silke, J., Ekert, P. G., Day, C. L., Hawkins, C. J., Baca, M., Chew, J., Pakusch, M., Verhagen, A. M., and Vaux, D. L. Direct inhibition of caspase 3 is dispensable for the anti-apoptotic activity of XIAP. EMBO J., 20: 3114-3123, 2001.

5. Salvesen, G. S. and Duckett, C. S. IAP proteins: blocking the road to death's door. Nat.Rev.Mol.Cell Biol., 3: 401-410, 2002.

6. Blanc-Brude, O. P., Mesri, M., Wall, N. R., Plescia, J., Dohi, T., and Altieri, D. C. Therapeutic targeting of the survivin pathway in cancer: initiation of mitochondrial apoptosis and suppression of tumor-associated angiogenesis. Clin.Cancer Res., 9: 2683-2692, 2003. 
7. O'Connor, D. S., Grossman, D., Plescia, J., Li, F., Zhang, H., Villa, A., Tognin, S., Marchisio, P. C., and Altieri, D. C. Regulation of apoptosis at cell division by p34cdc2 phosphorylation of survivin. Proc.Natl.Acad.Sci.U.S.A, 97: 13103-13107, 2000.

8. Shin, S., Sung, B. J., Cho, Y. S., Kim, H. J., Ha, N. C., Hwang, J. I., Chung, C. W., Jung, Y. K., and Oh, B. H. An anti-apoptotic protein human survivin is a direct inhibitor of caspase-3 and -7. Biochemistry, 40: 1117-1123, 2001.

9. Monzo, M., Rosell, R., Felip, E., Astudillo, J., Sanchez, J. J., Maestre, J., Martin, C., Font, A., Barnadas, A., and Abad, A. A novel anti-apoptosis gene: Re-expression of survivin messenger RNA as a prognosis marker in non-small-cell lung cancers. J.Clin.Oncol., 17: 2100-2104, 1999.

10. Endo, T., Abe, S., Seidlar, H. B., Nagaoka, S., Takemura, T., Utsuyama, M., Kitagawa, M., and Hirokawa, K. Expression of IAP family proteins in colon cancers from patients with different age groups. Cancer Immunol.Immunother., 53: 770-776, 2004.

11. Ponnelle, T., Chapusot, C., Martin, L., Bouvier, A. M., Plenchette, S., Faivre, J., Solary, E., and Piard, F. Cellular localisation of survivin: impact on the prognosis in colorectal cancer. J.Cancer Res.Clin.Oncol., 131: 504-510, 2005.

12. Satoh, K., Kaneko, K., Hirota, M., Masamune, A., Satoh, A., and Shimosegawa, T. 
Expression of survivin is correlated with cancer cell apoptosis and is involved in the development of human pancreatic duct cell tumors. Cancer, 92: 271-278, 2001.

13. Kaur, P., Kallakury, B. S., Sheehan, C. E., Fisher, H. A., Kaufman, R. P., Jr., and Ross, J. S. Survivin and Bcl-2 expression in prostatic adenocarcinomas. Arch.Pathol.Lab Med., 128: 39-43, 2004.

14. Shariat, S. F., Lotan, Y., Saboorian, H., Khoddami, S. M., Roehrborn, C. G., Slawin, K. M., and Ashfaq, R. Survivin expression is associated with features of biologically aggressive prostate carcinoma. Cancer, 100: 751-757, 2004.

15. Tsuji, N., Furuse, K., Asanuma, K., Furuya, M., Kondoh, K., Kamagata, C., Sasaki, M., Kobayashi, D., Yagihashi, A., Takahashi, H., and Watanabe, N. Mutations of the p53 gene and loss of heterozygosity at chromosome 17p13.1 are associated with increased survivin expression in breast cancer. Breast Cancer Res.Treat., 87: 23-31, 2004.

16. Lu, C. D., Altieri, D. C., and Tanigawa, N. Expression of a novel antiapoptosis gene, survivin, correlated with tumor cell apoptosis and p53 accumulation in gastric carcinomas. Cancer Res., 58: 1808-1812, 1998.

17. Tu, S. P., Jiang, X. H., Lin, M. C., Cui, J. T., Yang, Y., Lum, C. T., Zou, B., Zhu, Y. B., Jiang, S. H., Wong, W. M., Chan, A. O., Yuen, M. F., Lam, S. K., Kung, H. F., and Wong, B. C. Suppression of survivin expression inhibits in vivo tumorigenicity 
and angiogenesis in gastric cancer. Cancer Res., 63: 7724-7732, 2003.

18. Cohen, C., Lohmann, C. M., Cotsonis, G., Lawson, D., and Santoianni, R. Survivin expression in ovarian carcinoma: correlation with apoptotic markers and prognosis. Mod.Pathol., 16: 574-583, 2003.

19. Komuro, Y., Watanabe, T., Tsurita, G., Muto, T., and Nagawa, H. Survivin expression in ovarian carcinoma: correlation with apoptotic markers and prognosis. Mod.Pathol., 17: 264, 2004.

20. Cai, Z., Bao, H. Y., and Lin, M. F. Correlation between survivin mRNA expression and homoharringtonine induced apoptosis of malignant hematopoietic cells. Chin Med.J.(Engl.), 118: 548-554, 2005.

21. Komuro, Y., Watanabe, T., Tsurita, G., Muto, T., and Nagawa, H. Survivin expression in ovarian carcinoma: correlation with apoptotic markers and prognosis. Mod.Pathol., 17: 264, 2004.

22. Mori, A., Wada, H., Nishimura, Y., Okamoto, T., Takemoto, Y., and Kakishita, E. Expression of the antiapoptosis gene survivin in human leukemia. Int.J.Hematol., 75: 161-165, 2002.

23. Moriai, R., Asanuma, K., Kobayashi, D., Yajima, T., Yagihashi, A., Yamada, M., and Watanabe, N. Quantitative analysis of the anti-apoptotic gene survivin 
expression in malignant haematopoietic cells. Anticancer Res., 21: 595-600, 2001.

24. Li, F., Ackermann, E. J., Bennett, C. F., Rothermel, A. L., Plescia, J., Tognin, S., Villa, A., Marchisio, P. C., and Altieri, D. C. Pleiotropic cell-division defects and apoptosis induced by interference with survivin function. Nat.Cell Biol., 1: 461-466, 1999.

25. Li, F., Ambrosini, G., Chu, E. Y., Plescia, J., Tognin, S., Marchisio, P. C., and Altieri, D. C. Control of apoptosis and mitotic spindle checkpoint by survivin. Nature, 396: 580-584, 1998.

26. Altieri, D. C. Survivin, versatile modulation of cell division and apoptosis in cancer. Oncogene, 22: 8581-8589, 2003.

27. Harfouche, R., Hassessian, H. M., Guo, Y., Faivre, V., Srikant, C. B., Yancopoulos, G. D., and Hussain, S. N. Mechanisms which mediate the antiapoptotic effects of angiopoietin-1 on endothelial cells. Microvasc.Res., 64: 135-147, 2002.

28. Papapetropoulos, A., Fulton, D., Mahboubi, K., Kalb, R. G., O'Connor, D. S., Li, F., Altieri, D. C., and Sessa, W. C. Angiopoietin-1 inhibits endothelial cell apoptosis via the Akt/survivin pathway. J.Biol.Chem., 275: 9102-9105, 2000.

29. Carter, B. Z., Milella, M., Altieri, D. C., and Andreeff, M. Cytokine-regulated expression of survivin in myeloid leukemia. Blood, 97: 2784-2790, 2001. 
30. Mesri, M., Morales-Ruiz, M., Ackermann, E. J., Bennett, C. F., Pober, J. S., Sessa, W. C., and Altieri, D. C. Suppression of vascular endothelial growth factor-mediated endothelial cell protection by survivin targeting. Am.J.Pathol., 158: $1757-1765,2001$.

31. O'Connor, D. S., Schechner, J. S., Adida, C., Mesri, M., Rothermel, A. L., Li, F., Nath, A. K., Pober, J. S., and Altieri, D. C. Control of apoptosis during angiogenesis by survivin expression in endothelial cells. Am.J.Pathol., 156: 393-398, 2000.

32. Tran, J., Rak, J., Sheehan, C., Saibil, S. D., LaCasse, E., Korneluk, R. G., and Kerbel, R. S. Marked induction of the IAP family antiapoptotic proteins survivin and XIAP by VEGF in vascular endothelial cells. Biochem.Biophys.Res.Commun., 264: 781-788, 1999.

33. Beierle, E. A., Nagaram, A., Dai, W., Iyengar, M., and Chen, M. K. VEGF-mediated survivin expression in neuroblastoma cells. J.Surg.Res., 127: 21-28, 2005.

34. Kim, S., Kang, J., Qiao, J., Thomas, R. P., Evers, B. M., and Chung, D. H. Phosphatidylinositol 3-kinase inhibition down-regulates survivin and facilitates TRAIL-mediated apoptosis in neuroblastomas. J.Pediatr.Surg., 39: 516-521, 2004.

35. Dan, H. C., Jiang, K., Coppola, D., Hamilton, A., Nicosia, S. V., Sebti, S. M., and Cheng, J. Q. Phosphatidylinositol-3-OH kinase/AKT and survivin pathways as critical targets for geranylgeranyltransferase I inhibitor-induced apoptosis. 
Oncogene, 23: 706-715, 2004.

36. Asanuma, H., Torigoe, T., Kamiguchi, K., Hirohashi, Y., Ohmura, T., Hirata, K., Sato, M., and Sato, N. Survivin expression is regulated by coexpression of human epidermal growth factor receptor 2 and epidermal growth factor receptor via phosphatidylinositol 3-kinase/AKT signaling pathway in breast cancer cells. Cancer Res., 65: 11018-11025, 2005.

37. Komuro, Y., Watanabe, T., Tsurita, G., Muto, T., and Nagawa, H. Survivin expression in ovarian carcinoma: correlation with apoptotic markers and prognosis. Mod.Pathol., 17: 264, 2004.

38. Zaffaroni, N., Pennati, M., Colella, G., Perego, P., Supino, R., Gatti, L., Pilotti, S., Zunino, F., and Daidone, M. G. Expression of the anti-apoptotic gene survivin correlates with taxol resistance in human ovarian cancer. Cell Mol.Life Sci., 59: 1406-1412, 2002.

39. Aoki, M., Batista, O., Bellacosa, A., Tsichlis, P., and Vogt, P. K. The akt kinase: molecular determinants of oncogenicity. Proc.Natl.Acad.Sci.U.S.A, 95: 14950-14955, 1998.

40. Chang, H. W., Aoki, M., Fruman, D., Auger, K. R., Bellacosa, A., Tsichlis, P. N., Cantley, L. C., Roberts, T. M., and Vogt, P. K. Transformation of chicken cells by the gene encoding the catalytic subunit of PI 3-kinase. Science, 276: 1848-1850, 
1997.

41. Jiang, B. H., Aoki, M., Zheng, J. Z., Li, J., and Vogt, P. K. Myogenic signaling of phosphatidylinositol 3-kinase requires the serine-threonine kinase Akt/protein kinase B. Proc.Natl.Acad.Sci.U.S.A, 96: 2077-2081, 1999.

42. Ling, X., Bernacki, R. J., Brattain, M. G., and Li, F. Induction of survivin expression by taxol (paclitaxel) is an early event, which is independent of taxol-mediated G2/M arrest. J.Biol.Chem., 279: 15196-15203, 2004.

43. Tran, J., Master, Z., Yu, J. L., Rak, J., Dumont, D. J., and Kerbel, R. S. A role for survivin in chemoresistance of endothelial cells mediated by VEGF. Proc.Natl.Acad.Sci.U.S.A, 99: 4349-4354, 2002.

44. Asanuma, K., Kobayashi, D., Furuya, D., Tsuji, N., Yagihashi, A., and Watanabe, N. A role for survivin in radioresistance of pancreatic cancer cells. Jpn.J.Cancer Res., 93: 1057-1062, 2002.

45. O'Connor, D. S., Wall, N. R., Porter, A. C., and Altieri, D. C. A p34(cdc2) survival checkpoint in cancer. Cancer Cell, 2: 43-54, 2002.

46. Giodini, A., Kallio, M. J., Wall, N. R., Gorbsky, G. J., Tognin, S., Marchisio, P. C., Symons, M., and Altieri, D. C. Regulation of microtubule stability and mitotic progression by survivin. Cancer Res., 62: 2462-2467, 2002. 


\section{FIGURE LEGENDS}

Fig. 1. PI3K is sufficient to induce survivin mRNA expression. (A) The transfected CEF cells were treated without or with $10 \mu \mathrm{M}$ LY294002 in serum-free medium for $1 \mathrm{~h}$. The total cellular protein extracts were prepared and subjected to immunoblotting analysis using antibody specific to phosphorylation of Akt (Ser473) and total Akt. (B) RCAS alone or RCAS carrying v-P3k or was transfected into CEF cells and cultured for two weeks. Cells were cultured to $80 \%$ confluence, and then changed to serum-free medium for $8 \mathrm{~h}$. Total RNAs $(10 \mu \mathrm{g})$ were analyzed by Northern blotting. (C) RCAS carrying PTEN or PTEN mutant $(\mathrm{C} 124 \mathrm{~S})$ was transfected into CEF cells and cultured for two weeks. Cells were cultured to $80 \%$ confluence and then changed to serum-free medium

for $8 \mathrm{~h}$. Total RNAs $(10 \mu \mathrm{g})$ were analyzed by Northern blotting. (D) The level of Akt phosphorylation at Ser-473 or total Akt was detected by immunoblotting using phospho-Akt (Ser-473) or total Akt antibodies. (E) CEF cells expressing RCAS vector control were cultured in complete medium until 70-80\% confluence and then treated with $10 \mu \mathrm{M}$ LY294002 for $8 \mathrm{~h}$. Total RNAs $(10 \mu \mathrm{g})$ were analyzed by Northern blotting. (F) CEF cells expressing RCAS vector control were cultured in complete medium until $70-80 \%$ confluence, changed to serum-free medium for $12 \mathrm{~h}$ and then treated with complete medium without or with $10 \mu \mathrm{M}$ LY294002 for $1 \mathrm{~h}$. Total cellular extracts were prepared and subjected to immunoblotting using anti-phospho-Akt at Ser-473 and anti-Akt antibodies. 
Fig. 2. Akt is a downstream signaling molecule of $P I 3 K$ that regulates survivin mRNA expression. (A) RCAS empty vector alone or RCAS carrying Myr-Akt was transfected into CEF cells and cultured for two weeks. Cells were cultured to $80 \%$ confluence and then changed to serum-free medium for $8 \mathrm{~h}$. The cells that transfected with Myr-Akt were treated with $10 \mu \mathrm{M}$ LY294002 in serum-free medium for $8 \mathrm{~h}$. The mRNA level of survivin was detected by Northern blotting. (B) CEF cells were transfected with RCAS carrying Myr-Akt or empty vector alone and cultured for two weeks. The CEF cells transfected with Myr-Akt or RCAS vector were serum starved for $12 \mathrm{~h}$. Then the CEF cells transfected with Myr-Akt were incubated in the presence or absence of $10 \mu \mathrm{M}$ or 20 $\mu \mathrm{M}$ LY294002 for 1h. The levels of phosphorylation of Akt at Ser-473 and total Akt were determined by immunoblotting.

Fig. 3. PI3K/Akt upregulates survivin mRNA expression through p70S6K1. (A) RCAS vector alone or RCAS carrying v-P3k was transfected into CEF cells and cultured for two weeks. Cells expressing RCAS were cultured to $80 \%$ confluence and then changed to serum-free medium for $8 \mathrm{~h}$. The cells that transfected with v-P3k were treated with or without $10 \mathrm{nM}$ rapamycin in serum-free medium for $8 \mathrm{~h}$. The expression of survivin was determined by Northern blotting as described in Materials and Methods. (B) CEF cells were transfected with v-P3k or empty vector and treated without or with $10 \mathrm{nM}$ rapamycin in serum-free medium for $1 \mathrm{~h}$. Proteins of these transfected cells were 
detected by immunoblotting using antibody specific to phosphorylation of p70S6K1 at Thr-421/Ser-424 and total p70S6K1. (C) RCAS empty vector alone or RCAS carrying Myr-Akt was transfected into CEF cells and cultured for two weeks. Cells expressing RCAS were cultured to $80 \%$ confluence and then changed to serum-free medium for $8 \mathrm{~h}$. The cells that transfected with Myr-Akt were treated with $10 \mathrm{nM}$ rapamycin in serum-free medium for $8 \mathrm{~h}$. The expression of survivin was determined by Northern blotting as described in Materials and Methods. (D) CEF cells were transfected with empty vector or Myr-Akt and serum starved for $12 \mathrm{~h}$. The cells that transfected with Myr-Akt treated with or without $10 \mathrm{nM}$ rapamycin for $1 \mathrm{~h}$. The activation of p70S6K1 was detected by immunoblotting using the antibody specific to phospho-p70S6K1 at Thr-421/Se-r424 and total p70S6K1. (E) RCAS empty vector alon or RCAS carrying p70S6K1 (E389D3E) was transfected into CEF cells and cultured for one week. The cells transfected with vector alone were cultured to $80 \%$ confluence, then changed to serum-free medium for 8 h. The cells that transfected with p70S6K1 (E389D3E) were treated with or without 10 $\mathrm{nM}$ rapamycin in serum-free medium for $8 \mathrm{~h}$. The mRNA level of survivin was measured by Northern blotting. (F) CEF cells transfected with empty vector or p70S6K1 (E389D3E) were treated without or with $10 \mathrm{nM}$ rapamycin in serum-free medium for $1 \mathrm{~h}$. The phosphorylation of p70S6K1 at Thr-421/Se-r424 was determined by immunoblotting analysis using an antibody specific to phosphorylated p70S6K1 at Thr-421/Se-r424. The level of total p70S6K1 was determined by immunoblotting analysis using an antibody specific to p70S6K1. 
Fig. 4. Expression of siRNA against survivin in ovarian cancer cells induces apoptosis when combined with LY294002 or taxol treatment. (A) Generation of cells stably expressing si-survivin. The si-survivin and siSCR were transfected into OVCAR-3 cells by Lipofectamine. After two weeks selection in medium containing $500 \mu \mathrm{g} / \mathrm{ml} \mathrm{G} 418$, the clones stably expressing the siRNA were picked and cultured in fresh culture dishes. Cells expressing si-survivin or siSCR were cultured at a density of $5 \times 10^{5}$ cells/dish in RPMI 1640 medium with $10 \%$ FBS for $24 \mathrm{~h}$ at $37^{\circ} \mathrm{C}$ in $5 \% \mathrm{CO}_{2}$ incubator. The total RNAs were prepared and first strand cDNAs was synthesized using AMV and oligo(dT) primer. Survivin mRNA level in OVCAR-3 cells expressing si-survivin and siSCR was assayed by RT-PCR. The survivin mRNA level was compared with the signal from control GAPDH mRNA level. PCR products $(10 \mu 1)$ of siSCR and si-survivin were run on $2 \%$ agrose gel. Pictures were taken using Eagleeye system. (B) Cells expressing si-survivin or siSCR were cultured to $80 \%$ confluence in normal medium and lysed, and $50 \mu \mathrm{g}$ of protein was analyzed by immunoblotting with the antibodies against survivin and $\beta$-actin. (C) OVCAR-3 cells that express si-survivin or siSCR were cultured to 50-60\% confluence. Cells were changed to $0.5 \%$ fetal bovine serum and treated without or with $20 \mu \mathrm{M}$ LY294002 for $24 \mathrm{~h}$. Cells were washed with $1 \times \mathrm{PBS}$, fixed in $4 \%$ fresh paraformaldehyde, permeabilized by $0.1 \%$ Triton X-100 and labeled by Terminal deoxynucleotidyl transferase from calf thymus. * indicates a significant difference from the siSCR treated with LY294002 group $(p<0.05)$. (D) Cells were changed to $0.5 \%$ fetal bovine serum and treated without or with $0.5 \mu \mathrm{M}$ taxol for $24 \mathrm{~h}$. Cells were washed with 
$1 \times$ PBS, fixed in $4 \%$ fresh paraformaldehyde, permeabilized by $0.1 \%$ Triton $\mathrm{X}-100$ and labeled by Terminal deoxynucleotidyl transferase from calf thymus. Samples were analyzed by flow cytometry use an excitation wavelength in the range of 520-560 nm (maximum $540 \mathrm{~nm}$; green) and detection in the range of 570-620 nm (maximum $580 \mathrm{~nm}$, red). $*$ indicates a significant difference from the siSCR treated with taxol group $(p<$ $0.05)$. 
Fig. 1. PI3K is sufficient to induce survivin mRNA expression.

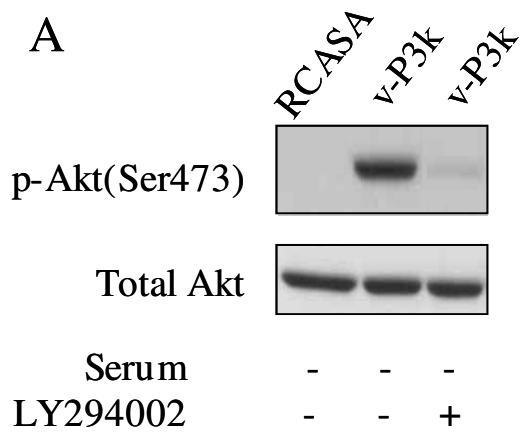

$\mathrm{C}$

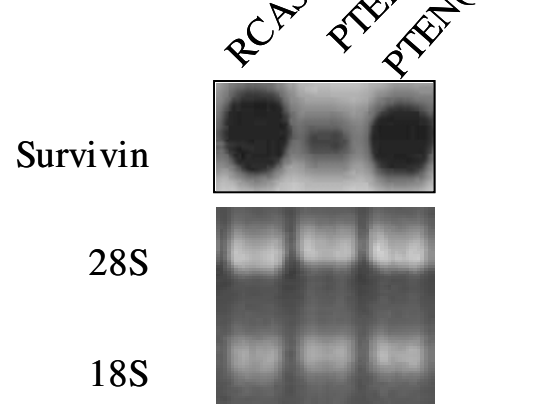

Serum +++

$\mathrm{E}$

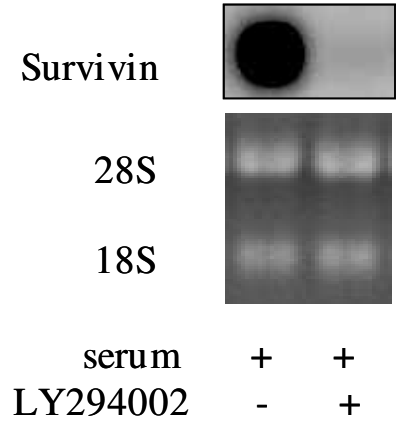

B

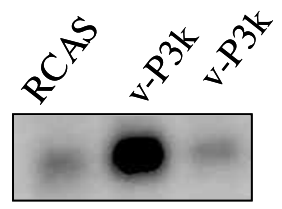

$28 \mathrm{~S}$

$18 \mathrm{~S}$

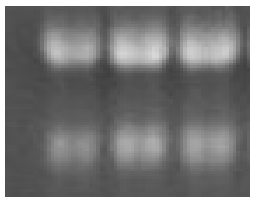

Serum

LY294002
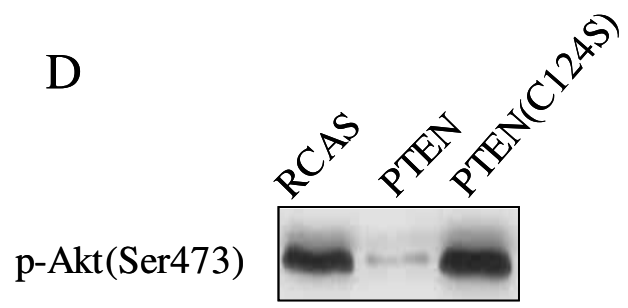

Total Akt

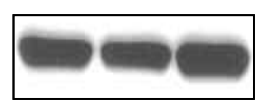

Serum +++

F p-Akt(Ser473)

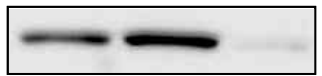

Total Akt

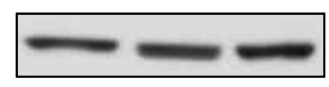
serum - $+\quad+$ LY294002 - - + 
Fig. 2. Akt is a downstream signaling molecule of PI3K that regulates survivin mRNA expression.

A

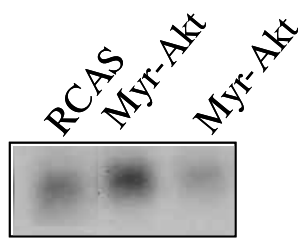

$28 \mathrm{~S}$

$18 \mathrm{~S}$

Serum

LY 294002

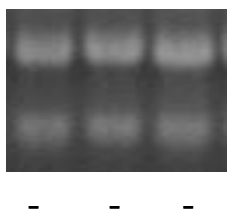

B

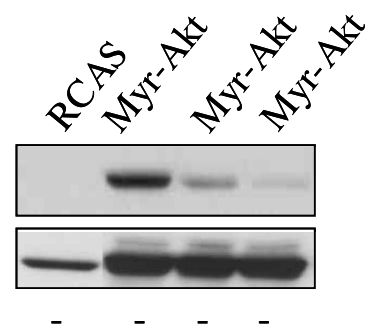

Serum

LY 294002 
Fig. 3. PI3K/Akt upregulates survivin mRNA expression through p70S6K1.

A

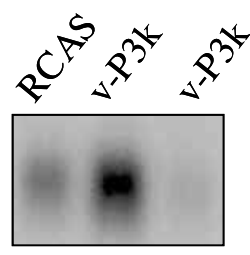

$28 \mathrm{~S}$

$18 \mathrm{~S}$

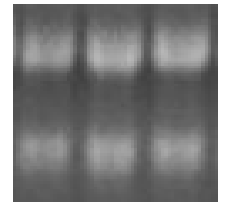

Serum

Rapamycin

$\mathrm{C}$

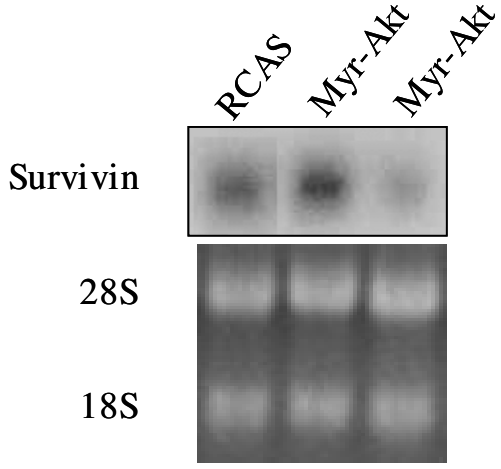

Serum

Rapamycin - - +

$\mathrm{E}$

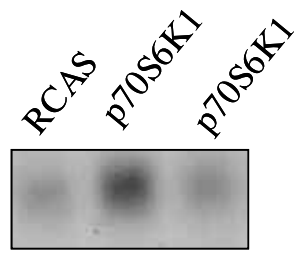

$28 \mathrm{~S}$

$18 S$

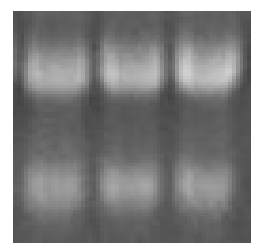

Serum

Rapamycin
B

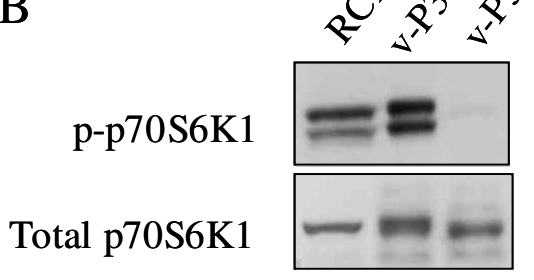

Serum

Rapamycin - - +

D

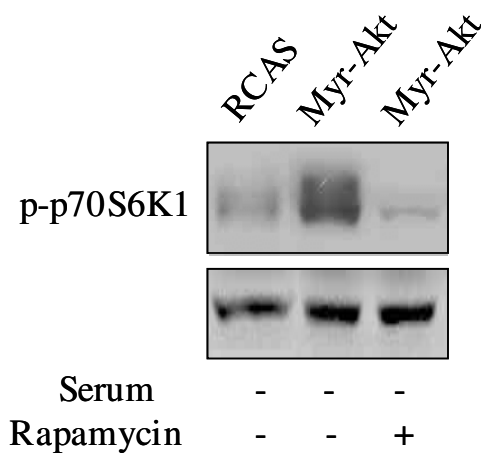

F

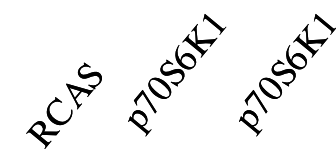

p-p70S6K1

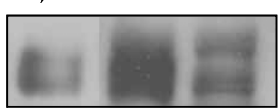

Serum

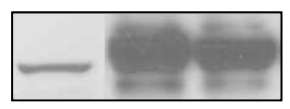

Rapamycin

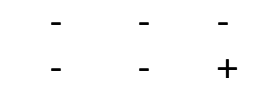


Fig. 4. Expression of siRNA specific to survivin in ovarian cancer cells induces apoptosis when combined with LY294002 or taxol treatment.
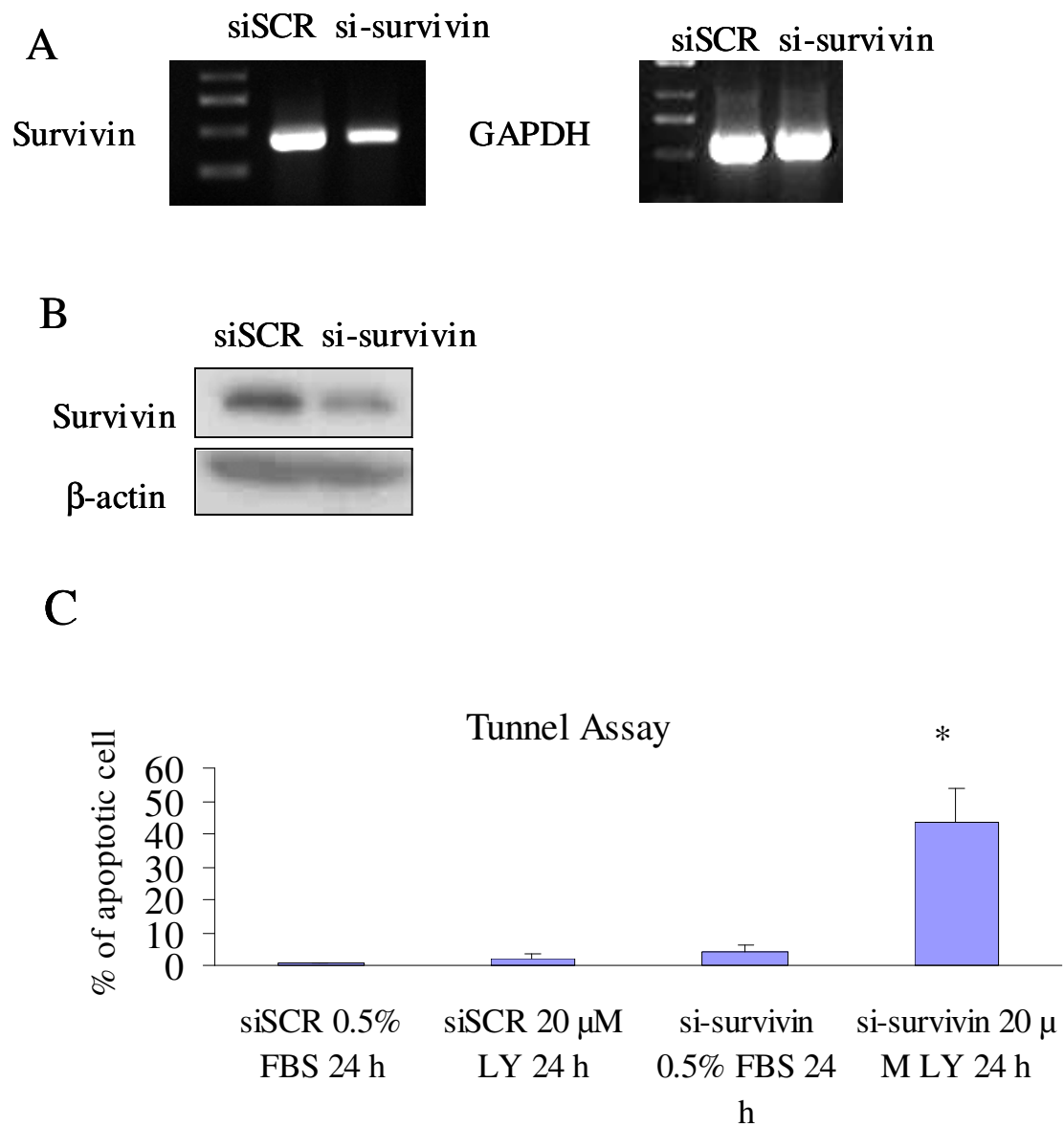

D

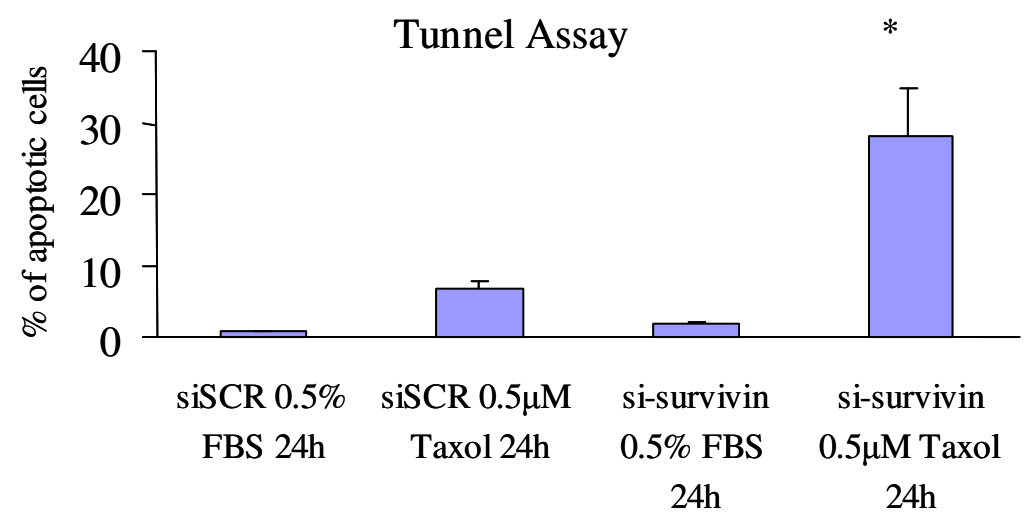




\section{CHAPTER V}

Summary and Conclusions 
The PI3K signaling pathway has previously been implicated in tumorigenesis, and recent studies suggest a pivotal role of PI3K catalytic subunit in human cancers. The PIK3CA gene, encoding the p110 alpha catalytic subunit of PI3K, is frequently mutated in human cancer. Both mutational and functional analyses have shown that PIK3CA is an oncogene that plays an important role in tumor progression ${ }^{1,2}$. LY294002 and wortmannin are two widely used PI3K inhibitors that inhibit the catalytic activity of PI3K. However, there are three major classes of PI3K isoforms existing in the cells ${ }^{3}$ and LY294002 has a broad inhibitory effect against all class I PI3Ks as well as other kinases such as ATM and $\mathrm{ATR}^{4}$. Wortmannin is a fungal metabolite that irreversibly inhibits $\mathrm{p} 110$ by reacting covalently with the catalytic site. Thus, in this study we wanted to specifically inhibit the p110 $\alpha$ subunit of PI3K by small interfering RNA (siRNA) in ovarian cancer cells. Expression of p110 $\alpha$ siRNA significantly decreased cell migration, invasion, and proliferation in contrast to the siSCR control cells. AKT is the primary downstream mediator of the effects of PI3K. AKT has three different isoforms: AKT1, AKT2 and AKT3. The three AKT isoforms are broadly expressed, although isoform-specific patterns of expression can exist in some tissues. It is reported that the isoforms AKT1 and AKT2 were expressed at the mRNA level in ovarian cancer cell lines, while no relevant AKT3 mRNA levels were detected in ovarian caner cell lines ${ }^{5}$. Among the specific AKT isoforms, increased AKT1 kinase activity has been reported in breast and ovarian cancers $^{6}$. In our study, we utilized siRNA to knockdown the expression of AKT1 
isoform and determined the role of AKT1 in ovarian caner cells. We found that inhibition of AKT1 is sufficient to decrease cell migration, invasion, and proliferation in ovarian cancer cells. Ribosomal S6 kinase is activated by PI3K/AKT pathway. The activity of p70S6K1 is inhibited in cells expressing siRNA specific to p110 $\alpha$ and AKT1. To study the role of p70S6K1 in ovarian cancer progression, we also designed siRNA specific to p70S6K1 and established stable cell lines that expressed p70S6K1 siRNA. Downregulation of p70S6K1 activity by p70S6K1 siRNA also decreased cell migration, invasion, and proliferation associated with the induction of p2 $7^{\mathrm{KIP} 1}$ levels. The study in Chapter II suggests that PI3K/AKT/mTOR/p70S6K1 pathway is critical for OVCAR-3 cell proliferation, migration and invasion. Inhibition of $\mathrm{PI} 3 \mathrm{~K} / \mathrm{AKT} / \mathrm{mTOR} / \mathrm{p} 70 \mathrm{~S} 6 \mathrm{~K} 1$ pathway could reduce proliferation and metastasis of tumor cells. They are ideal targets for the development of small molecule inhibitors for potential clinical application.

The invasion process is comprised of distinct events, which include the attachment of cells to the basement membrane, secretion of enzymes that degrade the basement membrane, and the migration of cells into the target tissue in response to specific chemotactic stimuli ${ }^{7}$. Several lines of evidence suggested that the mechanism by which PI3K/AKT/p70S6K1 pathway contributes to ovarian cancer cell migration and invasion involves the matrix metalloproteinases (MMPs), a group of zinc-dependent ECM-degrading enzymes. MMPs are thought to play a critical role in tumor cell invasion ${ }^{8}$. The ratio of MMP-9: MMP-2 is increased in ovarian tumor 
tissue compared with normal ovaries ${ }^{9}$. The elevated levels of MMP-9 protein have been detected in invasive epithelial ovarian carcinoma patient specimens ${ }^{10}$. Basal and EGF-induced MMP-9 protein expression involves both PI3K and MAPK signaling in ovarian cancer cells ${ }^{11}$. AKT increased HT1080 invasion, by increasing cell motility and MMP-9 production ${ }^{12}$. The increase of MMP-9 production was mediated by activation of nuclear factor- $\kappa \mathrm{B}$ transcriptional activity by AKT. HGF-induced invasion and migration is mediated by p70S6K1 through regulation of MMP in response to PI3K/Akt signaling ${ }^{13}$. P70S6K1 was found to be a direct transcriptional activator of MMP-9 synthesis. In the future, we can use our system to determine the role of PI3K/AKT/p70S6K1 in MMP-2 or MMP-9 expression in ovarian cancer cells.

The mammalian target of rapamycin (mTOR) mediates cell growth by stimulating protein synthesis. It is known that mTOR is a downstream target of AKT in vitro ${ }^{14}$. However, it is unknown how AKT activates mTOR in vivo. The tuberous sclerosis 2 complex (TSC2) protein has been the subject of much recent interest because it links AKT to mTOR in vivo. The TSC1 and TSC2 proteins form a complex in vivo. Several groups have demonstrated that TSC2 is phosphorylated and inhibited by $\mathrm{AKT}^{15,16}$. TSC1/TSC2 complex impedes signaling by mTOR due to the TSC2 GTPase-activating protein (GAP) activity towards the Ras family small GTPase Rheb ${ }^{17}$. AKT phosphorylates TSC2 and disrupts its interaction with TSC1. This leads to increased levels of GTP-bound Rheb, which results in the activation of 
the mTOR/p70S6K/eIF4E pathway. A common feature of TSC patient is cutaneous angiofibromas and renal angiomyolipomas ${ }^{18}$. TSC2 regulates VEGF through mTOR-dependent and independent pathway ${ }^{19}$. The role of TSC1 and TSC2 in tumor angiogenesis is not known yet. In this study, we study the function of TSC1 and TSC2 in regulating HIF-1 $\alpha$ and VEGF in ovarian cancer cells. It was reported that $T s c 2$-null cells had higher levels of HIF-1 $\alpha$ mRNA and protein than $T s c 2^{+/+}$cells. We showed that the protein level of HIF-1 $\alpha$ was induced in cells expressing siTSC1 or siTSC2 in both complete medium or serum free medium under normoxia condition. Further experiments will be performed to study whether TSC1 or TSC2 regulates HIF- $1 \alpha$ mRNA expression or affects protein stability in ovarian cancer cells. In this study, we showed that inhibition of TSC1 or TSC2 induced VEGF protein and mRNA expression, and induced tumor growth and angiogenesis in vivo. The induction of tumor growth and angiogenesis is significantly decreased by mTOR inhibitor rapamycin or p70S6K1 dominant negative construct. These data are consistent with our hypothesis that downregulation of TSC2 results in activation of mTOR/p70S6K1, which increases HIF-1 $\alpha$ and VEGF expression that may regulate tumor growth and angiogenesis. We showed that p70S6K1 was a downstream molecule of TSC1 or TSC2 that regulated VEGF transcriptional activation. To test the direct role of p70S6K1 in tumor angiogenesis, we showed that specifically knockdown of p70S6K1 expression decreased ovarian cancer tumor growth and angiogenesis in vivo. We demonstrated that inhibition of p70S6K1 expression decreased VEGF expression at 
the transcriptional level in ovarian cancer cells. P70S6K1 regulated VEGF transcriptional activation through HIF-1 $\alpha$, but not HIF-1 $\beta$ subunit expression. We also showed that p70S6K1 was required for VEGF and HIF-1 $\alpha$ expression in tumor tissues. We showed here for the first time that p70S6K1 down-regulation inhibited expression of VEGF at the transcriptional level through HIF-1 $\alpha$ expression and inhibition of p70S6K1 expression decreased ovarian tumor growth and angiogenesis in vivo. This novel finding provides a molecular basis for potentially targeting p70S6K1 for human ovarian cancer therapy in the future.

In addition, survivin gene is highly expressed in ovarian cancer cell lines and is a potential target for ovarian cancer. Expression of siRNA specific to survivin in ovarian cancer cells induces apoptosis when combined with LY294002 or taxol treatment. Our study demonstrates that suvivin mRNA is regulated by PI3K/AKT/p70S6K1 pathway. Survivin is an important downstream molecule of PI3K/AKT/p70S6K1 pathway that plays a role in antiapoptosis in ovarian cancer cells.

The last figure is the summary of this study. PI3K is activated by upstream activators including oncogenes and growth factors or is constitutively activated in ovarian cancer through PI3K gene amplification or mutations. Activated PI3K transmits signals to its downstream target AKT, which phosphorylates TSC2 and inactivates it. Inhibition of TSC2 induces activation of mTOR which regulates p70S6K1. Knock-down expression of TSC2 increases tumor growth through 
pathways as follows: TSC2/mTOR/p70S6K1 pathway or TSC2/MAPK pathway. Inhibition of TSC2 increased protein expression of HIF-1 and VEGF. TSC2 may regulate HIF-1 protein expression through p70S6K1 or ERK1/2. Activated p70S6K1 induces the transcriptional activation of VEGF through HIF-1 $\alpha$ expression to increase tumor angiogenesis. P70S6K1 is also an important downstream signaling molecule that mediates $\mathrm{PI} 3 \mathrm{~K}$ and AKT induced cell migration, invasion, proliferation and cell cycle progression. Survivin is another molecule that has important role in tumor progression. Survivin expression is regulated by PI3K/AKT/p70S6K1 pathway and survivin may regulate tumor growth through its antiapoptosis role in ovarian cancer. 


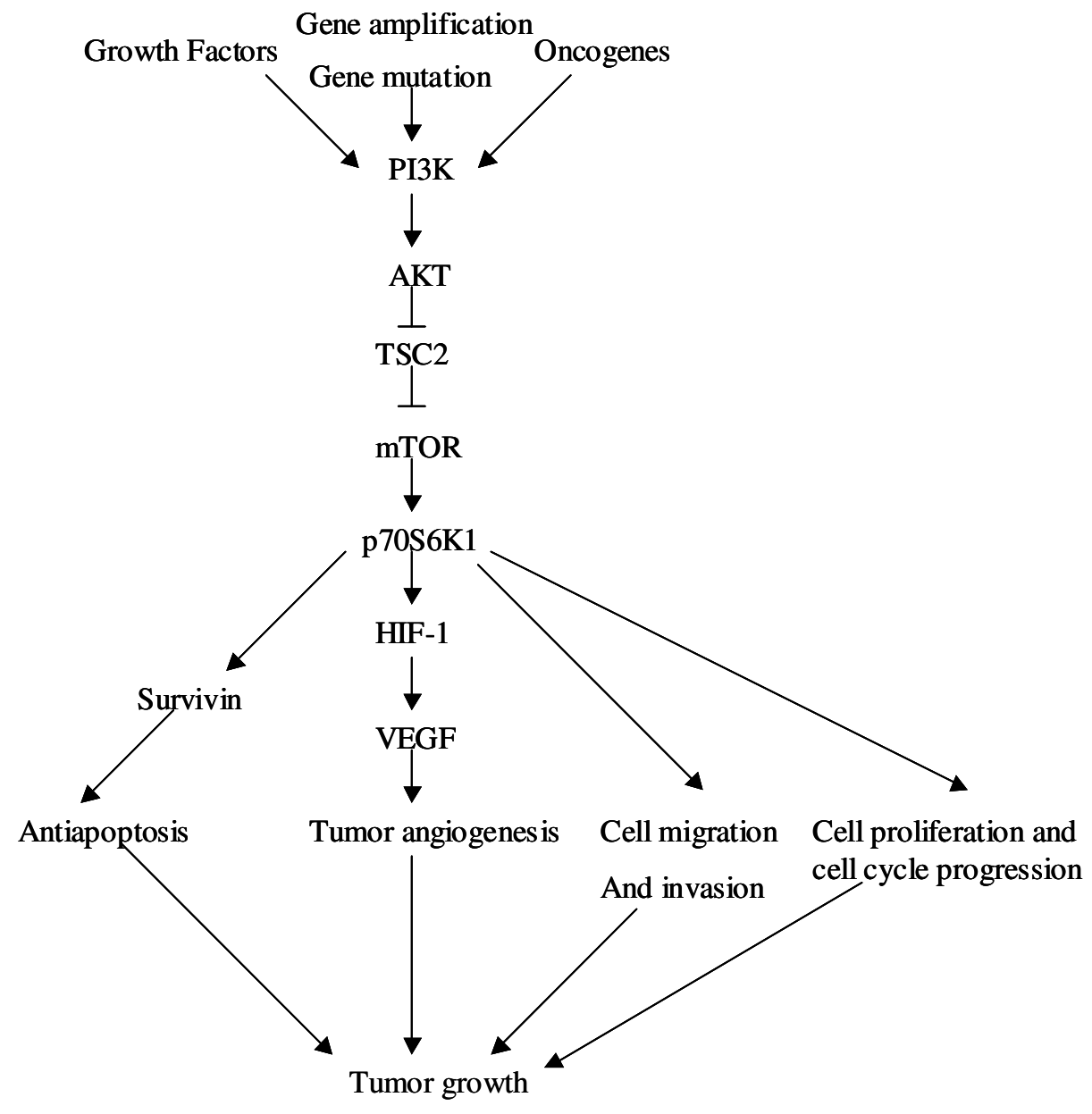

Figure Schematic representation of $\mathrm{PI} 3 \mathrm{~K} / \mathrm{AKT} / \mathrm{TSC} 2 / \mathrm{p} 70 \mathrm{~S} 6 \mathrm{~K} 1$ induced tumor angiogenesis and tumor growth. 


\section{Reference List}

1. Kang, S., Bader, A. G., and Vogt, P. K. Phosphatidylinositol 3-kinase mutations identified in human cancer are oncogenic. Proc.Natl.Acad.Sci.U.S.A, 102: 802-807, 2005.

2. Samuels, Y., Wang, Z., Bardelli, A., Silliman, N., Ptak, J., Szabo, S., Yan, H., Gazdar, A., Powell, S. M., Riggins, G. J., Willson, J. K., Markowitz, S., Kinzler, K. W., Vogelstein, B., and Velculescu, V. E. High frequency of mutations of the PIK3CA gene in human cancers. Science, 304: 554, 2004.

3. Toker, A. and Cantley, L. C. Signalling through the lipid products of phosphoinositide-3-OH kinase. Nature, 387: 673-676, 1997.

4. Hennessy, B. T., Smith, D. L., Ram, P. T., Lu, Y., and Mills, G. B. Exploiting the PI3K/AKT pathway for cancer drug discovery. Nat.Rev.Drug Discov., 4: 988-1004, 2005.

5. Noske, A., Kaszubiak, A., Weichert, W., Sers, C., Niesporek, S., Koch, I., Schaefer, B., Sehouli, J., Dietel, M., Lage, H., and Denkert, C. Specific inhibition of AKT2 by RNA interference results in reduction of ovarian cancer cell proliferation: Increased expression of AKT in advanced ovarian cancer. Cancer Lett., 2006.

6. Sun, M., Wang, G., Paciga, J. E., Feldman, R. I., Yuan, Z. Q., Ma, X. L., Shelley, 
S. A., Jove, R., Tsichlis, P. N., Nicosia, S. V., and Cheng, J. Q. AKT1/PKBalpha kinase is frequently elevated in human cancers and its constitutive activation is required for oncogenic transformation in NIH3T3 cells. Am.J.Pathol., 159: 431-437, 2001.

7. Lauffenburger, D. A. and Horwitz, A. F. Cell migration: a physically integrated molecular process. Cell, 84: 359-369, 1996.

8. Stetler-Stevenson, W. G., Aznavoorian, S., and Liotta, L. A. Tumor cell interactions with the extracellular matrix during invasion and metastasis. Annu.Rev.Cell Biol., 9: 541-573, 1993.

9. Kikkawa, F., Tamakoshi, K., Nawa, A., Shibata, K., Yamagata, S., Yamagata, T., and Suganuma, N. Positive correlation between inhibitors of matrix metalloproteinase 1 and matrix metalloproteinases in malignant ovarian tumor tissues. Cancer Lett., 120: 109-115, 1997.

10. Huang, L. W., Garrett, A. P., Bell, D. A., Welch, W. R., Berkowitz, R. S., and Mok, S. C. Differential expression of matrix metalloproteinase-9 and tissue inhibitor of metalloproteinase-1 protein and mRNA in epithelial ovarian tumors. Gynecol.Oncol., 77: 369-376, 2000.

11. Ellerbroek, S. M., Halbleib, J. M., Benavidez, M., Warmka, J. K., Wattenberg, E. V., Stack, M. S., and Hudson, L. G. Phosphatidylinositol 3-kinase activity in 
epidermal growth factor-stimulated matrix metalloproteinase-9 production and cell surface association. Cancer Res., 61: 1855-1861, 2001.

12. Kim, D., Kim, S., Koh, H., Yoon, S. O., Chung, A. S., Cho, K. S., and Chung, J. Akt/PKB promotes cancer cell invasion via increased motility and metalloproteinase production. FASEB J., 15: 1953-1962, 2001.

13. Zhou, H. Y. and Wong, A. S. Activation of p70S6K induces expression of matrix metalloproteinase 9 associated with hepatocyte growth factor-mediated invasion in human ovarian cancer cells. Endocrinology, 147: 2557-2566, 2006.

14. Nave, B. T., Ouwens, M., Withers, D. J., Alessi, D. R., and Shepherd, P. R. Mammalian target of rapamycin is a direct target for protein kinase B: identification of a convergence point for opposing effects of insulin and amino-acid deficiency on protein translation. Biochem.J., 344 Pt 2: 427-431, 1999.

15. Inoki, K., Li, Y., Zhu, T., Wu, J., and Guan, K. L. TSC2 is phosphorylated and inhibited by Akt and suppresses mTOR signalling. Nat.Cell Biol., 4: 648-657, 2002.

16. Potter, C. J., Pedraza, L. G., and Xu, T. Akt regulates growth by directly phosphorylating Tsc2. Nat.Cell Biol., 4: 658-665, 2002.

17. Zhang, Y., Gao, X., Saucedo, L. J., Ru, B., Edgar, B. A., and Pan, D. Rheb is a 
direct target of the tuberous sclerosis tumour suppressor proteins. Nat.Cell Biol., 5: 578-581, 2003.

18. Parry, L., Maynard, J. H., Patel, A., Clifford, S. C., Morrissey, C., Maher, E. R., Cheadle, J. P., and Sampson, J. R. Analysis of the TSC1 and TSC2 genes in sporadic renal cell carcinomas. Br.J Cancer, 85: 1226-1230, 2001.

19. Brugarolas, J. B., Vazquez, F., Reddy, A., Sellers, W. R., and Kaelin, W. G., Jr. TSC2 regulates VEGF through mTOR-dependent and -independent pathways. Cancer Cell, 4: 147-158, 2003. 


\title{
Qiao Meng
}

\section{EDUCATION}

\author{
2001-2006 West Virginia University, Morgantown, WV \\ Doctor of Philosophy, August 2006 \\ Genetics \& Developmental Biology Program \\ Advisor: Bing-Hua Jiang, Ph.D. \\ Dissertation title: The Role of PI3K/AKT/TSC/p70S6K1 Pathway \\ in Tumor Growth and Angiogenesis \\ 1998-2001 Hunan Medical University, Changsha, Hunan, P. R. China \\ Master of Science in Biochemistry and Molecular Biology \\ 1990-1995 Hunan Medical University, Changsha, Hunan, P. R. China \\ Bachelor of Medicine
}

\section{PUBLICATIONS}

Qiao Meng, Chang Xia, Jing Fang, Yon Rojanasakul and Bing-Hua Jiang. Role of PI3K and AKT specific isoforms in ovarian cancer cell migration, invasion and proliferation through the p70S6K1 pathway. Cell Signal. 2006 Jun 2; [Epub ahead of print]

Chang Xia, Qiao Meng, and Bing-Hua Jiang. Regulation of angiogenesis and tumor growth by p110 alpha and AKT1 via VEGF expression. J Cell Physiol. 2006 Jun 14.

Jing Fang, Qiao Meng, Ruiwen Zhang, and Bing-Hua Jiang. A Downstream kinase of the mammalian target of rapamycin, p70S6K1, regulates HDM2 protein phosphorylation and stability. Accepted by Journal of Cellular Physiology. In press.

Yong Qian, Linda Corum, Qiao Meng, John Blenis, Jenny Z. Zheng, Xianglin Shi, Daniel C. Flynn, and Bing-Hua Jiang. PI3K induced actin filament remodeling through Akt and p70S6K1: implication of essential role in cell migration. Am J Physiol Cell Physiol 286: C153-C163, 2004. 